DEPARTAMENTO DE INGENIERİA ENERGÉTICA

ESCUELA TÉCNICA SUPERIOR DE INGENIEROS INDUSTRIALES

\title{
Estudio de la transferencia de calor en un Sistema de Almacenamiento Térmico en sales fundidas con Generador de Vapor integrado
}

Esther Rivas Ramos

Máster en Física Aplicada por la Universidad Complutense de Madrid

\author{
Directores: \\ Dr. Javier Muñoz Antón
}

Doctor Ingeniero Industrial por la Universidad Politécnica de Madrid

Dra. Esther Rojas Bravo

Doctora en Física por la Universidad Complutense de Madrid 
TRIBUNAL DE LA TESIS DOCTORAL:

Estudio de la transferencia de calor en un Sistema de Almacenamiento Térmico en sales fundidas con Generador de Vapor integrado

Autora: Da Esther Rivas Ramos

Directores: Dr. D. Javier Muñoz Antón y Dra. D ${ }^{a}$ Esther Rojas Bravo

Tribunal nombrado por el Excmo. y Magfco. Sr. Rector de la Universidad Politécnica de

Madrid el día de de 2020 .

Presidente: Dr. D.

Vocal: Dr. D.

Vocal: Dr. D.

Vocal: Dr. D.

Secretario: Dr. D.

Suplente: Dr. D.

Suplente: Dr. D.

Realizado el acto de lectura y defensa de la Tesis el día de 2020 en la Escuela Técnica Superior de Ingenieros Industriales de la Universidad Politécnica de Madrid.

\section{CALIFICACIÓN:}

\section{EL PRESIDENTE:}

LOS VOCALES:

EL SECRETARIO: 
A mis padres 



\section{Agradecimientos}

Esta investigación se ha llevado a cabo bajo el soporte financiero y el marco formal de los proyectos SFERA (Grant Agreement No. 228296) y OPTS (Grant Agreement No. 283138), pertenecientes a los $6^{\underline{0}}$ y $7^{\underline{0}}$ programas marco de la Unión Europea respectivamente.

En primer lugar, he de agradecer la oportunidad que me brindó el Centro de Investigaciones Energéticas, Medioambientales y Tecnológicas (CIEMAT) al concederme una beca de formación como investigadora, la cual me ha permitido en gran medida desarrollar esta tesis.

Igualmente, me gustaría dar las gracias a mis directores, el Dr. Javier Muñoz Antón y la Dra. Esther Rojas Bravo, por su dedicación y buen hacer guiándome para llevar este trabajo a buen puerto. Sin su ayuda este manuscrito nunca habría visto la luz.

En segundo lugar, mostrar mi gratitud a todos los integrantes de la 'Unità Tecnica Fonti Rinnovabili (UTRINN)' del Centro Ricerca della Casaccia (ENEA) en Italia por su colaboración, en especial al Dr. Luca Rinaldi y D. Carlo Rocca, por su disponibilidad a la hora de resolver todas y cada una de mis dudas relacionadas con el dispositivo experimental y su instrumentación, tanto durante mis estancias doctorales como tiempo después.

También a la Dra. Rocío Bayón Cabeza, por estar siempre dispuesta a responderme cualquier pregunta sobre medios o sistemas de almacenamiento térmico. Al Dr. Jose Luis Santiago del Río, por su inestimable ayuda a la hora de lograr mallar los dominios computacionales y de implementar los modelos CFD que aquí se presentan. Al Dr. Manuel Gimenez Durán y al Dr. Abel Paz Gallardo por facilitarme las tareas de ejecución y visualización de las simulaciones en los clústeres Euler y Ceta-CIEMAT. Y al Dr. Francisco José Moralejo Vázquez por su paciente ayuda en la maquetación con LaTeX de este documento y ayudarme siempre a plasmar en papel mis ideas.

Finalmente, no quiero terminar sin agradecer por su compañerismo a otras muchas personas que han aportado conocimiento y contribuido en diferentes aspectos. Ello me obliga a considerarlos partícipes de un modo u otro en este trabajo.

A todos, muchas gracias. 



\section{Resumen}

Existe una gran cantidad de aplicaciones industriales donde se requiere aprovechar calor de proceso, y en las que es muy común el uso de sistemas de almacenamiento que permiten la utilización del calor en momentos posteriores a su generación. Un claro ejemplo se encuentra en las plantas termosolares, CSP (Concentrating Solar Power plant), que generan electricidad a partir de la radiación solar concentrada.

La consolidación de las plantas CSP necesita contribuciones innovadoras enfocadas al abaratamiento de los costes de producción eléctrica. En este sentido, los sistemas de almacenamiento térmico desempeñan un papel fundamental, puesto que mejoran las prestaciones de las plantas CSP al explotar su gestionabilidad.

Los sistemas de almacenamiento se clasifican atendiendo a la forma de almacenar el calor en: sistemas de almacenamiento en calor sensible, latente o termoquímico. Actualmente, los sistemas de almacenamiento en calor sensible de doble tanque en sales fundidas son los únicos utilizados en las plantas CSP a escala comercial. Aunque su eficiencia es suficientemente elevada, es necesario desarrollar conceptos novedosos de almacenamiento térmico e investigar en nuevos diseños más competitivos.

El objetivo de este trabajo es contribuir a la optimización y mejora del diseño de un tanque de almacenamiento térmico con generador de vapor integrado, TES-SG (Thermal Energy Storage with integrated Steam Generator), que emplea sales fundidas simultáneamente como HTF y como medio de almacenamiento térmico, Figura 1, para su implementación en las futuras plantas termosolares. La patente de este diseño pertenece al ENEA y a la empresa italiana ANSALDO NUCLEARE S.p.A. (Rinaldi et al. 2015). Para ello, se aborda el estudio de la transferencia de calor en un prototipo de almacenamiento térmico de $300 \mathrm{~kW}_{\text {th }}$, tanto desde el punto de vista teórico de su funcionamiento, como desde el punto de vista experimental de su operación. En este estudio se persigue obtener correlaciones específicas para la transferencia de calor, ya que la revisión del estado de la técnica revela que no las hay adaptadas a este tipo de sistema. La revisión también pone de manifiesto la falta de estudio en profundidad de la termo-hidráulica de este tipo de sistemas (Capítulo 1).

El prototipo es un tanque de $1.98 \mathrm{~m}$ de diámetro y $2.8 \mathrm{~m}$ de altura, cuyo interior alberga 
alrededor de $12000 \mathrm{~kg}$ de una mezcla de sales inorgánicas en estado líquido: $\mathrm{NaNO}_{3}(60 \%$ en peso) $+\mathrm{KNO}_{3}$ (40\% en peso), que se conoce comúnmente con el nombre de 'sal solar', en atmósfera de aire, Figura 2.

El generador de vapor lo constituyen dos carcasas cilíndricas concéntricas, tres tubos helicoidales, con distintas longitudes, radios de curvatura e inclinaciones, dispuestos en el espacio que delimitan ambas carcasas. Por el interior de los tubos helicoidales circula el agua a presión que cambia de fase, y por el espacio intersticial entre las carcasas cilíndricas circulan las sales fundidas a contra-corriente (Capítulo 2).

Mediante el análisis exhaustivo de los datos experimentales de uno de los ensayos de descarga 11 $^{1}$ del prototipo (Capítulo 3), se ha extraído la información para llevar a cabo las aportaciones principales de este trabajo, las cuales se resumen a continuación.

Se ha llevado a cabo el estudio de la transferencia de calor por circulación natural entre un flujo externo de sales fundidas y una matriz de tubos helicoidales, primero desde un punto de vista global y después desde un punto de vista local.

Para ello, se ha empleado una técnica de fluido-dinámica computacional, CFD (Computational Fluid Dynamics), ejecutándose un modelo 3D que simula un proceso de descarga del prototipo mediante un tratamiento de tipo URANS (Unsteady Reynolds-Averaged Navier-Stokes). La información extraída del análisis de datos previo ha servido, por un lado, para establecer las condiciones iniciales y de contorno del modelo y, por otro, para validar el propio modelo CFD (Capítulo 4).

Los resultados numéricos obtenidos para los campos de temperaturas, presiones y velocidades de las sales fundidas en el generador de vapor, y las distribuciones de temperaturas y flujos de calor alrededor de los tubos helicoidales, en la fase cuasi-estacionaria de la descarga, se han utilizado para calcular:

a) mediante la metodología generalizada de Vijayan et al. (2000), los números adimensionales globales de: $R e$ y $G r_{m}$

b) mediante dos modelos termo-hidráulicos locales construidos ad hoc, uno 3D basado en el diámetro hidráulico del generador de vapor y otro 2D basado en el diámetro exterior de los tubos helicoidales, los números adimensionales locales de: $\bar{R} e, \overline{\operatorname{Pr}}$ y $\bar{N} u$

A partir de la relación existente entre los números adimensionales globales de $R e$ y $G r_{m}$, se ha podido categorizar al TES-SG como un NCL (Natural Circulation Loop) simple en régimen de transición, en el que se puede emplear la correlación propuesta por Swapnalee y

\begin{tabular}{l}
\hline${ }^{1}$ Se entiende por descarga de un sistema de almacenamiento térmico al proceso por el cual la energía \\
almacenada en forma de calor en un medio de almacenamiento, en este caso en virtud de su temperatura, \\
\hline \hline es cedida.
\end{tabular}




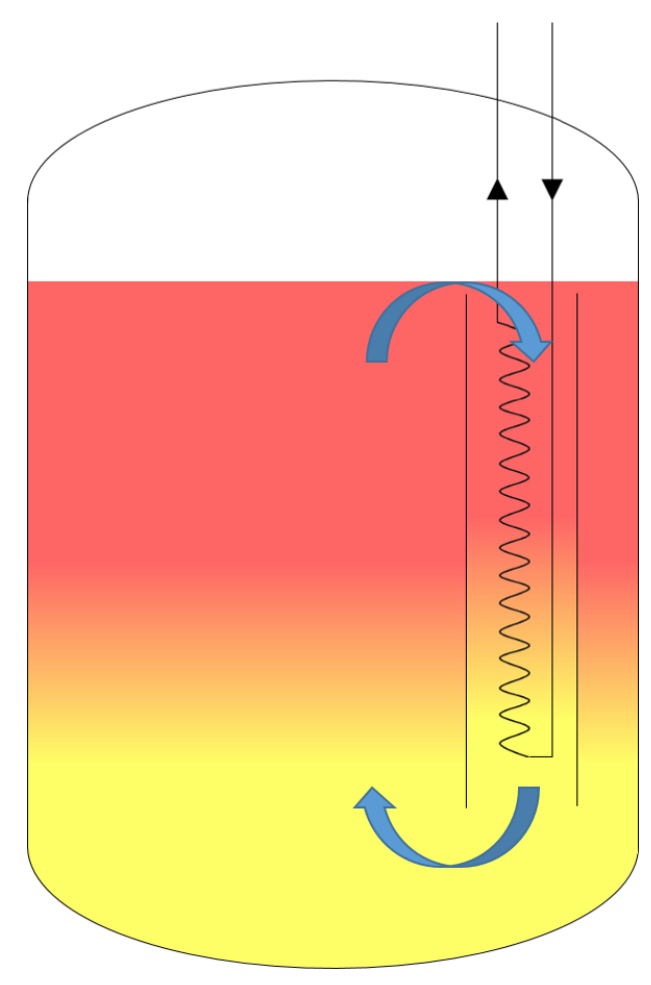

Figura 1: Esquema del TES-SG.

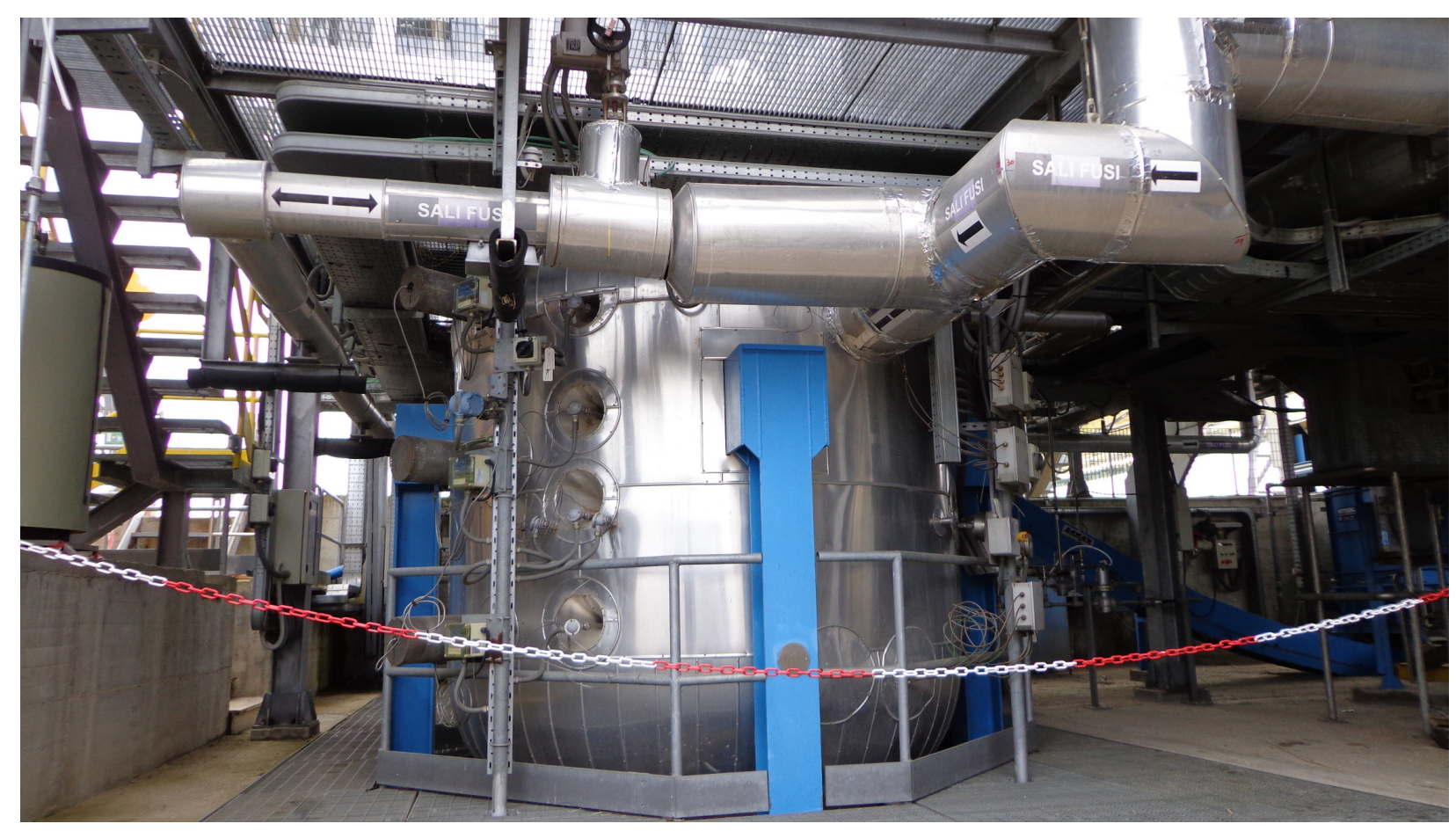

Figura 2: Prototipo experimental (Fuente: Elaboración propia). 
Vijayan (2011) para el cálculo del caudal de sales fundidas que circula por el generador de vapor durante las descargas del sistema (Capítulo 5).

Y a partir de la relación existente entre los números adimensionales locales de $\bar{R} e$ y $\overline{P r}$, ha sido posible deducir una nueva correlación para la transferencia de calor por circulación natural entre un flujo externo de sales fundidas y una matriz de tubos helicoidales (Capítulo 6) que es independiente de la longitud característica que se utilice. Se expresión es: $\bar{N} u=0.8150 \bar{R} e^{0.4608} \overline{P r}^{0.36}$, y presenta un parámetro estadístico de ajuste $R^{2}$ de 0.9807 (Capítulo 5).

Esta correlación se considera válida para:

- matrices de tubos helicoidales cuya configuración sea conforme a la propuesta por ENEA y ANSALDO NUCLEARE S.p.A: diámetro externo de los tubos de $0.0127 \mathrm{~m}$ y pasos vertical y horizontal de la matriz del mismo orden que el diámetro externo de los tubos, que equivale a bajos ángulos de inclinación $\left(<3^{\underline{O}}\right)$

- condiciones de operación dentro del rango descrito: $\bar{R} e$ entre 100 y $600, \overline{P r}$ entre 4 y 13

Se ha llevado a cabo el estudio de la ebullición en convección forzada en el interior de los tubos helicoidales (Capítulo 6).

En él se ha utilizado un modelo CFD-RANS de transferencia de calor conjugada entre las sales fundidas y el agua-vapor en 3D que simula varios instantes de un proceso de descarga del prototipo, y se ha aplicado una metodología numérica basada en el comportamiento promedio del flujo bifásico en cada ciclo de inestabilidad termo-hidráulica.

La evaluación comparativa llevada a cabo entre modelos bifásicos, semi-empírico versus mecanicista, ha permitido deducir que el modelo semi-empírico es capaz de simular la ebullición en convección forzada en el interior de los tubos helicoidales.

La validación del modelo se ha realizado utilizando los datos experimentales ya referidos, y diversos resultados derivados del modelo que se ha desarrollado de pérdidas de carga del tramo del circuito agua-vapor comprendido entre los colectores de entrada y salida del generador.

Los resultados numéricos obtenidos para los campos de velocidades tangenciales y los títulos de vapor, ambos tomados en las secciones transversales al flujo del agua-vapor, y las distribuciones de los títulos de vapor en las paredes, todos ellos en la fase cuasi-estacionaria de la descarga, han servido para:

a) demostrar la existencia de un flujo secundario en el interior de los tubos helicoidales, la cual supone la descripción de este fenómeno en unas condiciones de trabajo, geometría y 
forma de calentamiento que no habían sido consideradas hasta el momento

b) caracterizar el régimen de superficie seca, o dryout, a partir de la localización de su comienzo en el generador de vapor (altura y posición azimutal), y del cálculo de los títulos de vapor asociados al primer dryout y al dryout total en función del diámetro de hélice

Con esta información ha sido posible concluir que, dentro del rango de condiciones de operación establecido en este trabajo (ver Tabla 1), y teniendo en cuenta la configuración de la matriz de tubos helicoidales propuesta por ENEA y ANSALDO NUCLEARE S.p.A, el comportamiento del flujo bifásico es uniforme. En consecuencia, la operación del prototipo durante sus descargas no influye en el dryout, lo cual no se ha publicado previamente.

Tabla 1: Condiciones de operación del prototipo en la fase cuasi-estacionaria.

\begin{tabular}{|l|c|c|}
\hline & Agua-Vapor & Sales fundidas \\
\hline \hline$P_{I N}($ bar $)$ & {$[37.9,39.2]$} & Presión atmosférica \\
\hline$T_{I N}\left({ }^{\mathrm{o}} \mathrm{C}\right)$ & $\Delta T_{\text {sub }} \approx 0$ & {$[472,477]$} \\
\hline$\dot{m}\left(\mathrm{~kg} \cdot \mathrm{s}^{-1}\right)$ & 0.082 & {$[0.569,0.692]$} \\
\hline
\end{tabular}

Se ha analizado la validez de las correlaciones existentes para el cálculo de los títulos de vapor asociados al primer dryout y al dryout total, llegándose a las siguientes conclusiones:

- la correlación de Ruffel (a $270^{\circ}$ ) es la más adecuada para el primer dryout

- la correlación de Santini et al. ofrece resultados dentro del margen de error del $20 \%$ para el primer dryout, siendo además la más sencilla de utilizar puesto que no depende del flujo de calor en las paredes

- asumir un valor de 0.97 para el título de vapor del dryout total es una aproximación conservadora acertada.

Notar que ambas correlaciones fueron derivadas de experimentos en los que el calentamiento en las paredes es uniforme, en contraposición a lo que sucede en el prototipo de ENEA. Por lo tanto, y a pesar de su adaptación para describir el título de vapor asociado al primer dryout, esto puede suponer un límite a uso.

Finalmente, se pone de manifiesto cómo la metodología aplicada en este estudio, basada en modelos CFD, es capaz de describir la transferencia de calor en sistemas complejos, evidenciando así su potencia y capacidad a la hora de complementar a la teoría y a los experimentos.

Este trabajo de investigación ha estado enmarcado dentro del proyecto OPTS ( $\mathrm{N}^{\mathrm{o}}$ de Contrato: 283138) del $7^{\text {O }}$ Programa Marco de la U.E. financiado con Fondos Europeos. 



\section{Abstract}

Nowadays, there are many industrial applications where it is necessary to take advantage of process heat, and in which the use of storage systems is very common because it allows employing such process heat after its generation. Concentrating Solar Power plants, also known as CSP plants, are an example of them. These CSP plants generate electricity from concentrated solar radiation.

The consolidation of CSP plants requires innovative contributions focused on lowering the costs of electricity production. In this sense, thermal storage systems play a fundamental role, since they improve the performance of CSP plants by exploiting their dispatchability.

Storage systems are classified according to the form of heat they store in: sensible, latent or thermochemical heat storage systems. Currently, sensible heat storage systems in two tanks of molten salts are the only ones used in the CSP commercial plants. Although its efficiency is high enough, it is necessary to develop novel thermal storage concepts and investigate new more competitive designs.

The goal of this work is to contribute to the optimization and improvement of a Thermal Energy Storage with integrated Steam Generator design, TES-SG, which utilizes molten salts as HTF and storage medium, for its implementation in the future CSP plants. The patent of this design belongs to ENEA and the Italian company ANSALDO NUCLEARE S.p.A., Figure 3. For this purpose, the heat transfer study in a $300 \mathrm{~kW}_{\text {th }}$ thermal energy storage prototype is addressed from both, the theoretical point of view of its performance and the experimental point of view of its operation. This work aims to obtain specific correlations for the heat transfer because the state-of-the-art reveals that existing correlations are unsuitable for this system. The review also highlights the lack of in-depth thermo-hydraulic studies about such a system (Chapter 1).

The prototype is a $1.98 \mathrm{~m}$ in diameter and $2.8 \mathrm{~m}$ high tank, which contains about $12000 \mathrm{~kg}$ of a inorganic salts mixture in liquid state: $\mathrm{NaNO}_{3}(60 \%$ by weight $)+\mathrm{KNO}_{3}$ (40\% by weight), commonly known as 'solar salt', in air atmosphere, Figure 4 . 


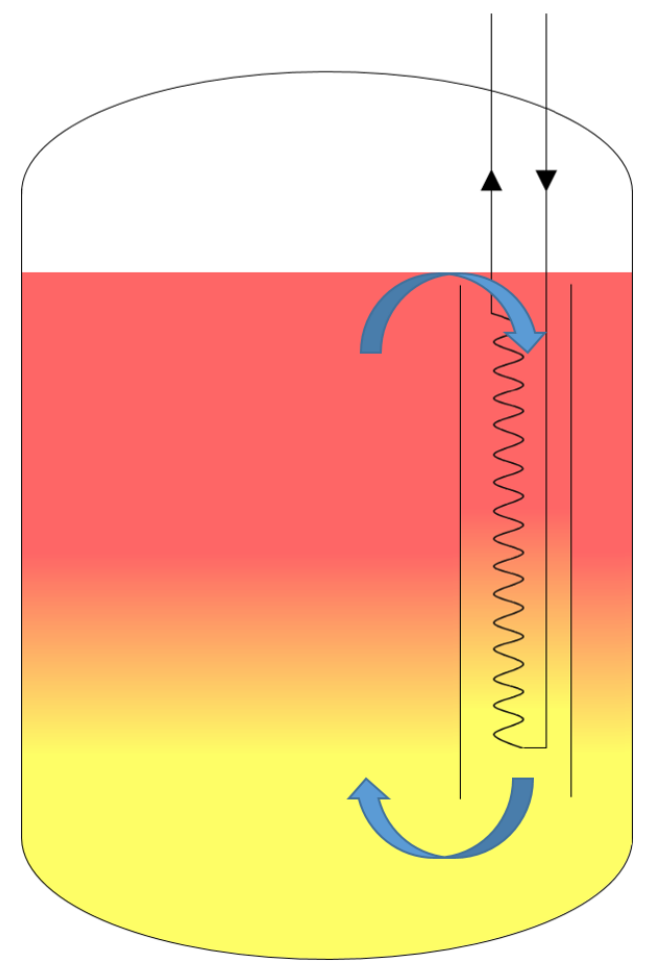

Figure 3: TES-SG scheme (Rinaldi et al. 2015).

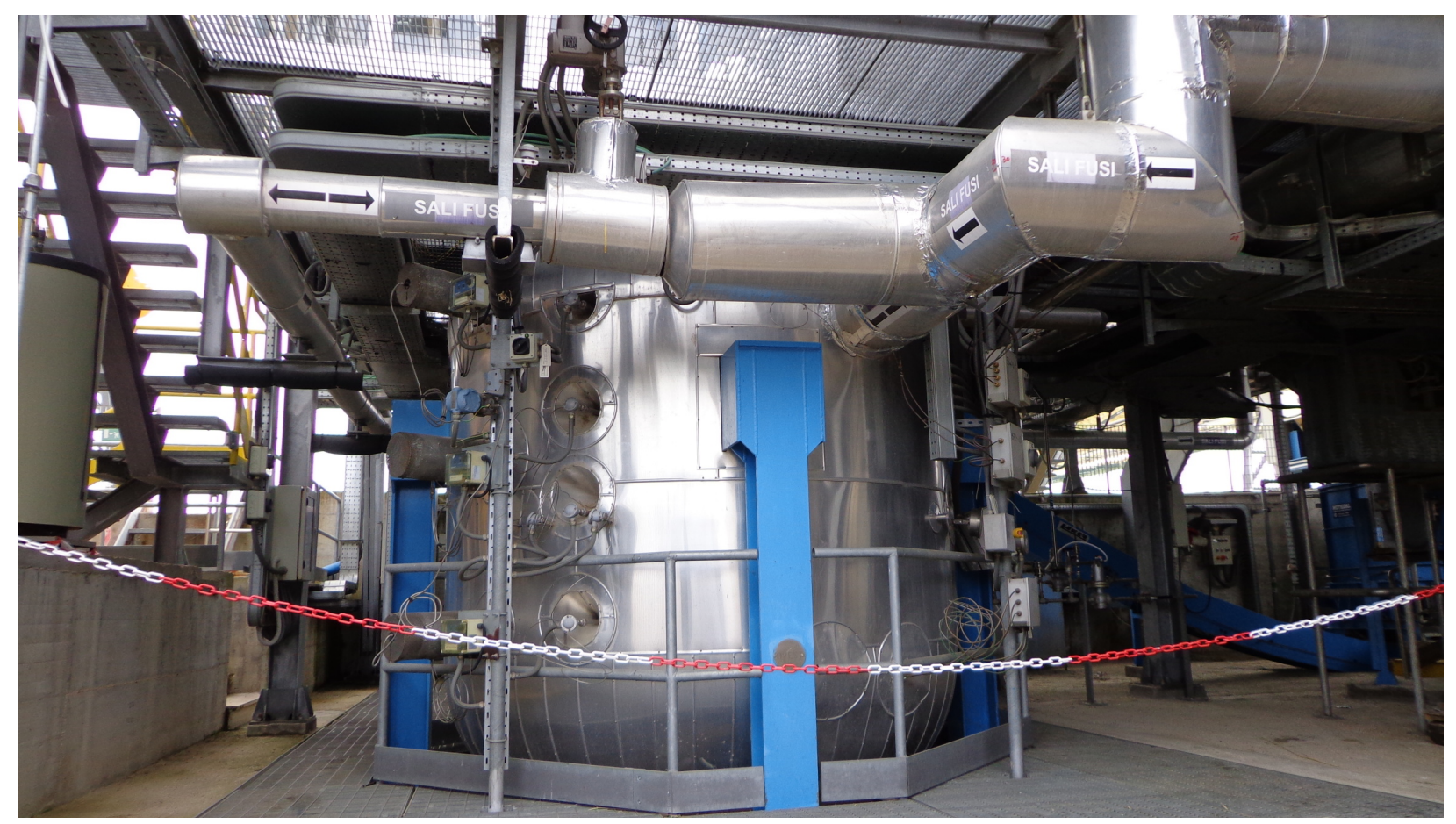

Figure 4: Experimental prototype (Source: Own elaboration). 
The steam generator is made up of two concentric cylindrical shells, and three helical tubes with different lengths, bending radii and inclinations, arranged in the delimited space between both shells. Pressurized water changing of phase flows inside the helical tubes, and molten salts flows through the interstitial space between both shells at counter-flow (Chapter 2.

The information has been extracted by means of a comprehensive analysis of the experimental data from a discharge test of the prototype (Chapter 3), in order to achieve the main contributions of this work summarized below.

The study of heat transfer by natural circulation between an external flow of molten salts and a helical tubes matrix has been carried out, both from a global and local perspective.

For that, a Computational Fluid-Dynamics technique, CFD technique, has been applied, running a 3D model which simulates a discharge process using an URANS (Unsteady Reynolds-Averaged Navier-Stokes) treatment. On the one hand, the extracted information from the previous data analysis has served to establish the CFD model initial and boundary conditions and, on the other hand, to validate just the CFD model (Chapter 4).

Numerical results obtained for temperature, pressure and velocity fields in molten salts of steam generator, and temperature and boundary heat flux distributions around helical tubes, during the steady-state system operation, have used to calculate:

a) the global dimensionless numbers of: $R e$ and $G r_{m}$, by means of the generalized methodology of Vijayan et al. (2000)

b) the local dimensionless numbers of: $\bar{R} e, \overline{P r}$ and $\bar{N} u$, by means of two ad hoc models: the first one, a 3D model based on the steam generator hydraulic diameter, and the second one, a $2 \mathrm{D}$ model based on helical tubes outer diameter

The TES-SG has been categorized as a simple NCL (Natural Circulation Loop) under transition regime from the relationship between the global dimensionless numbers of $R e$ and $G r_{m}$, in which the correlation proposed by Swapnalee y Vijayan (2011) can be used for computing mass flow of molten salts through the steam generator during the system discharges (Chapter 5).

It has been possible to deduce a new correlation for the heat transfer by natural circulation between an external flow of molten salts and a matrix of helical tubes from the relationship between the local dimensionless numbers of $\bar{R} e$ and $\overline{P r}$, which is independent of the characteristic length used. Resulting correlation is: $\bar{N} u=0.8150 \overline{\operatorname{Re}}{ }^{0.4608} \overline{P r}^{0.36}$ " and it presents a fit statistical parameter $R^{2}$ of 0.9807 (Chapter 5).

This correlation is considered valid for: 
- matrices configurations according to the design of ENEA and ANSALDO NUCLEARE S.p.A: tubes external diameter of $0.0127 \mathrm{~m}$ and vertical and horizontal matrix pitches of the same order than tubes external diameter, which is equivalent to consider low inclination angles $\left(<3^{\underline{O}}\right)$

- operating conditions within the described range: $\bar{R} e$ between 100 and 600 , and $\bar{P} r$ between 4 and 13

The study of forced convective boiling inside the helical tubes has been carried out by means of a CFD-RANS conjugated heat transfer 3D model between molten salts and water-steam, which simulates several moments of the prototype discharge process, and a numerical methodology based on the average behavior of the two-phase flow in each instability cycle (Chapter 6).

The realized comparative evaluation between two-phase flow models: semi-empirical versus mechanistic, has allowed to infer that semi-empirical model can successfully simulate the forced convective boiling flow inside helical tubes.

The model validation has been carried out by using both experimental data already referred to, and some results derived from a pressure drops model developed to the water-steam circuit comprised between the inlet and outlet manifolds of steam generator.

The obtained numerical results for tangential velocity fields and steam qualities, both taken in the cross sections of water-steam flow, and steam quality distributions on the walls, all of them during the steady-state system operation, have served:

a) to demonstrate the existence of a secondary flow within the helical tubes, which implies the description of this phenomenon in a working condition, geometry and heating methodologies that have not been considered up to now

b) to characterize the dryout based on its location in the steam generator (height and azimuthal position) and the steam qualities associated with its first dryout and total dryout, depending on the helix diameter

From this information has been possible to conclude the two-phase flow behavior is uniform within the operating conditions range given in this work (see Table 2) and taking into account the helical tube matrix configuration proposed by ENEA and ANSALDO NUCLEARE S.p.A. Therefore, the operation of the prototype during its discharges does not influence the dryout. This information has not been published previously.

Existing correlations validity for calculating the associated steam qualities to the first dryout and total dryout has been analyzed, establishing the following conclusions:

- the Ruffel's correlation (at $270^{\mathrm{O}}$ ) is the most suitable for the first dryout 
- the Santini et al. correlation provides results within the $20 \%$ margin of error for the first dryout being, at the same time, the easiest to use since it does not depend on the heat flux on the walls

- the assumption of 0.97 as the steam quality for the total dryout is a successful conservative approximation

Table 2: Prototype working conditions.

\begin{tabular}{|l|c|c|}
\hline & Water-Steam & Molten salts \\
\hline \hline$P_{I N}(\mathrm{bar})$ & {$[37.9,39.2]$} & Atmosferic pressure \\
\hline$T_{I N}\left({ }^{\mathrm{o}} \mathrm{C}\right)$ & $\Delta T_{\text {sub }} \approx 0$ & {$[472,477]$} \\
\hline$\dot{m}\left(\mathrm{~kg} \cdot \mathrm{s}^{-1}\right)$ & 0.082 & {$[0.569,0.692]$} \\
\hline
\end{tabular}

Note that both correlations were derived from experiments in which walls heating were uniform, against that happens in the ENEA prototype. Therefore, this can be a limit to use them despite of its adaptation to describe the steam quality associated with the first dryout. Finally, it lays bare how the applied methodology in this study, based on CFD models, is able to describe heat transfer in complex systems, demonstrating its power and ability to complement theory and experiments.

This research work has been framed in the OPTS project (Contract No. 283138) of the $7^{\text {th }}$ Framework Programme for Research and Technological Development funded by European Commission. 



\section{Índice general}

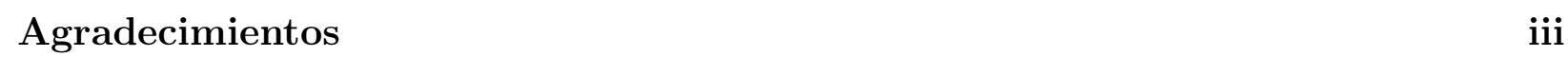

Resumen $\quad$ v

Abstract $\quad x i$

Îndice general xvii

Nomenclatura $\quad x x i$

Acrónimos $\quad$ xxv

Lista de figuras $\quad$ xxvii

Lista de tablas $\quad$ xxxv

\begin{tabular}{lll}
\hline & Introducción y motivación & 1
\end{tabular}

$1.1 \quad$ Sistemas de almacenamiento térmico para plantas termosolares . . . . . . . . 2

1.2 Sistema de almacenamiento térmico en sales fundidas con generador de vapor integrado. . . . . . . . . . . . . . . . . . . . . . . . . . . . . 15

1.3 Fenómenos físicos involucrados en el lado sales fundidas . . . . . . . . . . . . 22

1.3.1 Transferencia de calor por convección forzada alrededor de matrices de tubos......................... . . . 25

1.3 .2 Revisión del estado de la técnica de las correlaciones para la transferencia de calor por convección forzada alrededor de matrices de tubos . . . . . . . . . . . . . . . . . . . . . 28

1.3.3 Revisión del estado de la técnica de las correlaciones para la transferencia de calor por convección forzada alrededor de matrices de tubos helicoidales . . . . . . . . . . . . . . . . . 33

$1.4 \quad$ Fenómenos físicos involucrados en el lado agua-vapor $\ldots$. . . . . . . . . . . 35

1.4.1 Transferencia de calor por convección forzada en flujos internos en

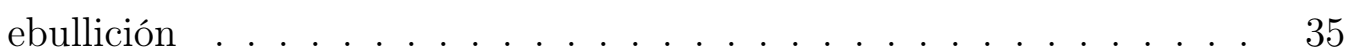


1.4.2 Revisión del estado de la técnica de las correlaciones para el cálculo del título de vapor local asociado al comienzo del régimen de superficie seca en flujos en ebullición en convección forzada en tubos helicoidales en vertical . . . . . . . . . . . . . . . . . . . . 37

1.5 Objetivos $\ldots \ldots \ldots \ldots \ldots \ldots \ldots \ldots$

1.5.1 Metodología . . . . . . . . . . . . . . . . . 44

\begin{tabular}{|lll}
\hline 2 & Dispositivo experimental & 47
\end{tabular}

$2.1 \quad$ Instalación experimental . . . . . . . . . . . . . . . . . . . 47

2.2 Tanque de almacenamiento térmico . . . . . . . . . . . . . . . . 52

2.3 Generador de vapor . . . . . . . . . . . . . . . . . . . . . . 54

2.4 Metodología durante las descargas . . . . . . . . . . . . . . . . 60

\begin{tabular}{|lll}
\hline & Análisis de datos experimentales & 63
\end{tabular}

$3.1 \quad$ Identificación de puntos relevantes durante el ensayo . . . . . . . . . . . . . . 64

3.2 Caudales másicos individuales agua-vapor $\ldots \ldots$. . . . . . . . . . . . . . . 69

3.3 Temperaturas de las sales fundidas en el tanque . . . . . . . . . . . . . . . 74

3.4 Pérdidas térmicas . . . . . . . . . . . . . . . . . . . . . . 80

3.5 Temperaturas en el generador de vapor . . . . . . . . . . . . . . . . . . . . . 82

4 Modelización de la transferencia de calor en el lado de las sales fundidas 89

4.1 Pre-procesado del modelo CFD . . . . . . . . . . . . . . . . . . . . . . 90

4.1 .1 Geometría y mallado . . . . . . . . . . . . . . . . . . . . . . 90

4.1 .2 Modelos físicos empleados . . . . . . . . . . . . . . . . . . . . . 94

4.1 .3 Condiciones iniciales y de contorno . . . . . . . . . . . . . . . . 96

4.2 Procesado del modelo CFD $\ldots \ldots \ldots \ldots$

4.3 Validación del modelo CFD . . . . . . . . . . . . . . . . . . . . . . . . . . . 100

$4.3 .1 \quad$ Validación mediante parámetros numéricos . . . . . . . . . . . . . 100

4.3 .2 Validación mediante datos experimentales . . . . . . . . . . . . . . 103

4.4 Coeficientes de transferencia de calor locales . . . . . . . . . . . . . . . . . . 108

4.5 Resumen . . . . . . . . . . . . . . . . . . . . . . . . . . . . . . . . 113

5 Correlación para la transferencia de calor por convección entre un flujo de sales fundidas y una matriz de tubos helicoidales $\quad 115$

5.1 Circuito termo-hidráulico equivalente del TES-SG . . . . . . . . . . . . . . 117

$5.1 .1 \quad$ Metodología para el cálculo de los números adimensionales globales . 117

$5.1 .2 \quad$ Correlación entre los números adimensionales globales . . . . . . . . . 119

5.2 Correlación para la transferencia de calor en el lado de las sales fundidas . . 121 5.2.1 Modelos 3D y 2D para el cálculo de los números adimensionales locales 121 
5.2 .2 Correlaciones con números adimensionales locales . . . . . . . . . . . 123

5.3 Resumen . . . . . . . . . . . . . . . . . . . . . . . . . . . . . . . . 126

6 Estudio del comienzo del régimen de superficie seca en un generador de vapor de tubos helicoidales de un solo paso 129

6.1 Pre-procesado del modelo CFD . . . . . . . . . . . . . . . . . . . . 130

6.1 .1 Geometría y mallado . . . . . . . . . . . . . . . . . . . . . 130

6.1 .2 Modelos físicos empleados . . . . . . . . . . . . . . . . . . 133

6.1 .3 Condiciones de contorno y metodología . . . . . . . . . . . . . . . . . 142

6.2 Procesado del modelo CFD . . . . . . . . . . . . . . . . . . . . . 145

6.3 Validación del modelo CFD . . . . . . . . . . . . . . . . . . . . . . . . . 145

6.4 Estudio del dryout $\ldots \ldots \ldots \ldots$. . . . . . . . . . . . . . . 150

6.4 .1 Posición azimutal y títulos de vapor locales . . . . . . . . . . . . . . . 150

6.4 .2 Comparación con las correlaciones de la literatura . . . . . . . . . . . 155

6.5 Resumen . . . . . . . . . . . . . . . . . . . . . . . . . . . . . . . . . . . . 158

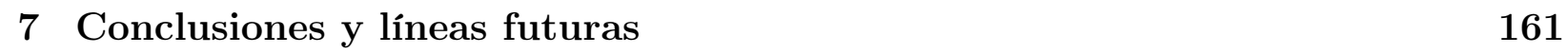

7.1 Conclusiones . . . . . . . . . . . . . . . . . . . . 161

7.2 Líneas futuras $\ldots \ldots \ldots \ldots$. . . . . . . . . . . . . . . . . . . 164

\begin{tabular}{|l|l}
\hline Publicaciones del autor relacionadas con este trabajo & 167
\end{tabular}

\begin{tabular}{lr}
\hline A Fundamentos teóricos & 169
\end{tabular}

A.1 Coeficientes de transferencia de calor por convección. . . . . . . . . . . . . . 170

A.2 Ecuaciones básicas para la transferencia de calor por convección . . . . . . . 172

A.2.1 Ecuación de conservación de la energía . . . . . . . . . . . . . . . . . 172

A.2.2 Ecuaciones de Reynolds . . . . . . . . . . . . . . . 176

A.3 Números adimensionales y principio de similaridad . . . . . . . . . . . . . 178

\begin{tabular}{lll}
\hline B Inestabilidades termo-hidráulicas en flujos bifásicos & 183
\end{tabular}

B.1 Clasificación . . . . . . . . . . . . . . . . . . . 183

B.2 Análisis experimental . . . . . . . . . . . . . . . . . . . . . . 186

\begin{tabular}{|l|l|}
\hline C Modelización de las pérdidas de carga en el lado agua-vapor & 191
\end{tabular}

C.1 Descripción del modelo . . . . . . . . . . . . . . . . . . . . . . . . 191

C.2 Metodología para la determinación de las longitudes de los tubos en los subtramos 2 y $3 \ldots \ldots \ldots \ldots$. . . . . . . . . . . . . . . . . 197

C.3 Validación del modelo . . . . . . . . . . . . . . . . . . . . . . . . 200

C.4 Resultados del modelo . . . . . . . . . . . . . . . . . . . . . . . . . . 201 
$\mathrm{xx}$

D Técnicas para la determinación del comienzo del régimen de superficie seca en flujos bifásicos 203

\begin{tabular}{ll}
\hline E Parámetros estadísticos utilizados & 205
\end{tabular}

\begin{tabular}{|lll}
\hline F & Cálculo de la incertidumbre en el título de vapor local & 207
\end{tabular}

\begin{tabular}{ll}
\hline Referencias & 213
\end{tabular} 


\section{Nomenclatura}

\begin{tabular}{|c|c|}
\hline$C$ & Índice de concentración \\
\hline$C p$ & Calor específico $\left(\mathrm{J} \cdot \mathrm{kg}^{-1} \cdot \mathrm{K}^{-1}\right)$ \\
\hline$C F L$ & Número de Courant \\
\hline$d$ & Diámetro de tubo $(\mathrm{m})$ \\
\hline$D$ & Diámetro de hélice (m) \\
\hline$D e$ & Número de Dean \\
\hline$e$ & Energía interna específica $\left(\mathrm{J} \cdot \mathrm{kg}^{-1}\right)$ \\
\hline$E$ & Energía (J) \\
\hline$f$ & Fuerza $(\mathrm{N})$ \\
\hline$f f$ & Factor de fricción \\
\hline $\mathrm{Fr}$ & Número de Froude \\
\hline$g$ & Gravedad $\left(9.80665 \mathrm{~m} \cdot \mathrm{s}^{-2}\right)$ \\
\hline$G$ & Flujo másico $\left(\mathrm{kg} \cdot \mathrm{s}^{-1} \cdot \mathrm{m}^{-2}\right)$ \\
\hline$G r$ & Número de Grashof \\
\hline$G r_{m}$ & Número de Grashof modificado \\
\hline$h$ & Coeficiente de transferencia de calor $\left(\mathrm{W} \cdot \mathrm{m}^{-2} \cdot \mathrm{K}^{-1}\right)$ \\
\hline $\bar{h}$ & Coeficiente de transferencia de calor local $\left(\mathrm{W} \cdot \mathrm{m}^{-2} \cdot \mathrm{K}^{-1}\right)$ \\
\hline$H$ & Entalpía $\left(\mathrm{J} \cdot \mathrm{kg}^{-1}\right)$ \\
\hline$H_{e s t}$ & Entalpía estática $\left(\mathrm{J} \cdot \mathrm{kg}^{-1}\right)$ \\
\hline$I$ & Intensidad de la turbulencia \\
\hline $\mathbf{I}$ & Irradiancia $\left(\mathrm{W} \cdot \mathrm{m}^{-2}\right)$ \\
\hline$k$ & Conductividad térmica $\left(\mathrm{W} \cdot \mathrm{m}^{-1} \cdot \mathrm{K}^{-1}\right)$ \\
\hline$l$ & Caudal volumétrico $\left(1 \cdot h^{-1}\right)$ \\
\hline$L$ & Longitud (m) \\
\hline$\dot{m}$ & Caudal másico $\left(\mathrm{kg} \cdot \mathrm{s}^{-1}\right)$ \\
\hline$N u$ & Número de Nusselt \\
\hline $\bar{N} u$ & Número de Nusselt local \\
\hline$p$ & Perímetro (m) \\
\hline$P$ & Presión (Pa) \\
\hline
\end{tabular}


$\operatorname{Pr} \quad$ Número de Prandtl

$\bar{P} r \quad$ Número de Prandtl local

$Q \quad$ Flujo de calor $\left(\mathrm{W} \cdot \mathrm{m}^{-2}\right)$

$\dot{Q} \quad$ Potencia $(\mathrm{W})$

$R \quad$ Resistencia térmica $\left(\mathrm{W}^{-1} \cdot \mathrm{m} \cdot \mathrm{K}\right)$

$R a \quad$ Número de Rayleigh

Re Número de Reynolds

$\bar{R} e \quad$ Número de Reynolds local

$\Delta s \quad$ Tamaño característico $(\mathrm{m})$

$S \quad$ Superficie $\left(\mathrm{m}^{2}\right)$

$t \quad$ Tiempo (s)

$\Delta t \quad$ Paso de tiempo (s)

$T \quad$ Temperatura $(\mathrm{K})$

$\Delta T_{l n} \quad$ Diferencia de temperaturas logarítmica $(\mathrm{K})$

$U \quad$ Coeficiente de transferencia de calor global $\left(\mathrm{W} \cdot \mathrm{m}^{-2} \cdot \mathrm{K}^{-1}\right)$

$v \quad$ Velocidad $\left(\mathrm{m} \cdot \mathrm{s}^{-1}\right)$

$V \quad$ Volumen $\left(\mathrm{m}^{3}\right)$

We Número de Weber

$x \quad$ Título de vapor

$\bar{x} \quad$ Título de vapor local

$\left\{x_{0}, y_{0}\right\} \quad$ Números de B\&J

$\{x, y, z\} \quad$ Coordenadas Cartesianas $(\mathrm{m})$

$X \quad$ Paso $(\mathrm{m})$

$Y+\quad$ Distancia en perpendicular desde la pared hasta el centroide de la primera celda $(\mathrm{m})$

\section{Letras griegas}

$\alpha$

$\alpha$

$\beta$

$\delta$

$\Delta$

$\varepsilon$

$\varepsilon$

$\eta$

$\{r, \theta\}$

$\{r, \theta, z\}$
Fracción de volumen de vapor

Absortancia

Coeficiente de expansión térmica $\left(\mathrm{K}^{-1}\right)$

Espesor (m)

Incremento

Tasa de disipación de la turbulencia $\left(\mathrm{m}^{2} \cdot \mathrm{s}^{-3}\right)$

Emitancia

Eficiencia

Coordenadas Polares $(\mathrm{m}, \underline{\mathrm{O}})$

Coordenadas Cilíndricas (m, $\stackrel{0}{ }, \mathrm{~m})$ 


$\begin{array}{ll}\kappa & \text { Energía cinética turbulenta }\left(\mathrm{J} \cdot \mathrm{s}^{-1}\right) \\ \mu & \text { Viscosidad dinámica }(\mathrm{Pa} \cdot \mathrm{s}) \\ \nu & \text { Viscosidad cinemática }\left(\mathrm{m}^{2} \cdot \mathrm{s}^{-1}\right) \\ \pi & \text { Número pi }(3.14159265359) \\ \rho & \text { Densidad }\left(\mathrm{kg} \cdot \mathrm{m}^{-3}\right) \\ \sigma & \text { Tensión superficial }\left(\mathrm{N} \cdot \mathrm{m}^{-1}\right) \\ \sigma & \text { Constante de Stefan-Boltzmann }\left(5.67 \cdot 10^{-8} \mathrm{~W} \cdot \mathrm{m}^{-2} \cdot \mathrm{K}^{-4}\right) \\ v & \text { Volumen específico }\left(\mathrm{kg}^{-1} \cdot \mathrm{m}^{3}\right) \\ \Phi & \text { Factor bifásico } \\ \varphi & \text { Ángulo de inclinación }\left(^{\circ}\right)\end{array}$

\section{Subíndices}

$\infty$

1

bif

bulk

$c$

cold

con

correlac

cri

dis

e

eff

$e q$

exp

EXT

$f$

fri

$g$

$h$

hel

hom

hor

hot

$\mathrm{H}_{2} \mathrm{O}$

$i$
Seno sales fundidas

Primer

Bifásico

Seno agua-vapor

Centro

Sumidero

Concentradas

Correlacionado

Crítica

Distribuidas

Eléctricos

Efectiva

Equivalente

Experimental

Exterior

Fluido

Fricción

Gravedad

Hidráulico

Helicoidal

Homogéneo

Horizontal

Fuente

agua

Interno 


$\begin{array}{ll}\text { int } & \text { Intercambiada } \\ \text { IN } & \text { Entrada } \\ \text { INT } & \text { Interior } \\ l & \text { Líquido } \\ l a t & \text { Latente } \\ m & \text { Mezcla } \\ \text { med } & \text { Media } \\ \text { ms } & \text { Sales fundidas } \\ \text { Max } & \text { Máximo } \\ \text { Min } & \text { Mínimo } \\ \text { mod } & \text { Modelado } \\ \text { nec } & \text { Necesaria } \\ o & \text { Externo } \\ \text { OUT } & \text { Salida } \\ s & \text { Solidificación } \\ \text { SAT } & \text { Saturado } \\ \text { simu } & \text { Simulado } \\ \text { sub } & \text { Subenfriado } \\ t & \text { Turbulento } \\ \text { th } & \text { Térmico } \\ \text { Tot } & \text { Total } \\ v & \text { Vapor } \\ \text { ver } & \text { Vertical } \\ w & \text { Pared } \\ \text { ws } & \text { Agua-vapor } \\ & \end{array}$




\section{Acrónimos}

CCP Colector Cilindro-Parabólico

CE Comisión Europea

CEA Commissariat a l'energie atomique et aux energies alternatives

CETA Centro Extremeño de Tecnologías Avanzadas

CFD Computational Fluid Dynamics

CIEMAT Centro de Investigaciones Energéticas, Medioambientales y Tecnológicas

CNRS Centre National de la Recherche Scientifique

CREF Cyprus Research and Educational Foundation

CSP Concentrating Solar Power

CT Computed Tomography

DAQ Data Acquisition System

DCS Distributed Control System

DNI Direct Normal Irradiance

DNS Direct Numerical Simulation

DWOs Density Wave Oscillations

ENEA Agenzia nazionale per le nuove tecnologie, l'energia e lo sviluppo económico sostenibile

GPU Unidad de Procesamiento de Gráficos

HHHC Horizontal heater and horizontal cooler

HHVC Horizontal heater and vertical cooler

HTF Heat Transfer Fluid

IAPWS-IF97 International Association for the Properties of Water and Steam, Industrial Formulation 1997

LES Large Eddy Simulation

LNEG Laboratório Nacional de Energia e Geologia

MASEN Moroccan Agency for Sustainable Energy

NCL Natural Circulation Loop

NDL Non uniform Diameter Loop 
OECD/NEA Organisation for Economic Cooperation and Development Nuclear Energy Agency

OPTS OPtimization of a Thermal energy Storage system with integrated Steam Generator

RANS Reynolds Averaged Navier-Stokes

RLF Reflector Lineal de Fresnel

SEGS Solar Energy Generating Systems

SFR Sodium-cooled Fast Reactors

SIMPLE Semi-Implicit Method for Pressure Linked Equations

SOLATERM Grande progetto solare termodinámico

TES-SG Thermal Energy Storage-Steam Generator

UDF User Defined Function

UDL Uniform Diameter Loop

VHHC Vertical heater and horizontal cooler

VHVC Vertical heater and vertical cooler 


\section{Lista de figuras}

Figura 1 Esquema del TES-SG. . . . . . . . . . . . . . . . . . . . vii

Figura $2 \quad$ Prototipo experimental (Fuente: Elaboración propia). . . . . . . . . . vii

Figura 3 TES-SG scheme (Rinaldi et al.]2015). . . . . . . . . . . . . . . . xii

Figura $4 \quad$ Experimental prototype (Source: Own elaboration). . . . . . . . . . . xii

Figura 1.1 Eficiencia teórica frente a la temperatura de trabajo del fluido caloportador, para diferentes índices de concentración asumiendo que $\mathbf{I}=1000$ $W \cdot m^{-2}$ y $T_{\text {cold }}=300 K$ (elaboración propia). . . . . . . . . . . . . . . 4

Figura 1.2 Esquemas de las principales tecnologías de concentración solar. (Fuente: Elaboración propia a partir de ESTELA, the European Solar Thermal Electricity Association $(2020))$. . . . . . . . . . . . . . . . 4

Figura 1.3 Localización geográfica de proyectos termosolares anunciados, planeados, en desarrollo o en construcción (enero de 2017). (Fuente: Elaboración propia a partir de SOLARGIS $\mid(2016)$ y $\mid$ New Energy Update $[(2017))$. . . . . . . . . 5

Figura 1.4 Esquema planta con sistema de almacenamiento térmico de doble tanque indirecto $\left(\right.$ Libby $_{6}[2009)$. . . . . . . . . . . . . . . . . 8

Figura 1.5 Esquema planta con sistema de almacenamiento térmico de doble tanque directo $($ Libby $[2009) . \ldots \ldots$. . . . . . . . . . . . . 9

Figura 1.6 Esquema planta con sistema de almacenamiento térmico de tanque termoclino (Libby, 2009). . . . . . . . . . . . . . . . . . . 11

Figura 1.7 Plantas termosolares SEGS-NextEra Energy Resources (Teske et al.,

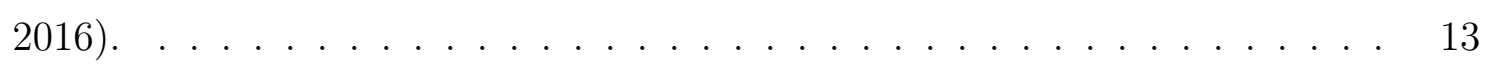

Figura 1.8 Planta termosolar Andasol 2-ACS Cobra (Fuente: Elaboración propia). 13

Figura 1.9 Planta termosolar Solar Two $($ Pacheco $[2002)$. . . . . . . . . . . . . . . 14

Figura 1.10 Planta termosolar Gemasolar-Torresol Energy (Fuente: Elaboración propia). . . . . . . . . . . . . . . . . . . . 15

Figura 1.11 Planta termosolar Archimede-ENEL (Fuà, 2018). . . . . . . . . . . . 16

Figura 1.12 Esquema de funcionamiento del prototipo en modo descarga. . . . . . 18

Figura 1.13 Campo de temperaturas simplificado en el lado sales fundidas en dos instantes de tiempo $t_{1}$ y $t_{2}$, siendo $t_{1}<t_{2}$, durante una de las descargas del prototipo. (Fuente: modelo CFD del Capítulo 4 ). . . . . . . . . . . . . . 19 
Figura 1.14 Modelo simplificado para el cálculo de la transferencia de calor en el generador de vapor integrado con resistencias térmicas equivalentes.

Figura 1.15 Circulación natural en un NCL. (Fuente: Elaboración propia a partir de Nuclear-Power(2020)). . . . . . . . . . . . . . . . . 22

Figura 1.16 NCL equivalante del TES-SG en modo descarga. . . . . . . . . . . . . 23

Figura 1.17 Patrones de flujo para matrices de tubos en línea (Wallis, [1939). El flujo en todas las imágenes es ascendente. . . . . . . . . . . . . . . . . . 26

Figura 1.18 Patrones de flujo para matrices de tubos escalonados (Wallis, 1939). El flujo en todas las imágenes es ascendente. . . . . . . . . . . . . . . . 26

Figura 1.19 LIC (Line Integral Convolution) $\left.\right|^{2}$ del campo de velocidaes en el lado sales fundidas durante una de las descargas del prototipo. Fuente: modelo CFD del Capítulo 4 . . . . . . . . . . . . . . . . . . 28

Figura 1.20 Esquema de las configuraciones más comunes de matrices de tubos y parámetros característicos: a) en línea; b y c) escalonados (Kakaç et al. (1987)). 28

Figura 1.21 Clasificación de la compacidad en matrices de tubos. . . . . . . . . . . 29

Figura 1.22 Variación de la transferencia de calor local alrededor de 1) un tubo individual y una matriz de tubos separados configurada 2) en linea o 3 ) escalonada (Zukauskas y Ulinskas, 1988). . . . . . . . . . . . . . . . . 29

Figura 1.23 Variación de la transferencia de calor local en una matriz cuadrada de tubos cuasi-compactos $\left(X / d_{o}=1.5\right)$ configurada en linea, para diferentes

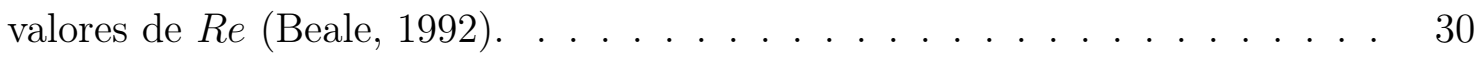

Figura 1.24 Factor de corrección para la transferencia de calor, $c z_{n}$, en función del número de filas de una matriz de tubos (Kakaç et al. [1987). . . . . . . . . . 32

Figura 1.25 Regímenes de flujo y mecanismos de transferencia de calor en un tubo recto calentado uniformemente $\mid$ Akimoto et al. $\mid(2016)$. . . . . . . . . . . . . . 35

Figura 1.26 Simulación del comienzo del régimen de superficie seca (primer dryout y dryout total) en un tubo helicoidal. Fuente: modelo CFD del Capítulo 6. . 38

Figura 1.27 Mecanismos que gobiernan el primer dryout en tubos helicoidales. Mapa 2D de Berthoud y Jayanti|(1990). . . . . . . . . . . . . . . . . . . 42

Figura 2.1 Esquema del circuito de sales del cual forma parte el tanque de almacenamiento térmico (SA. 1.01). La línea roja muestra el recorrido de las sales fundidas en el modo circulación estándar (Gaggioli[ 2007). . . . . . 48

Figura 2.2 Circuito agua-vapor. La zona roja es la rama caliente y la azul la fría. Fuente: ENEA. . . . . . . . . . . . . . . . . . . . . . 50

Figura 2.3 Interfaz gráfica del circuito agua-vapor en un determinado instante de un ensayo de descarga del prototipo. Fuente: ENEA. . . . . . . . . . . . . . 51

Figura 2.4 Tanque de almacenamiento térmico con generador de vapor integrado (Fabrizi et al. $\mid 2012)$. . . . . . . . . . . . . . . . . . . . . 52 
Figura $2.5 \quad$ Elementos presentes en el prototipo (Fabrizi et al. $[2012)$. . . . . . . . 53

Figura 2.6 Generador de vapor: downcomer. Fuente: ENEA. . . . . . . . . . . . 55

Figura 2.7 Generador de vapor. shell y abertura variable. Fuente: ENEA. . . . . 55

Figura 2.8 Difusor. Fuente: ENEA. . . . . . . . . . . . . . . . . . . . . . . 56

Figura 2.9 Generador de vapor. Tubos helicoidales 1, 2 y 3. Fuente: ENEA. . . . 56

Figura 2.10 Generador de vapor. Impeler. Fuente: ENEA . . . . . . . . . . . . . . 57

Figura 2.11 Colectores de: a) entrada y b) salida. Fuente: ENEA. . . . . . . . . . 58

Figura 2.12 Esquema instrumentación en el prototipo (Fabrizi et al. $[2012)$. . . . . 60

Figura $3.1 \quad$ Esquema detallado de una sección transversal del generador de vapor identificando los tubos, así como, posición y la nomenclatura de los termopares asociados al tubo interno, $\mid$ Fabrizi et al. $[(2012)$. . . . . . . . . . . . . . . . . 64

Figura $3.2 \quad$ Medidas principales del ensayo considerado. . . . . . . . . . . . . . . 66

Figura $3.3 \quad$ Otras medidas del ensayo considerado . . . . . . . . . . . . . . . . . . . . 68

Figura $3.4 \quad$ Caudal másico total en el circuito agua-vapor. . . . . . . . . . . . . . 70

Figura $3.5 \quad$ Caudal másico en el tubo helicoidal exterior (Tubo 1). . . . . . . . . 72

Figura $3.6 \quad$ Caudal másico en el tubo helicoidal central (Tubo 2). . . . . . . . . . 72

Figura $3.7 \quad$ Caudal másico en el tubo helicoidal interior (Tubo 3). . . . . . . . . . 73

Figura 3.8 Temperaturas de las sales fundidas próximas a las paredes externas del tanque durante el ensayo. . . . . . . . . . . . . . . . . . 75

Figura 3.9 Temperaturas de las sales fundidas en seno del tanque durante el ensayo. 76

Figura 3.10 Temperaturas de las sales fundidas en seno del tanque y temperaturas de la pared exterior aislante del generador durante el ensayo. En el primer caso no se aplica el código de colores. . . . . . . . . . . . . . . . . . . . . . . 78

Figura 3.11 Temperaturas observadas (puntos) de las sales fundidas durante el ensayo (a partir de los 14 termopares) y ajustes a curvas logísticas (líneas). . 78

Figura 3.12 Ensayo del 29 de octubre de 2012: algunas medidas principales y derivadas. . . . . . . . . . . . . . . . . . 80

Figura 3.13 Temperaturas de las sales fundidas en seno del tanque y próximas a las paredes externas durante el ensayo. En el primer caso no se aplica el código de colores. . . . . . . . . . . . . . . . . . . . 81

Figura 3.14 Temperaturas en pared del tubo helicoidal interno durante el ensayo. 83

Figura 3.15 Temperaturas de pared en función de la altura del generador. En cada

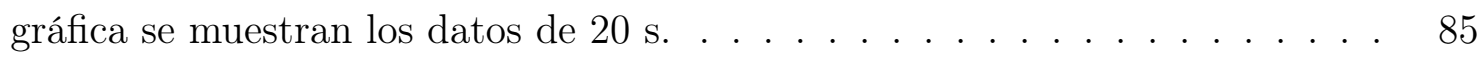

Figura 3.16 Temperaturas cerca de la superficie del tubo helicoidal interno durante el ensayo. . . . . . . . . . . . . . . . . . . . . 87

Figura 3.17 Temperaturas "en el seno" del generador durante el ensayo y a la entrada y a la salida del generador. . . . . . . . . . . . . . . . . . 88 
Figura 4.1 Vista en perspectiva del interior del prototipo. Las flechas indican la circulación de las sales a través del generador de vapor integrado.

Figura 4.2 Modelo geométrico del generador, vistas en perspectiva. a) Exterior: abertura, shell y difusor. Interior: b) tubos helicoidales y c) downcomer. . . . 91

Figura 4.3 Subdominios geométricos del modelo CFD. . . . . . . . . . . . . . . . 92

Figura 4.4 Detalles del mallado: a) seno del tanque, b) interior del generador (tubos helicoidales), c) entorno de entrada (abertura) y d) entorno de salida (difusor). . . . . . . . . . . . . . . . . . 93

Figura $4.5 \quad$ Condiciones de contorno del modelo CFD. $\ldots \ldots$. . . . . . . . . . . 97

Figura $4.6 \quad$ Medidas principales durante el ensayo. La flecha negra indica el tramo simulado. . . . . . . . . . . . . . . . . . . . . . 97

Figura 4.7 Temperaturas en la pared del tubo helicoidal interno y promedios temporales cada 20 minutos durante el ensayo. Se aplica el código de colores. $\quad 98$

Figura 4.8 Perfiles de temperatura de pared del tubo helicoidal interno cada 20 minutos. . . . . . . . . . . . . . . . . . . . . . . . 99

Figura 4.9 Condiciones de contorno de los tubos helicoidales basadas en los datos experimentales. . . . . . . . . . . . . . . . . 100

Figura 4.10 Análisis de sensibilidad del paso de tiempo: evolución temporal de la velocidad máxima en el punto donde está situado el termopar TI_8_110 (termopar en el interior del difusor o sálida de las sales del generador de vapor).101

Figura $4.11 C F L$ a $\operatorname{los} 7050 \mathrm{~s}$ en el difusor. . . . . . . . . . . . . . . . . . . . . . 102

Figura 4.12 Comportamiento numérico de la velocidad máxima en el punto donde está situado el termopar TI_8_110 en un tramo de la descarga a medida que el modelo itera. Se observa la convergencia del modelo en cada paso de tiempo. 103

Figura 4.13 Evolución temporal de la temperatura de las sales fundidas a la salida del generador. . . . . . . . . . . . . . . . . . . . . 104

Figura 4.14 Evolución temporal de la potencia intercambiada entre las sales fundidas y el agua-vapor. . . . . . . . . . . . . . . . . . . 105

Figura 4.15 Evolución temporal del caudal másico de sales fundidas. . . . . . . . 106

Figura 4.16 Evolución temporal de las temperaturas de las sales fundidas en el seno del tanque. . . . . . . . . . . . . . . . . . . . . . . . 107

Figura 4.17 Zoom del campo de temperaturas alrededor del tubo helicoidal interno a los 7050 s sobre el mallado. El circulo rojo punteado delimita el ámbito de medida de los termopares TI_8_3n2 $(2 \mathrm{~mm}$, ver $\S 3.4)$. . . . . . . . . . . 108

Figura 4.18 Izda.) elementos de superficie considerados para el cálculo de las velocidades locales y los coeficientes de transferencia calor locales en un modelo 2D; dcha.) n-ésima vuelta de hélice. . . . . . . . . . . . . . . . . . . 109 
Figura 4.19 Distribuciones de los coeficientes de transferencia de calor alrededor de los tubos helicoidales. . . . . . . . . . . . . . . . . . . . . . . . . . . 110

Figura 4.20 Zoom de los campos de a) presiones y b) velocidades alrededor de los tubos helicoidales a los $7050 \mathrm{~s}$ (campos escalares en código de colores y carácter vectorial superpuesto con flechas). .

Figura 4.21 Coeficientes de transferencia de calor locales a lo largo del generador.

Figura 5.1 Medidas principales durante el ensayo. La flecha roja indica el tramo adicional simulado.

Figura 5.2 Vista frontal de la sección de paso en el generador de vapor (en color salmón). . . . . . . . . . . . . . . . . . . . . . . . 119

Figura 5.3 Comparación entre los resultados calculados y los modelados. . . . . . 120

Figura 5.4 Izda.) elementos de volumen considerados para el cálculo de las velocidades locales y los coeficientes de transferencia calor locales en un modelo 3D; dcha.) n-ésima vuelta de hélice.

Figura $5.5 \quad$ Ajustes de los datos de transferencia de calor del problema. . . . . . . 124

Figura $5.6 \quad$ Nuevo ajuste de los datos de transferencia de calor del problema. . . 124

Figura 5.7 Comparación entre los resultados obtenidos y los calculados mediante las correlaciones de Genić et al. [2012) y $\operatorname{Smith}[(2006)$, considerando $\overline{P r}=7.8$ $\mathrm{y} \frac{\mu}{\mu_{w}}=0.70$.

Figura 6.1 Modelo geométrico del generador, vista en perspectiva interior: tubos helicoidales y detalle de los mismos.

Figura 6.2 Vista en detalle del mallado. Subdominios: lado sales fundidas (en amarillo), paredes de los tubos (en gris) y lado agua-vapor (en azul). . . . . 131

Figura $6.3 \quad$ Fracciones de vapor en función de la altura del primer tubo. . . . . . 140

Figura $6.4 \quad$ Fracciones de vapor en función de la altura del segundo tubo. . . . . 141

Figura 6.5 Temperaturas (en ambos lados) y caudal másico lado sales fundidas durante el ensayo. Tramos en color rojo, zonas transitorias y tramo en color verde zona cuasi-estacionaria. . . . . . . . . . . . . . . . . . . . . . . . . . . 143

Figura 6.6 Presiones individuales y caudal másico total lado agua-vapor durante el ensayo. Tramos en color rojo, zonas transitorias y tramo en color verde zona cuasi-estacionaria. . . . . . . . . . . . . . . . . . . . . . . . . 144

Figura 6.7 Izda.) distribución de termopares de pared a lo largo del tubo helicoidal interno; dcha.) zoom del n-ésimo. . . . . . . . . . . . . . . . . 146

Figura 6.8 Comparación entre las temperaturas de pared simuladas y observadas (en el tubo helicoidal interno). . . . . . . . . . . . . . . . . . . . . . . . . 148 
Figura 6.9 Comparación entre las hipótesis de equilibrio versus no equilibrio \begin{tabular}{|c|}
\hline termodinámico para describir el régimen postdryout en un tubo recto en \\
\hline
\end{tabular} vertical calentado uniformemente (Collier y Thome, 1994)] . . . . . . . . . . 149

Figura 6.10 Título de vapor alrededor de los tubos helicoidales y en el seno del fluido al comienzo del régimen de superficie seca, en $\bar{t}_{1}$ (izda.) y $\bar{t}_{5}$ (dcha.). . 152

Figura 6.11 Integral de convolución del campo de velocidades en el interior de los tubos helicoidales en $z_{6}$ y en $\bar{t}_{1}$ (eje del generador situado a la izquierda de la imagen). . . . . . . . . . . . . . . . . 152

Figura 6.12 Campo de velocidades en el interior de los tubos helicoidales en $z_{6} \mathrm{y}$ en $\bar{t}_{1}$ (eje del generador situado a la izquierda de la imagen). . . . . . . . . . 153

Figura 6.13 Temperatura alrededor de los tubos helicoidales y en el seno del fluido al comienzo del régimen de superficie seca, en $t_{1}$ (izda.) y $\bar{t}_{5}$ (dcha.). . . . . . 153

Figura 6.14 Mapa 2D de B\&J durante el primer dryout en $\bar{t}_{1} \mathrm{y} \bar{t}_{5}$. . . . . . . . . 154

Figura 6.15 Título de vapor en el interior de los tubos helicoidales en $z_{6}$ y $\bar{t}_{1}$ (eje del generador situado a la izquierda de la imagen). . . . . . . . . . . . . 155

Figura 6.16 Comparación entre los resultados simulados (representados por la línea vertical) y los calculados mediante correlaciones de la literatura para el primer dryout. . . . . . . . . . . . . . . . . 156

Figura 6.17 Comparación entre los resultados simulados (representados por la línea vertical) y los calculados mediante correlaciones de la literatura para el dryout total. . . . . . . . . . . . . . . . . . . . . . 158

Figura A.1 Resistencias térmicas relativas locales a lo largo del generador (tubo helicoidal central). Fuente: modelo CFD del Capítulo 6. . . . . . . . . . . . . 169

Figura A.2 Capas límite dinámica y térmica para un fluido con $\operatorname{Pr}>1$. Elaboración propia a partir de Akimoto et al. $[(2016)$. . . . . . . . . . . . . . 171

Figura A.3 Volumen de control en coordenadas cartesianas. Elaboración propia a partir de Akimoto et al. $\mid(2016)$. . . . . . . . . . . . . . . . . . . . . . . 173

Figura B.1 Inestabilidades completamente desarrolladas en la zona central de la fase cuasi-estacionaria y su efecto sobre las presiones en los colectores del generador. . . . . . . . . . . . . . . . . . 187

Figura B.2 Inestabilidades completamente desarrolladas en la zona central de la fase cuasi-estacionaria y su efecto sobre las temperaturas al comienzo y final de los tubos helicoidales. . . . . . . . . . . . . . . . . . . . . . . . . . . . . . 188

Figura B.3 Efecto de las inestabilidades sobre las temperaturas de pared del tubo helicoidal interno . . . . . . . . . . . . . . . . . . . . . . . . . . . . . . . . . 189 
Figura C.1 Izda.eje del generador: conjunto de alturas $\left\{z_{n}\right\}_{n=0,1, \ldots, 9}$. Dcha. eje del generador: conjunto de termopares de pared del tubo helicoidal 3 (TI_8_3n1).198

Figura C.2 Títulos de vapor locales en función de la altura del generador. . . . . 199

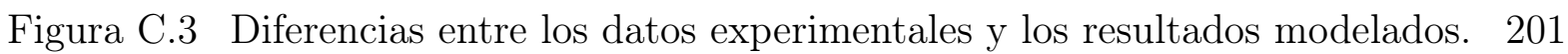

Figura C.4 Presiones modeladas al comienzo y al final de las helicoides durante el ensayo. Tramos en color rojo, zonas transitorias y tramo en color verde zona cuasi-estacionaria. . . . . . . . . . . . . . . . . . . . 202 


\section{Lista de tablas}

Tabla 1 Condiciones de operación del prototipo en la fase cuasi-estacionaria. . ix

Tabla $2 \quad$ Prototype working conditions. . . . . . . . . . . . . . . $\quad \mathrm{xv}$

Tabla $1.1 \quad$ Impacto macroeconómico de las renovables en España en 2017: Solar termoeléctrica (PROTERMOSOLAR, 2017). . . . . . . . . . . . 6

Tabla 1.2 Centrales en operación, desarrollo o construcción con más de 9 h de almacenamiento térmico. Elaboración propia a partir de $\mid$ NREL[2018). . . . 12

Tabla 1.3 Centrales con almacenamiento térmico del programa de demostración de China. Elaboración propia a partir de $\operatorname{NREL}(2018)$. . . . . . . . . . . . . 12

Tabla 1.4 Correlaciones propuestas por Zukauskas para flujos cruzados alrededor de matrices de tubos en línea, en función del número de Reynolds (Kakaç et

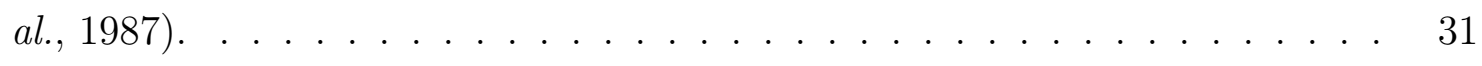

Tabla 1.5 Correlaciones propuestas por Zukauskas para flujos cruzados alrededor de matrices de tubos escalonados en función del número de Reynolds (Kakaç

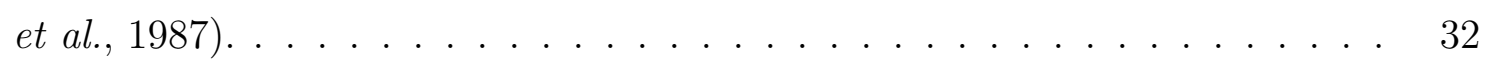

Tabla 1.6 Correlaciones para la transferencia de calor por convección forzada alrededor matrices de tubos helicoidales y rectos. . . . . . . . . . . . . . . 34

Tabla 1.7 Correlaciones para el cálculo del título de vapor durante el primer dryout y en el dryout total en tubos helicoidales . . . . . . . . . . . . . . . . . 40

Tabla 2.1 Precisión de la instrumentación utilizada en el lado agua-vapor. Fuente: ENEA. . . . . . . . . . . . . . . . . . . 52

Tabla 2.2 Instrumentación en el tanque de almacenamiento. Fuente: ENEA. . . . 54

Tabla $2.3 \quad$ Datos de diseño del generador de vapor integrado. Fuente: ENEA. . . 57

Tabla $2.4 \quad$ Instrumentación en el generador de vapor. Fuente: ENEA. . . . . . . . . 59

Tabla 2.5 Parámetros nominales. . . . . . . . . . . . . . . . . . . . . . . . . . . . 61

Tabla 2.6 Condiciones límite de operación del generador de vapor (especificaciones técnicas). Fuente: ENEA. . . . . . . . . . . . . . . . 61

Tabla $3.1 \quad$ Ensayo del 29 de octubre de 2012: condiciones de diseño . . . . . . . . . 63

Tabla 3.2 Fases de funcionamiento e información de interés durante el ensayo del 29 de octubre de 2012 . . . . . . . . . . . . . . . . . . . . . . 65 
Tabla 3.3 Medidas principales en la fase cuasi-estacionaria: valores máximo, mínimo, medio y desviación estándar. . . . . . . . . . . . . . . . 67

Tabla 3.4 Medidas derivadas de las principales en la fase cuasi-estacionaria: valores máximo, mínimo, medio y desviación estándar. . . . . . . . . . . . . 69

Tabla $3.5 \quad$ Condiciones nominales durante el ensayo considerado. . . . . . . . . . 69

Tabla 3.6 Caudal másico total agua-vapor en la zona central de la fase cuasi-estacionaria: valores máximo, mínimo, medio y desviación estándar. . . 71

Tabla 3.7 Caudales másicos individuales agua-vapor en la zona central de la fase cuasi-estacionaria: valores máximo, mínimo, medio y desviación estándar. . . 73

Tabla 3.8 Amplitudes de oscilación de las temperaturas de pared $\left({ }^{\circ} \mathrm{C}\right)$.

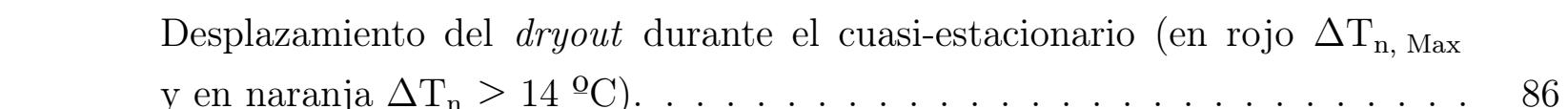

Tabla 4.1 Tamaños característicos del mallado . . . . . . . . . . . . . . . . . . . . . 92

Tabla 4.2 Diagnóstico topológico del mallado seleccionado. . . . . . . . . . . . . 94

Tabla 4.3 Parámetros del modelo Realizable $\kappa-\varepsilon$ Two Layer (CD adapco, 2014). 95

Tabla 4.4 Parámetros característicos de las funciones logísticas cada 20 minutos. 99

Tabla $4.5 \quad$ Diferencias máximas de temperatura (y error relativo porcentual) entre sus valores experimentales y simulados. . . . . . . . . . . . . . . 107

Tabla 5.1 Correlaciones para la transferencia de calor. . . . . . . . . . . . . . . . . 123

Tabla 6.1 Resumen de valores de las variables de mayor interés del problema en

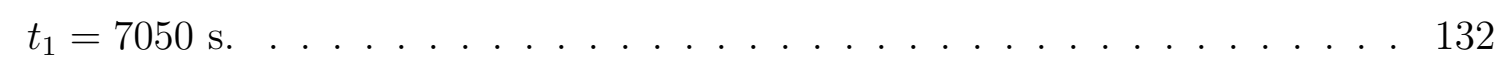

Tabla 6.2 Diagnóstico topológico del mallado seleccionado. . . . . . . . . . . . . 133

Tabla 6.3 Condiciones de trabajo de los experimentos de Bartolomei et al. . . . . 140

Tabla 6.4 Parámetros estadísticos de ambos modelos. Todos ellos son adimensionales. 141

Tabla 6.5 Comparación entre las temperaturas simuladas y observadas. . . . . . 146

Tabla 6.6 Comparación entre las potencias intercambiadas simuladas y observadas. 146

Tabla 6.7 Comparación entre las presiones simuladas y observadas. . . . . . . . . 147

Tabla $6.8 \quad$ Localización del dryout en el tubo helicoidal interno. . . . . . . . . . . . . 149

Tabla 6.9 Localización del primer dryout y del dryout total en los tres tubos

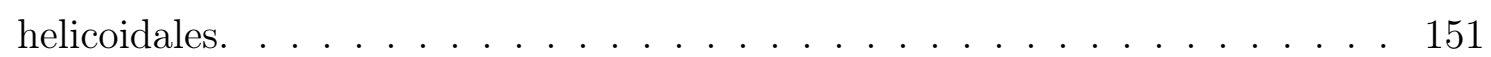

Tabla A.1 Números adimensionales para describir la transferencia de calor por

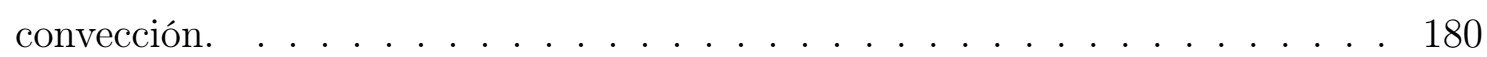

Tabla B.1 Clasificación de las inestabilidades termo-hidráulicas en flujos bifásicos. 184

Tabla C.1 Tipos y características de los tubos considerados en el modelo. . . . . 194 
Tabla C.2 Tipos y características de las pérdidas de carga concentradas consideradas en el modelo, CRANE[(1989). . . . . . . . . . . . . . . . . . 195

Tabla C.3 Alturas del subtramo 2 de la zona cuasi-estacionaria de la descarga. . 200

Tabla C.4 $\left\{\right.$ PI_8_210-P mod,\# $_{\#=1,2,3}$ en la zona cuasi-estacionaria de la descarga: valores máximo, mínimo, medio y desviación estándar. ...... . 201

Tabla F.1 Datos para el cálculo de la entalpía $H_{l, S A T_{\#}}$ del agua en la Región 1. . 208

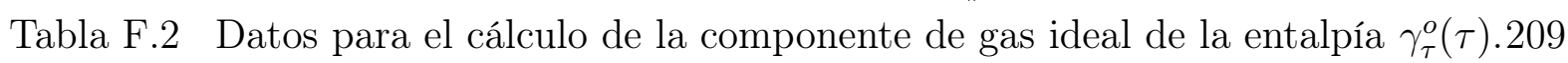

$\begin{array}{llll}\text { Tabla } & \text { F.3 } & \text { Datos para el cálculo de la componente residual de la entalpía } \gamma_{\tau}^{r}(\tau, \pi) . & 210\end{array}$

Tabla $\overline{\text { F.4 }}$ Datos para el cálculo de la presión de saturación $\frac{P_{S A T}}{P_{4}^{*}}(T)$. . . . . . . . 211

Tabla $\overline{\text { F.5 }}$ Errores en la medida de $\left\{\dot{m}_{w s_{\#}}\right\}_{\#=1,2,3} \mathrm{y}\left\{T_{S A T_{\#}}\right\}_{\#=1,2,3} \cdot \ldots \ldots$ 


\section{Capítulo 1}

\section{Introducción y motivación}

Los sistemas de almacenamiento térmico para aplicaciones industriales aportan a aquellas tecnologías energéticas que, de otra manera, no permiten la gestión de su producción, la posibilidad de desplazarla y, por lo tanto, ajustarla a la demanda. Un ejemplo son las plantas de energía solar termoeléctrica dotada de almacenamiento térmico.

Cuando se revisa el estado de la técnica de los sistemas de almacenamiento térmico para plantas termosolares a nivel comercial, se observa que el sistema más habitual es el de doble tanque en sales fundidas. Éste combina el uso de un medio de almacenamiento de coste reducido y un diseño con eficiencia elevada. Aun así, es necesario fomentar la $\mathrm{I}+\mathrm{D}+\mathrm{i}$ en estos sistemas con objeto de demostrar la competitividad de esta tipología de planta como reemplazo a otras basadas en el uso de combustibles fósiles.

Este trabajo versa sobre el desarrollo tecnológico de un nuevo sistema de almacenamiento térmico, patentado por ENEA y la empresa ANSALDO NUCLEARE S.p.A. El diseño, a escala de prototipo, está compuesto por un solo tanque de sales fundidas y un generador de vapor integrado en el mismo, TES-SG (Thermal Energy Storage with integrated Steam Generator).

Este capítulo profundiza en el estado de la técnica de la física asociada y el modelado de la misma para analizar la forma en que se transfiere el calor en este sistema. Se contemplan tanto la fenomenología del lado primario (sales) como del secundario (agua-vapor). La metodología seguida en este estudio es el modelado numérico CFD (Computational Fluid Dynamics) apoyado en el análisis de datos experimentales de un prototipo de ENEA. Se cumple así con el objetivo de obtener la información necesaria para el correcto escalado de este diseño y la promoción de su potencial de uso en aplicaciones industriales de calor de proceso y/o generación de electricidad. 


\subsection{Sistemas de almacenamiento térmico para plantas termosolares}

En muchos países se está avanzando en el uso de la energía solar destacando la termosolar debido a su gestionabilidad. Es decir, a la capacidad de desacoplar la generación de energía asociada a las horas de sol de la producción que sigue la curva de demanda. Desacoplando con sistemas de almacenamiento se puede programar la producción de forma similar a como en una central fósil convencional. Una planta termosolar, CSP plant (Concentrating Solar Power plant), es aquella que aprovecha la radiación solar concentrada transformándola en energía térmica para producir electricidad mediante un ciclo termodinámico.

Las plantas termosolares emplean diferentes tecnologías de concentración para transformar la radiación solar en energía térmica. Dichas tecnologías utilizan espejos para concentrar la radiación solar incidente en los receptores donde se pretende concentrar la radiación solar. Así, los espejos conforman el campo solar que recibe la radiación y la dirige adecuadamente sobre un captador de menor superficie, consiguiendo así la concentración perseguida. En el receptor circula el fluido caloportador (o HTF, Heat Transfer Fluid), el cual es el encargado de llevar la energía térmica concentrada en el receptor incrementando su entalpía hasta un ciclo termodinámico que convierte el calor en electricidad.

Los sistemas de concentración solar aprovechan únicamente la radiación solar directa (o DNI, Direct Normal Irradiance) por lo que necesitan dispositivos de seguimiento del movimiento aparente del Sol. Los dispositivos de seguimiento pueden ser de uno o dos ejes, y su misión es maximizar la cantidad de radiación solar reflejada en los captadores, logrando que el HTF alcance mayor temperatura en el receptor respecto a la configuración sin concentración. La temperatura alcanzada dependerá del índice de concentración, $C^{1}$, y de las condiciones de refrigeración del receptor. Aunque la eficiencia de este tipo de plantas no se incrementa simplemente con la temperatura del receptor, Figura 1.1. Su máxima eficiencia, $\eta$, es:

$$
\eta=\eta_{\text {receptor }} \eta_{\text {Carnot }}
$$

Siendo $\eta_{\text {receptor }}$ la eficiencia del receptor (transformación sol-calor) y $\eta_{\text {Carnot }}$ la eficiencia del ciclo termodinámico (transformación calor-trabajo). Puesto que:

$$
\eta_{\text {receptor }}=\frac{Q_{a b s}-Q_{\text {los }}}{Q_{\text {inc }}}
$$

\footnotetext{
${ }^{1}$ Razón entre el área del concentrador y el área del receptor
} 
y:

$$
\eta_{\text {Carnot }}=\left(1-\frac{T_{\text {cold }}}{T_{h o t}}\right)
$$

donde $Q_{a b s}, Q_{l o s}$ y $Q_{\text {inc }}$ son los flujos de calor absorbido, perdido e incidente en el receptor respectivamente, $T_{\text {cold }}$ la temperatura ambiente y $T_{\text {hot }}$ la temperatura del fluido caloportador en el receptor. Y, los flujos de calor son:

$$
\begin{gathered}
Q_{a b s}=\boldsymbol{\alpha} Q_{i n c} \\
Q_{l o s}=\boldsymbol{\sigma} \varepsilon S_{l o s} T_{h o t}^{4} \\
Q_{i n c}=\eta_{\text {optica }} \mathbf{I} S_{i n c} C
\end{gathered}
$$

Siendo $\boldsymbol{\alpha}$ y $\boldsymbol{\varepsilon}$ la absortancia y emisividad del receptor y $\boldsymbol{\sigma}$, la constante de Stefan-Boltzmann, $S_{l o s}$ y $S_{i n c}$ las superficies de pérdidas e incidencia en el receptor respectivamente, $\eta_{\text {optica }}$ la eficiencia óptica del receptor e I la irradiancia solar. Bajo las siguientes suposiciones:

- se cumple la ley de Kirchhoff, $\boldsymbol{\alpha}=\boldsymbol{\varepsilon}=1$

- las superficies de pérdidas e incidencia en el receptor son idénticas, $S_{l o s}=S_{i n c}$

- el receptor es un sistema óptico ideal, $\eta_{\text {optica }}=1$

se tiene que $\eta$, viene dada por:

$$
\eta=\left(1-\frac{T_{\text {cold }}}{T_{\text {hot }}}\right)\left(1-\frac{\boldsymbol{\sigma} T_{h o t}^{4}}{\mathbf{I} C}\right)
$$

De aquí que mientras más alta sea $T_{h o t}$, más alta será $\eta_{C a r n o t}$, pero también será más baja $\eta_{\text {receptor }}$. Por tanto, para cada tecnología existe una temperatura de operación óptima para la cual la eficiencia de la planta será máxima, Figura 1.1.

Existen 4 tipos principales de tecnologías de concentración: reflectores lineales de Fresnel (RLF), colectores cilindro-parabólicos (CCP), receptor central o de torre y discos parabólicos, Figura 1.2, cada una de ellas en distinta fase de desarrollo e implantación. Todas estas tecnologías utilizan un bloque de potencia centralizado para generar electricidad, excepto la tecnología de discos parabólicos, que habitualmente funciona con un receptor constituido por un motor Stirling para cada disco parabólico. La configuración de bloque centralizado permite que estas tecnologías sean adecuadas para aplicaciones de generación a gran escala, con valores habituales por encima de $50 \mathrm{MW}_{\mathrm{e}}$ (Libby, 2009), y alcanzándose hasta los 200 $\mathrm{MW}_{\mathrm{e}}$ en las más actuales. Sirva como ejemplo la planta Noor II, de MASEN (Moroccan Agency for Sustainable Energy), en Marruecos (PROTERMOSOLAR, 2018b). 


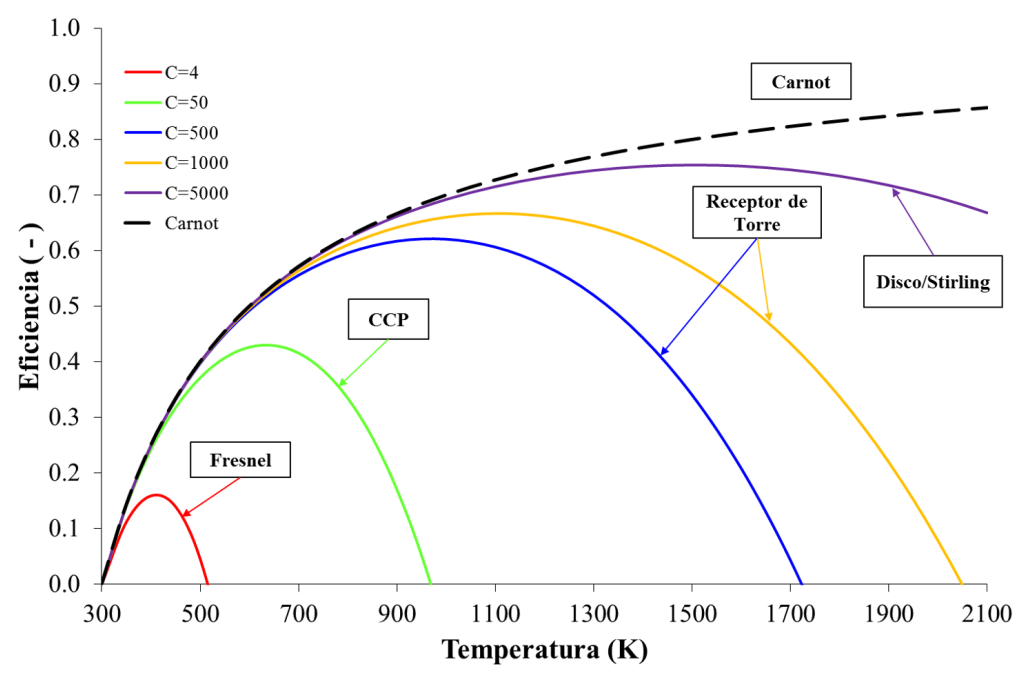

Figura 1.1: Eficiencia teórica frente a la temperatura de trabajo del fluido caloportador, para diferentes índices de concentración asumiendo que $\mathbf{I}=1000 \mathrm{~W} \cdot \mathrm{m}^{-2}$ y $T_{\text {cold }}=300 \mathrm{~K}$ (elaboración propia).

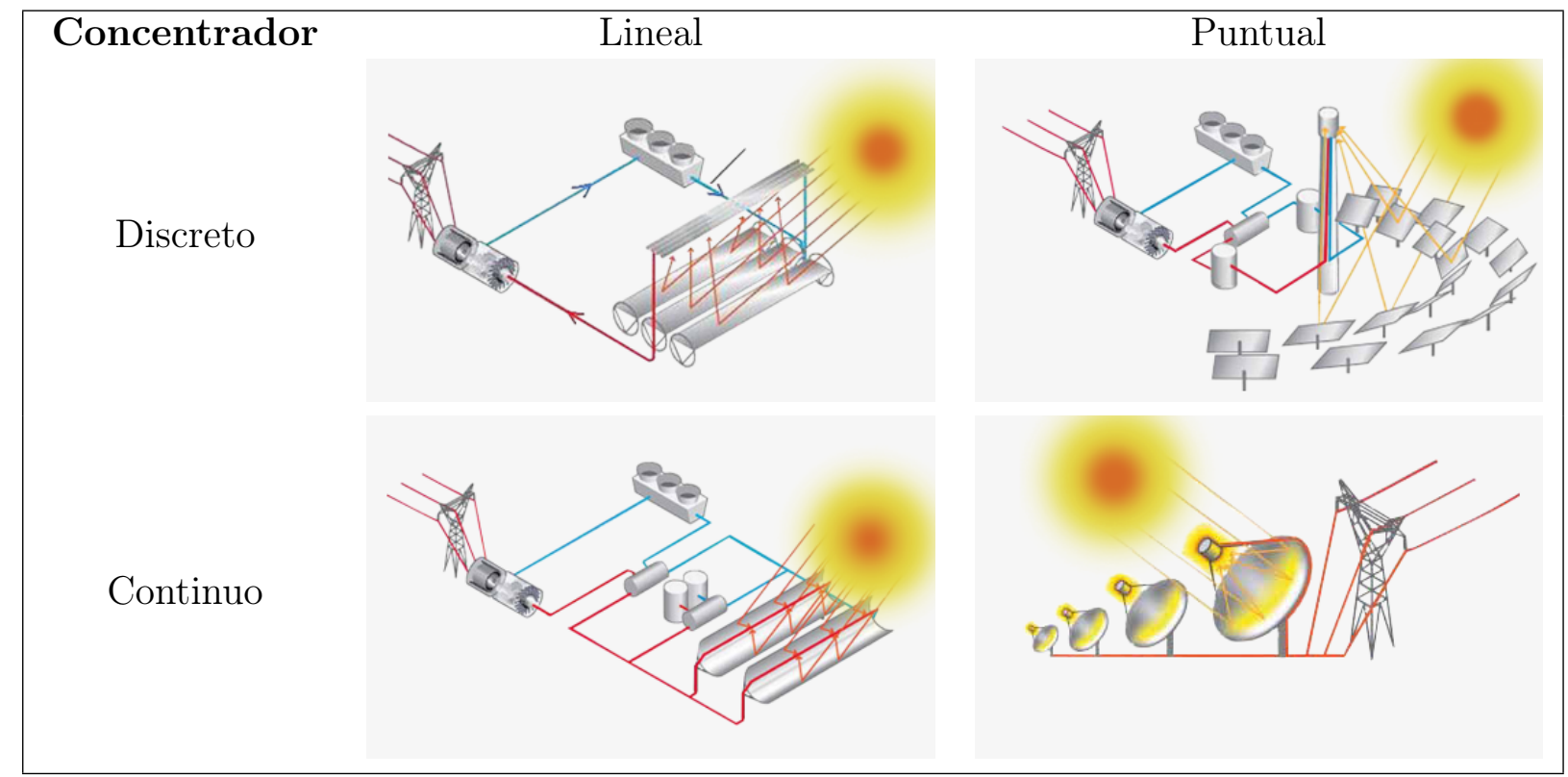

Figura 1.2: Esquemas de las principales tecnologías de concentración solar. (Fuente: Elaboración propia a partir de ESTELA, the European Solar Thermal Electricity Association (2020)).

El HTF puede efectuar directamente el ciclo termodinámico, por ejemplo, en el caso de que sea aire o vapor de agua. En otros casos, el HTF empleado en el campo solar intercambia su energía térmica con el fluido que se utilice en el bloque de potencia, o con algún otro fluido intermedio que posteriormente intercambie su energía térmica con el fluido de trabajo en el bloque de potencia.

Desde las primeras plantas termosolares comerciales (las plantas SEGS, de Solar Energy Generating Systems, en EE.UU., 1985 (Zarza y Sufrategui, 2006)) hasta las de más 
reciente operación como por ejemplo la planta Kathu Solar One, de Sudáfrica, en 2018 (PROTERMOSOLAR, 2018b), los avances se hacen palpables analizando:

- el número de plantas en operación: de 9 en 2007 a 97 en 2019 (PROTERMOSOLAR, 2018b), especialmente en los países con niveles de insolación altos, Figura 1.3

- el número de solicitudes de patente relacionadas con la termosolar (clasificación F24S23/00): de 293 en 2007 a 2381 en 2019 (EPO, 2020)

- el tamaño de las nuevas plantas en construcción, por ejemplo, la planta Noor Energy 1, en Dubai, que alcanzará los $600 \mathrm{MW}_{\mathrm{e}}$ (PROTERMOSOLAR, 2018b)

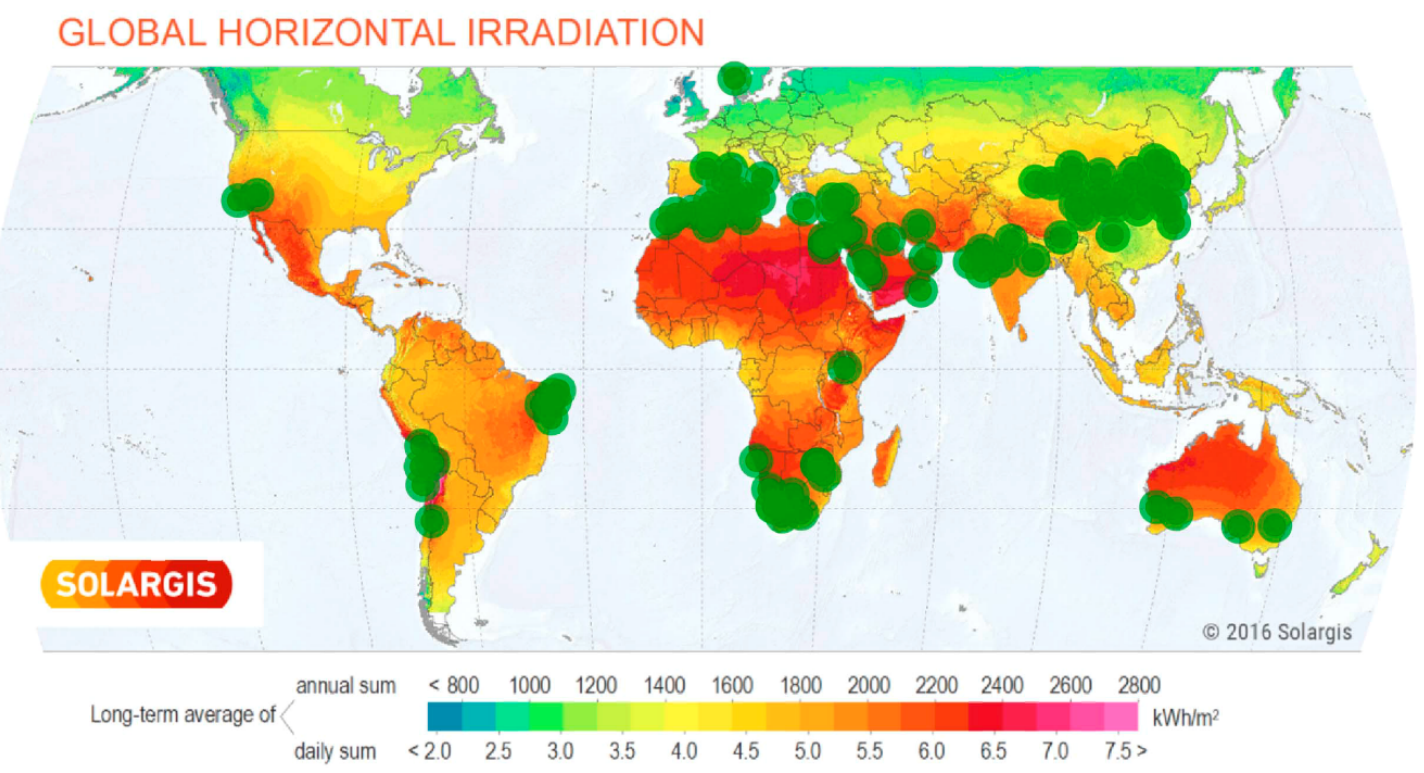

Figura 1.3: Localización geográfica de proyectos termosolares anunciados, planeados, en desarrollo o en construcción (enero de 2017). (Fuente: Elaboración propia a partir de SOLARGIS (2016) y New Energy Update (2017)).

El auge comercial descrito (Figura 1.3) responde al objetivo de promover la instalación de plantas que puedan contribuir a la producción de energía eléctrica sin emisiones de efecto invernadero en estos países. Es por ello, que gran parte de las ayudas públicas al sector de la producción de energía hayan sido destinadas a la CSP, bien sea como primas a la electricidad generada o como desgravaciones fiscales a la inversión. Estas políticas repercuten positivamente a nivel global, como muestra la Tabla 1.1 para el caso de España.

Para poder dar continuidad a este despliegue comercial se requiere que, manteniendo la sostenibilidad medioambiental, se aumente la competitividad de las plantas termosolares frente a las centrales convencionales de carbón y gas natural. Ello, iría acompañado de una progresiva reducción de sus costes que permitiría una paulatina disminución de las ayudas públicas. De ahí que se requiera un esfuerzo constante por parte de los centros de 
investigación, fabricantes, propietarios, ingenierías, etc., así como por parte de los organismos e instituciones públicas (Zarza, 2012).

Tabla 1.1: Impacto macroeconómico de las renovables en España en 2017: Solar termoeléctrica (PROTERMOSOLAR, 2017).

\begin{tabular}{|l|c|}
\hline PIB & $1464 \mathrm{M} €$ \\
○ Contribución directa & $1140 \mathrm{M} €$ \\
○ Contribución indirecta & $323 \mathrm{M} €$ \\
\hline Producción & $5347 \mathrm{GWh}$ \\
\hline Empleo & 5269 \\
\hline
\end{tabular}

Una de las opciones para la reducción de costes consiste en usar nuevos fluidos caloportadores para centrales de colectores cilindro-parabólicos, CCP. Esta tecnología ha venido empleando aceites térmicos, como mezclas de bifenilo, $\mathrm{C}_{12} \mathrm{H}_{10}$, y oxido de difenilo, $\mathrm{C}_{12} \mathrm{H}_{10} \mathrm{O}$ como fluidos caloportadores, cuyo coste de operación y mantenimiento es caro ya que se degradan por el ciclado térmico. Además, presentan riesgo de incendio cuando, estando calientes, tienen fugas al ambiente al mezclarse con el oxígeno del aire. También, al quemarse producen gases altamente contaminantes y tóxicos para el hombre. Por eso, su uso conlleva tener que instalar sistemas auxiliares de inertización, sistemas antincendios y sistemas de regeneración (Zarza y Sufrategui, 2006).

Asimismo, el uso de aceites térmicos limita la temperatura de trabajo de las plantas ya que a partir de los $398^{\circ} \mathrm{C}$ se degradan y son inestables, por lo que el bloque de potencia solo puede ser alimentado con vapor a $385^{\circ} \mathrm{C}$. Este hecho limita la temperatura máxima del ciclo Rankine y, con ello, su eficiencia y la de la planta.

Una de las alternativas a día de hoy como HTF que trata de evitar las limitaciones de los aceites térmicos son las sales de nitrato. La más habitual, la sal solar (SQM, 2018), es una mezcla de nitrato sódico, $\mathrm{NaNO}_{3}$, al $60 \%$ (en peso) y nitrato potásico, $\mathrm{KNO}_{3}$, al $40 \%$ (en peso).

Un valor añadido para una planta termosolar son los sistemas de almacenamiento, puesto que las convierten en plantas gestionables prolongando las horas operativas más allá de la puesta de sol y evitan las fluctuaciones asociadas a la intermitencia del recurso solar. Además, es relativamente fácil almacenar grandes cantidades de energía térmica, lo que supone una ventaja de la termosolar frente a otras energías renovables en las que no siempre es posible. Por ejemplo, mediante dos depósitos de $34 \mathrm{~m}$ de diámetro y $15 \mathrm{~m}$ de altura de sales fundidas bien aislados se puede almacenar $1 \mathrm{GWh}_{\mathrm{th}}$ (Zarza, 2012).

Un ejemplo del citado valor añadido es que ya en 2014 había $3.7 \mathrm{GW}_{\mathrm{e}}$ de plantas termosolares con almacenamiento térmico, en operación o en construcción. Esto significa que ya entonces el $59 \%$ de la capacidad en desarrollo contaba con sistemas de almacenamiento. 
Los aceites térmicos y las sales fundidas empleados como HTF, como anteriormente se ha descrito, son también medios líquidos de almacenamiento térmico en forma de calor sensible. Siendo la sal solar el medio de almacenamiento más comúnmente empleado, sus principales ventajas e inconvenientes frente a los aceites térmicos son las siguientes:

Ventajas: permanecen estables hasta casi los $600{ }^{\circ} \mathrm{C}$ (Bradshaw y Carling, 1987), si fugan se solidifican de inmediato y se pueden recuperar (no son inflamables, ni contaminantes, ni tóxicas), tienen un coste reducido (comúnmente son usadas como fertilizantes), y presentan propiedades térmicas adecuadas a esta aplicación, lo que redunda en un menor coste. Por ejemplo, su mayor capacidad calorífica volumétrica permite tamaños más pequeños del sistema de almacenamiento y conduce a requisitos de tuberías y sistemas auxiliares también más pequeños.

Inconvenientes: su alta temperatura de solidificación, que obliga a las instalaciones a estar preparadas para asegurar la correcta circulación del fluido bajo cualquier condición de operación, es decir, obliga a un diseño más complejo del campo solar y origina consumos parásitos altos. Por ello, es necesaria $\mathrm{I}+\mathrm{D}$ en sales nuevas con menor punto de fusión y que sean estables al ciclarse (Bauer et al., 2012, 2014). También su posible incompatibilidad con los materiales estructurales de los tanques, tuberías, intercambiadores de calor, etc. Muchos autores reportan el comportamiento corrosivo de las sales fundidas en aceros en función del tipo de acero, la composición y calidad de las sales fundidas y las condiciones de operación (Bradshaw y Carling, 1987; Goods et al., 1994, Bradshaw y Goods, 2001; Sequeira, 2003. Goods y Bradshaw, 2004, Bradshaw et al., 2009).

Las opciones de diseño prevalecientes para medios líquidos son los sistemas de almacenamiento de doble tanque y los de tanque termoclino, los cuales, se pueden combinar con el campo solar, ya sea de forma directa o indirecta. A continuación se describen las configuraciones más comunes de estos sistemas de almacenamiento aunque, desde el punto de vista comercial, solamente los primeros ya han sido implantados.

\section{Sistemas de doble tanque indirectos}

El HTF que circula por el campo solar no se utiliza como medio de almacenamiento. Generalmente, el HTF es el aceite sintético y el medio de almacenamiento sales fundidas. El sistema consta de:

- un depósito frío, que normalmente opera a $290{ }^{\circ} \mathrm{C}$

- un depósito caliente, que opera a $380{ }^{\circ} \mathrm{C}$

- el medio de almacenamiento, que es sal solar

- los intercambiadores de calor 
- las bombas del sistema de almacenamiento

- otros equipos asociados al sistema como, por ejemplo, un sistema de gas de relleno y un traceado eléctrico para todos los componentes en contacto con las sales fundidas.

El traceado eléctrico es necesario para mantener una temperatura mínima de seguridad en el caso de que se interrumpa la operación de la planta y el sistema de gas de relleno previene la posibilidad de incendio en caso de accidente en los intercambiadores de calor aceite-sales. Si el aceite se filtra hacia las sales fundidas no puede inflamarse ya que el espacio superior de los tanques de sales está lleno de un gas inerte y no hay oxígeno presente (ST. Laurent, 2000). Dicho gas se pretende que también sea inerte en relación con las sales, los conductos, la instrumentación, etc. Un diagrama esquemático de planta CSP con colectores cilindro-parabólicos y almacenamiento térmico se muestra en la Figura 1.4.

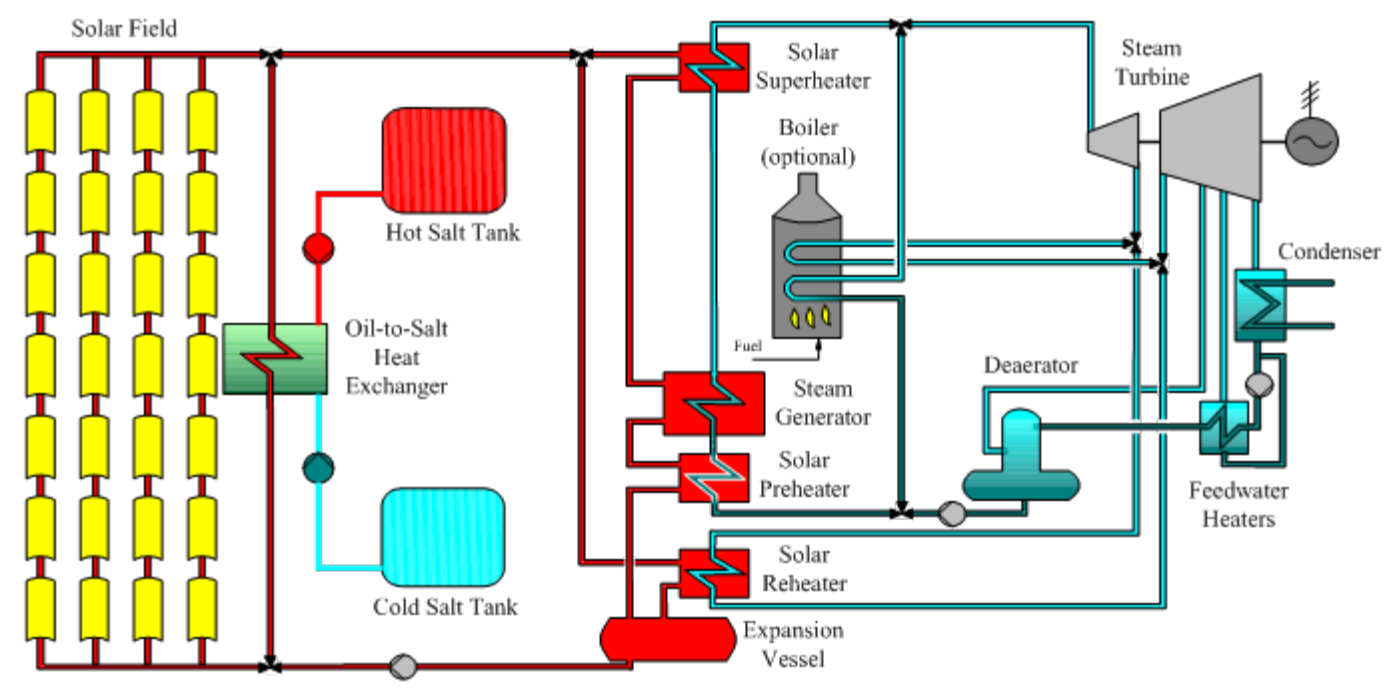

Figura 1.4: Esquema planta con sistema de almacenamiento térmico de doble tanque indirecto (Libby, 2009).

Estos sistemas de almacenamiento se cargan mediante el HTF caliente proveniente del campo solar, el cual pasa a través de los intercambiadores de calor aceite-sales. Al mismo tiempo, las sales fundidas frías son bombeadas desde el depósito frío al depósito caliente pasando por los intercambiadores. En éstos, el calor es transferido del HTF a las sales fundidas frías, las cuales ya calientes se almacenan en el depósito caliente. En los intercambiadores de calor, el HTF y las sales fundidas circulan a contracorriente para maximizar la transferencia de calor entre ambos fluidos.

Cuando se necesita disponer de la energía térmica almacenada, los flujos se invierten en los intercambiadores de calor aceite-sales con el fin de que el calor sea transferido de las sales fundidas al HTF. El HTF ya caliente es enviado al generador de vapor del bloque de potencia para producir vapor y completar así la operación. 
En la actualidad, este concepto se considera como el de menor riesgo tecnológico. Sin embargo, la transferencia de calor entre el HTF y las sales, durante la carga, y entre las sales y el HTF, durante la descarga, da lugar a una disminución de temperatura en el intercambiador de calor. Este hecho implica que la temperatura del HTF al llegar al generador de vapor, cuando opera desde el almacenamiento térmico, es de entre $10{ }^{\circ} \mathrm{C}$ y $20{ }^{\circ} \mathrm{C}$ más baja que cuando se opera directamente desde el campo solar (Libby, 2009).

Debido a estas disminuciones de temperatura y a las eficiencias asociadas a los intercambiadores de calor, la eficiencia del ciclo Rankine es inevitablemente inferior cuando se opera desde el almacenamiento térmico.

\section{Sistemas de doble tanque directos}

En un sistema de doble tanque directo (Libby, 2009), el HTF que circula por el campo solar se utiliza también como medio de almacenamiento. Al igual que el sistema indirecto, consta de un depósito frío y otro caliente, el medio de almacenamiento, los equipos asociados al sistema, y otros equipos auxiliares.

A diferencia del sistema indirecto, éste utiliza el mismo medio líquido que circula por el campo solar como medio de almacenamiento, eliminando así la necesidad del conjunto de intercambiadores de calor entre el HTF y el medio de almacenamiento. Cuando se utilizan sales como fluido caloportador, los tanques frío y caliente pueden funcionar a $290{ }^{\circ} \mathrm{C}$ y 565 ${ }^{\mathrm{o}} \mathrm{C}$, respectivamente. Un diagrama esquemático de esta configuración se muestra en la Figura 1.5 .

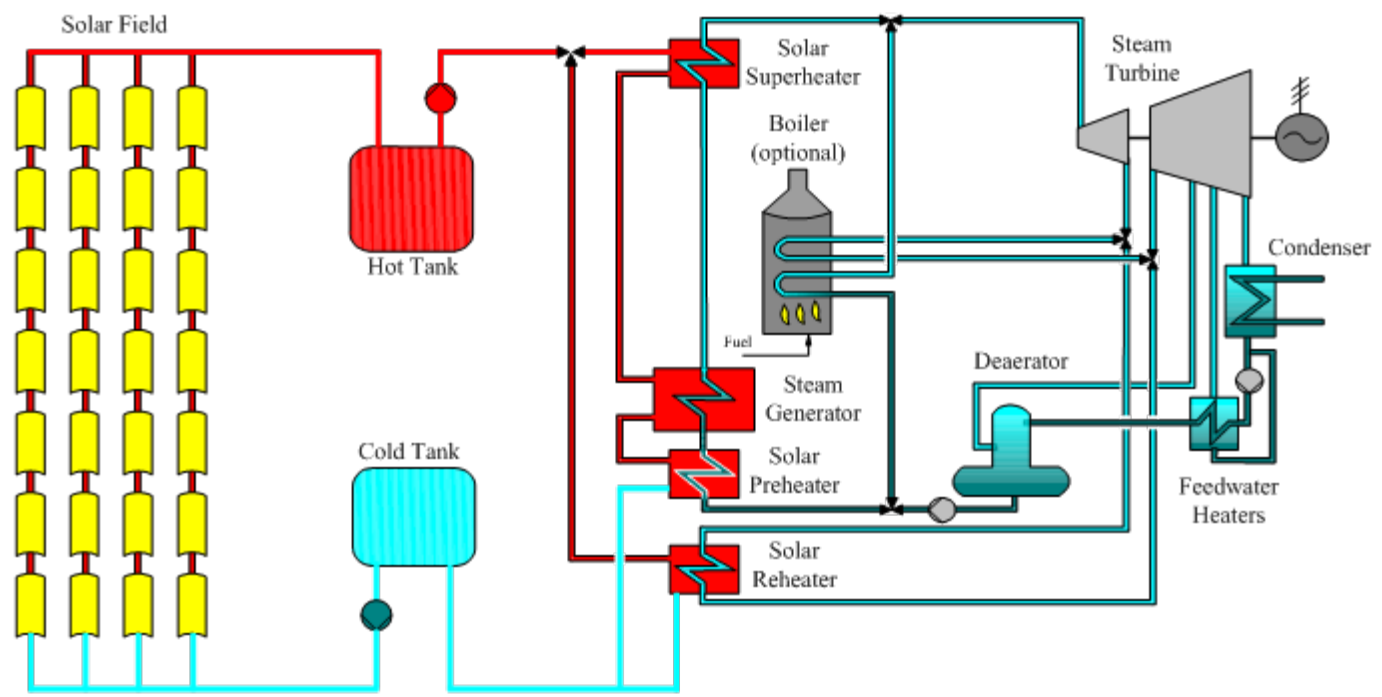

Figura 1.5: Esquema planta con sistema de almacenamiento térmico de doble tanque directo (Libby, 2009).

Para cargar este sistema, el líquido es bombeado desde el depósito frío al depósito caliente pasando por el campo solar; y para descargar el sistema, el líquido es bombeado desde el 
depósito caliente al generador de vapor desde donde regresa al depósito frío. Todo el líquido que pasa por el campo solar también pasa por el depósito caliente.

Dependiendo del tiempo de residencia del líquido en el depósito caliente, su temperatura de salida es, típicamente, de entre $0{ }^{\circ} \mathrm{C}$ y $1.5{ }^{\circ} \mathrm{C}$ más baja que su temperatura de entrada (Libby, 2009). Como resultado, el rendimiento del ciclo Rankine de una planta con un sistema de almacenamiento térmico de este tipo es esencialmente el de una planta sin almacenamiento térmico.

En este caso, podría parecer que sólo es necesario un tanque para la carga del almacenamiento, pero el depósito frío también se necesita para contener el volumen de líquido que ya se ha descargado en el generador de vapor. Durante las descargas del sistema de almacenamiento, es probable que el campo solar ya no reciba energía. En estas condiciones, si el líquido frío es bombeado hacia el sistema puede llegar a alcanzar el depósito caliente e interferir en su funcionamiento debido a la introducción de líquido a menor temperatura. Por lo tanto, el beneficio de los sistemas de doble tanque es separar los medios de almacenamiento frío y caliente.

Los sistemas de doble tanque directos generalmente usan sal solar como medio de almacenamiento. La principal desventaja de éstas es, como ya se ha mencionado, su alta temperatura de solidificación, por lo que debe asegurarse que esto no suceda en el campo solar o en otro lugar del sistema de almacenamiento. Además, el mantenimiento de las temperaturas requeridas por las sales fundidas tiene otros impactos negativos como son: mayores pérdidas térmicas en el campo solar, menor durabilidad de la capa selectiva de los receptores y la necesidad de equipos más costosos, tales como tuberías y empaquetaduras, aptos para soportarlas.

\section{Sistemas de tanque termoclino (con o sin relleno)}

$\mathrm{Al}$ igual que los sistemas de doble tanque, un tanque termoclino puede funcionar directa o indirectamente (Libby, 2009). Un sistema termoclino supone el uso de un solo tanque, el cual, se utiliza para almacenar tanto el fluido frío como el caliente, tratando de evitar la isotermalización del volumen de fluido.

En esta configuración el líquido caliente se almacena en la parte superior del tanque y el frío en la inferior. La zona de transición entre ambos fluidos se llama termoclina. Aunque, un termoclino puede combinar simplemente los fluidos frío y caliente en el tanque, la principal ventaja de este sistema es que la mayor parte del líquido de almacenamiento puede sustituirse por un material de relleno de bajo coste. Este relleno reemplazaría la mayoría de sal solar utilizada en un sistema similar de doble tanque reduciéndose el coste del sistema (Pacheco et al., 2002; Libby, 2010; Libby et al., 2010) y proporcionaría un medio de almacenamiento robusto. Aunque puede presentar otros inconvenientes, como por ejemplo, fallos estructurales 
del tanque debidos al ciclado térmico (Flueckiger et al., 2011; Kolb, 2011). Un sistema de este tipo se considera un almacenamiento dual ya que utiliza ambos medios (sólido y líquido) para almacenar energía.

Para las cargas del sistema, el fluido caliente se introduce por la parte superior del tanque, fluye a través del relleno, si lo tuviera, y sale por la parte inferior. Durante este proceso, el calor es transferido del fluido caliente al material de relleno. Para las descargas del sistema, el flujo se invierte, es decir, el fluido frío entra por la parte inferior del tanque y se calienta cuando fluye a través del relleno. Un diagrama esquemático de una planta CSP con un sistema directo de tanque termoclino se muestra en la Figura 1.6.

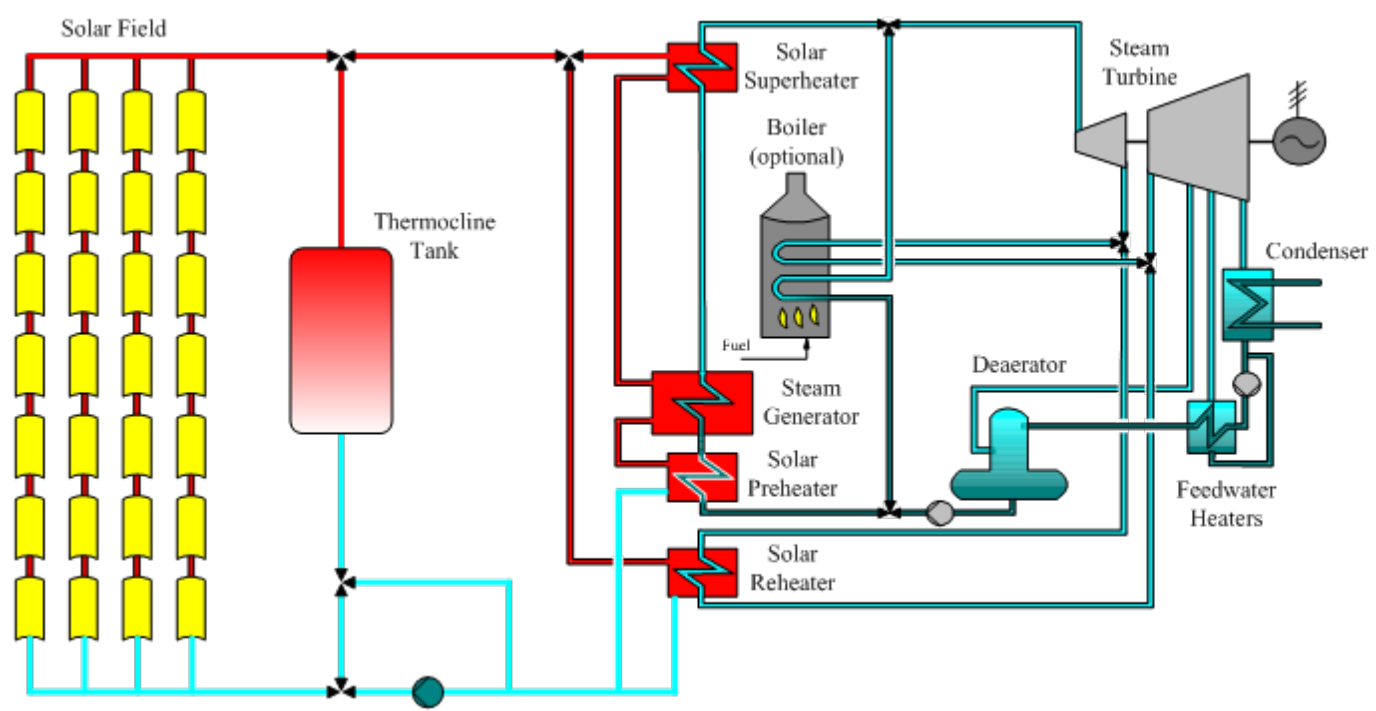

Figura 1.6: Esquema planta con sistema de almacenamiento térmico de tanque termoclino (Libby, 2009).

En la rama fría del circuito, el sistema incluye una línea de baipás para devolver el fluido frío a la zona de succión de la bomba del tanque durante las cargas.

La principal limitación en el diseño de este tipo de sistemas es que la termoclina puede ir creciendo durante los ciclados térmicos (y/o periodos de stand-by, se verán en §2.2) hasta ocupar toda la altura del tanque. Este crecimiento se debe principalmente a la difusión térmica y al intercambio de calor no ideal entre el fluido y el material de relleno. De ahí que el estudio del comportamiento de los sistemas de tanque termoclino haya sido motivo de numerosos trabajos numéricos (Bayón et al., 2012; Bayón y Rojas, 2013; Bayón et al., 2013 Bayón y Rojas, 2014, 2018), ya que requieren de una forma de operación específica (Biencinto et al., 2014).

La tendencia que siguen las últimas plantas es hacia sistemas de más horas de almacenamiento (excepto donde existan limitaciones impuestas por las regulaciones locales), es decir, se está optando por sistemas de gran escala, puesto que esto es positivo desde 
el punto de vista de la eficiencia de las plantas, su gestionabilidad y la adecuación de la producción eléctrica con la demanda de la red. Ejemplos de ello se muestran en las Tablas 1.2 y 1.3 .

Tabla 1.2: Centrales en operación, desarrollo o construcción con más de 9 h de almacenamiento térmico. Elaboración propia a partir de NREL (2018).

\begin{tabular}{|l|c|c|c|c|}
\hline Central-País (Estado) & Tecnología & HTF & MWe & h \\
\hline \hline Gemasolar-España (en operación) & Torre & Sales fundidas & 19.9 & 15 \\
\hline $\begin{array}{l}\text { Crescente Dunes (Tonopah)-EE. UU } \\
\text { (en operación) }\end{array}$ & Torre & Sales fundidas & 110 & 10 \\
\hline Bokpoort-Sudafrica (en operación) & CCP & Aceite térmico & 50 & 9.3 \\
\hline Shagaya-Kuwait (en desarrollo) & CCP & Aceite térmico & 50 & 10 \\
\hline Redstone-Sudafrica (en desarrollo) & Torre & Sales fundidas & 100 & 12 \\
\hline $\begin{array}{l}\text { Cerro Dominador. Atacama 1-Chile } \\
\text { (en construcción) }\end{array}$ & Torre & Sales fundidas & 110 & 17.5 \\
\hline Noor Energy 1-Dubai (en construcción) & Torre & Sales fundidas & 100 & 15 \\
\hline
\end{tabular}

Tabla 1.3: Centrales con almacenamiento térmico del programa de demostración de China. Elaboración propia a partir de NREL (2018).

\begin{tabular}{|l|c|c|c|c|}
\hline Central & Tecnología & HTF & MWe & h \\
\hline \hline CGN Delingha & CCP & Aceite térmico & 50 & 9 \\
\hline Qinghai SUPCON Solar Delingha & Torre & Sales fundidas & 50 & 6 \\
\hline $\begin{array}{l}\text { Beijing Shouhang IHW Resources } \\
\text { Saving Technology }\end{array}$ & Torre & Sales fundidas & 100 & 11 \\
\hline Yumen Xinneng & Torre & Sales fundidas & 50 & 6 \\
\hline Shenzhen Junfan Akesai & CCP & Sales fundidas & 50 & 15 \\
\hline $\begin{array}{l}\text { Inner Mongolia China Nuclear Royal } \\
\text { Tech Wuzhongqi }\end{array}$ & CCP & Aceite térmico & 100 & 4 \\
\hline DCTC Dunhuang & RLF & Sales fundidas & 50 & 13 \\
\hline Zhangbei Huaqiang Group Zhangjiakou & RLF & Agua-vapor & 50 & 14 \\
\hline Rayspower Group Yumen & CCP & Aceite térmico & 50 & 7 \\
\hline $\begin{array}{l}\text { Northwest Electric Power Design Institute } \\
\text { Hami }\end{array}$ & Torre & Sales fundidas & 50 & 8 \\
\hline
\end{tabular}

No obstante, el tamaño óptimo de un sistema de almacenamiento también depende de las condiciones establecidas por el tomador o por el mercado, condiciones como por ejemplo los planes o incentivos de compra de electricidad, (CSPToday, 2016).

La primera planta comercial con almacenamiento térmico fue la planta SEGS I (Figura 1.7), de Luz International, en EE.UU., con 3 horas de almacenamiento a plena carga, que funcionó desde 1985 hasta 1999 cuando, a causa de un incendio, el sistema resultó dañado y nunca fue reemplazado. Esta planta CCP contaba con un sistema de almacenamiento de doble tanque directo en aceite (la única comercial con este sistema). 


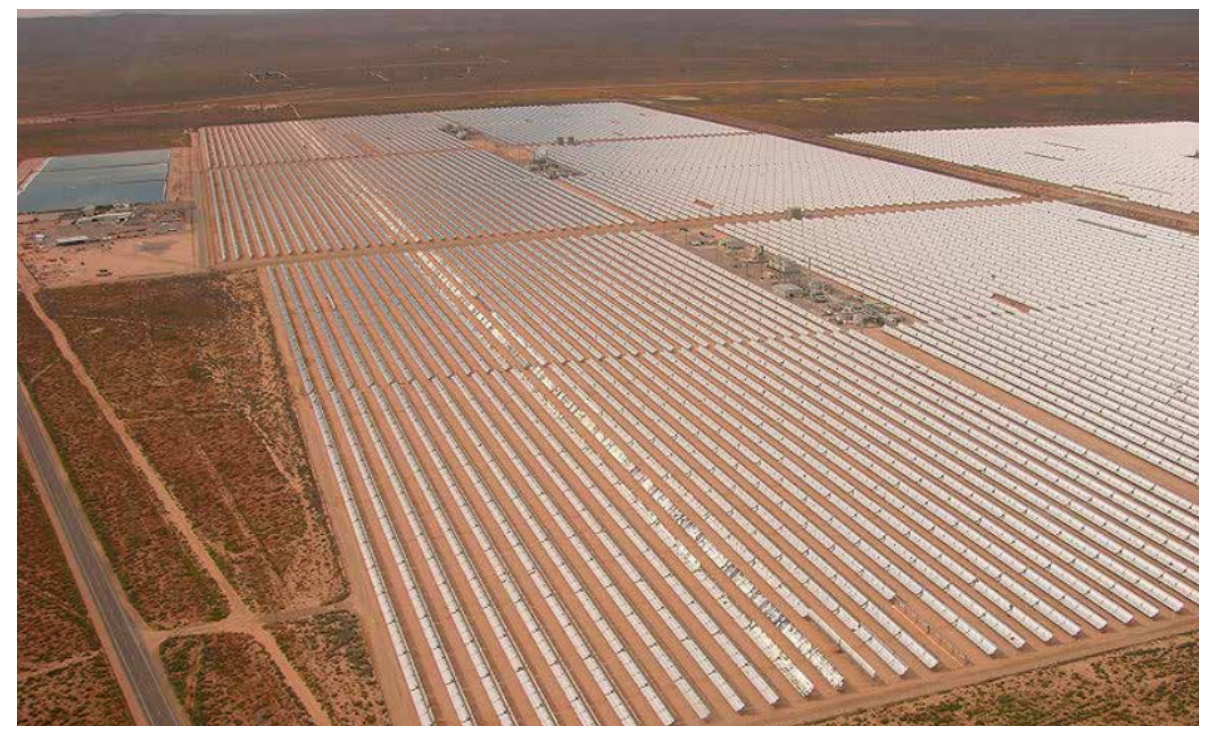

Figura 1.7: Plantas termosolares SEGS-NextEra Energy Resources (Teske et al., 2016).

Tras la SEGS I, hubo que esperar hasta 2008 para volver a ver una planta comercial CSP con almacenamiento. En este caso, fue la planta Andasol 1 (Relloso y Gutiérrez, 2008, Relloso y Delgado, 2009) de ACS-Cobra, en España, con 7.5 horas de almacenamiento a plena carga, que posteriormente dio lugar a Andasol 2 (Figura 1.8) y Andasol 3, en 2009 y 2011 respectivamante. Andasol 1 de tecnología CCP y que emplea un aceite térmico como $\mathrm{HTF}$, tiene un sistema de almacenamiento de doble tanque indirecto con sal solar (la primera planta comercial en Europa).

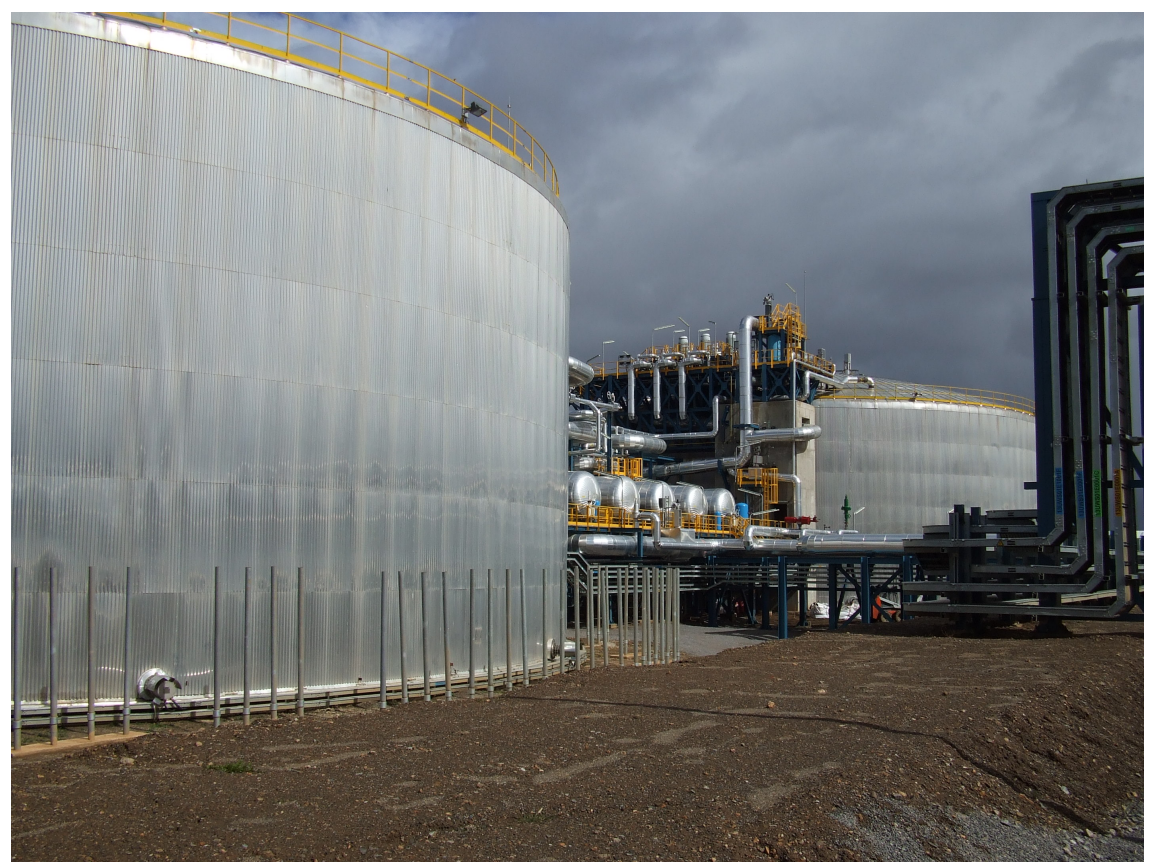

Figura 1.8: Planta termosolar Andasol 2-ACS Cobra (Fuente: Elaboración propia). 
Otra de las pioneras en contar con almacenamiento fue la planta piloto Solar Two, del Departamento de Energía de los EE.UU. junto con otros socios gubernamentales e industriales, en EE.UU., con 3 horas de almacenamiento a plena carga, que funcionó desde 1996 hasta 1999 cuando paró al finalizar el proyecto. Aunque la planta no estaba optimizada y aún se estaban identificando mejoras (Pacheco, 2002). Esta planta de torre contaba con un sistema de almacenamiento de doble tanque directo en sales fundidas (Figura 1.9).

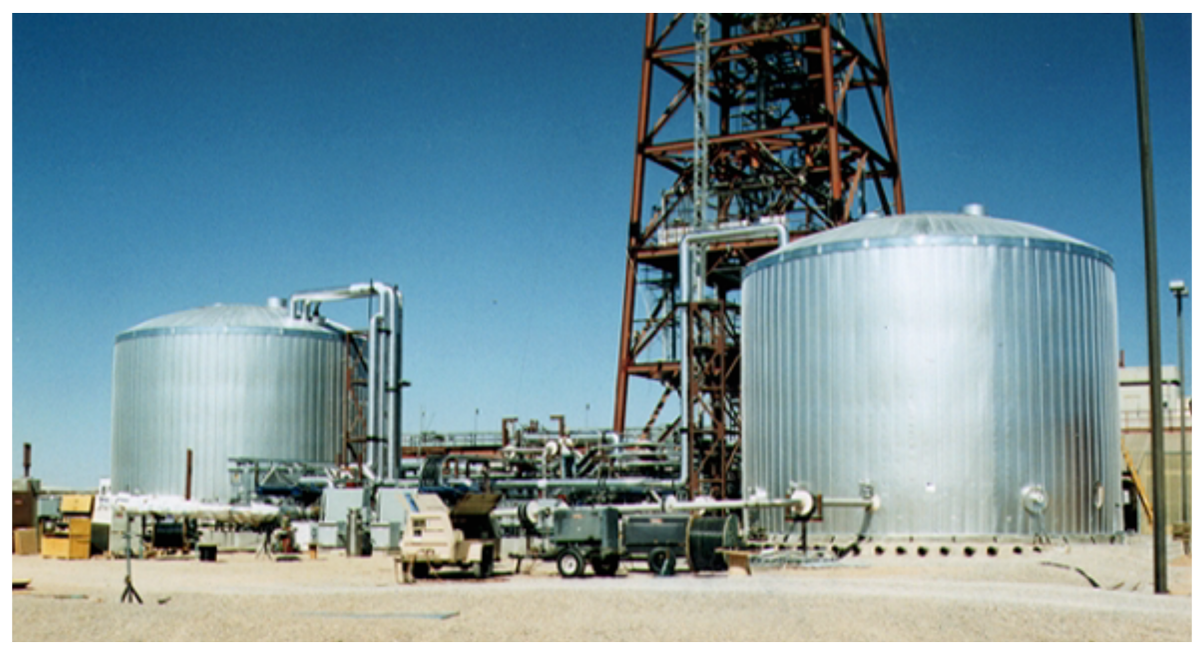

Figura 1.9: Planta termosolar Solar Two (Pacheco, 2002).

Tras Solar Two, también hubo que esperar hasta 2011 para ver una planta comercial de torre con almacenamiento. Fue el caso de Gemasolar (Burgaleta et al., 2011; Relloso y Lata, 2011), de Torresol Energy (Figura 1.10), en España, con 15 horas de almacenamiento a plena carga. Esta planta de torre cuenta con un sistema de almacenamiento de doble tanque directo en sales fundidas (la primera planta comercial del mundo de este tipo).

Una vez se revisan los diseños de las nuevas plantas en construcción y las de más reciente operación que cuentan con almacenamiento térmico (New Energy Update, 2017), se comprueba que en la mayoría se emplea el sistema de doble tanque anteriormente descrito: en el caso de plantas CCP, indirectamente, como en Andasol 1; y en el caso de plantas de torre, directamente, como en Gemasolar.

Ejemplos de ello son la mayoría de las plantas CCP que hay en España con almacenamiento en operación como: Andasol 2 y 3, Extresol 1, 2 y 3, La Florida, La Dehesa, Manchasol 1 y 2, Arcosol 50, Termesol 50, La Africana y Casablanca, (PROTERMOSOLAR, 2018a). 


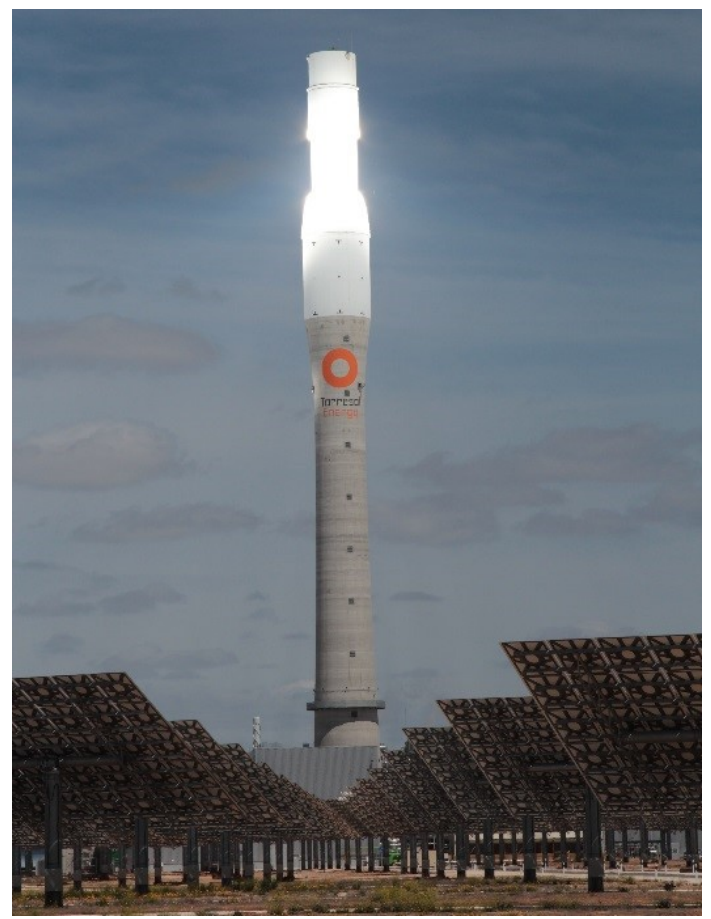

Figura 1.10: Planta termosolar Gemasolar-Torresol Energy (Fuente: Elaboración propia).

\subsection{Sistema de almacenamiento térmico en sales fundidas con generador de vapor integrado}

En Italia, el nacimiento y crecimiento de la industria termosolar ha ido de la mano de los avances llevados a cabo por el centro de investigación estatal ENEA (Agenzia nazionale per le nuove tecnologie, l'energia e lo sviluppo económico sostenible).

ENEA, tuvo su punto de partida en la Ley presupuestaria para el 2001 (Legge 23 Dicembre 2000, $N^{0}$ 388: Disposizioni per la formazione del bilancio annuale e pluriennale dello Stato (legge finanziaria 2001)) en la cual, según su Art. 111. (Contributo straordinario all'ENEA), en ENEA se pondría en marcha un programa de investigación, desarrollo e innovación en tecnologías solares de concentración orientado a la producción de electricidad a corto y medio plazo, llevado a cabo bajo el paraguas del proyecto SOLATERM (Solare Termodinámico), (Rubbia, 2001; Falchetta, 2006).

Dicho programa comprendería las siguientes áreas de actividad:

- el desarrollo y construcción de prototipos innovadores (componentes y sistemas) para plantas termosolares

- la construcción de instalaciones de ensayo para actividades experimentales 
- el diseño de plantas termosolares demostradoras a través de inversiones conjuntas con socios industriales.

ENEA apostó por la tecnología CCP empleando un sistema de almacenamiento de doble tanque directo en sales fundidas, es decir, apostó por éstas como fluido de transferencia de calor y medio de almacenamiento a la vez. Una vez demostrada su viabilidad técnica (Fabrizi et al. 2006) su viabilidad comercial comenzó a probarse en 2010 con la planta Archimede de $5 \mathrm{MW}_{\mathrm{e}}$, de Enel en Priolo Gargallo, Italia. Consta de 7 horas de almacenamiento (Falchetta et al. 2010) y tecnología $100 \%$ italiana. Se constituye como la primera planta comercial del mundo de este tipo, Figura 1.11 .

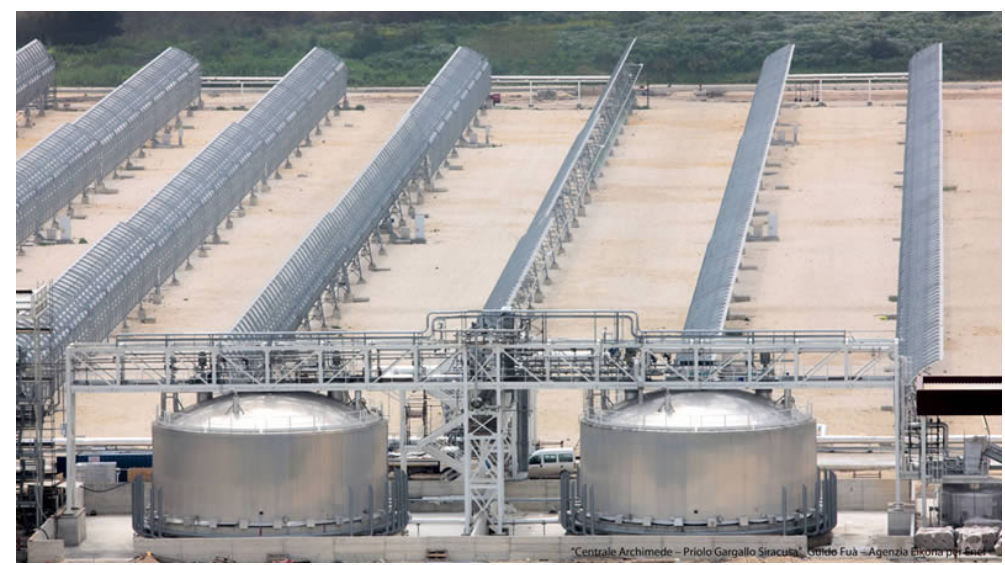

Figura 1.11: Planta termosolar Archimede-ENEL (Fuà, 2018).

Aunque la eficiencia de éstos sistemas de doble tanque en sales fundidas es muy alta (> $93 \%$ (Zarza, 2012)) y las sales de nitrato tienen un bajo coste, McMullen (2016), aún es necesario desarrollar conceptos innovadores de almacenamiento térmico e investigar nuevos diseños más rentables. Ello, permitiría demostrar que esta tecnología tiene el potencial suficiente como para reemplazar a otras más convencionales basadas en el uso de combustibles fósiles.

Por todo ello, es razonable pensar que los desarrollos tecnológicos y los proyectos sobre almacenamiento térmico para plantas termosolares que utilicen sales fundidas como HTF u otras aplicaciones industriales de calor de proceso que puedan intercambiar calor con este fluido pretendan avanzar siguiendo estas líneas.

El desarrollo tecnológico de un tanque de almacenamiento térmico con generador de vapor integrado, TES-SG (Thermal Energy Storage with integrated Steam Generator), ha sido patentado por ENEA y la empresa italiana ANSALDO NUCLEARE S.p.A (Rinaldi et al. 2015). Este diseño, inspirado en la tecnología para reactores rápidos refrigerados por sodio líquido, SFR (Sodium-cooled Fast Reactors), engloba tres puntos fundamentales:

- el uso de sales fundidas como fluido de transferencia de calor y como medio de almacenamiento térmico 
- la sustitución del sistema de almacenamiento de doble tanque por el sistema de un solo tanque o tanque termoclino

- la implementación de buena parte del circuito agua-vapor que alimenta al bloque de potencia (procesos de generación y sobrecalentamiento de vapor) en el propio sistema de almacenamiento (Fabrizi et al., 2011).

Y, fundamenta su competitividad respecto de los sistemas de doble tanque en las siguientes características:

- la simplificación del esquema de planta, que se consigue, por un lado, empleando un solo tanque de almacenamiento y, por otro, integrando el generador de vapor dentro del propio tanque

- la simplificación de la operación de la planta, ya que el funcionamiento del sistema permite producir vapor directamente (se verá a continuación)

- el generador de vapor se mantiene siempre caliente durante los periodos de stand-by de la planta (se verán en $§ 2.2$ ).

Otras ventajas intrínsecas del diseño son:

- su seguridad en caso de accidente, siempre y cuando la cúpula del tanque esté bien diseñada, así como los venteos

- su accesibilidad para labores de mantenimiento por la parte superior del tanque

- su posibilidad de escalado, por lo que se puede enfocar no solo a grandes plantas de producción sino también a plantas pequeñas y medianas (de entre 1-5 $\mathrm{MW}_{\text {th }}$ ) de cogeneración para la producción de electricidad o calor de proceso industrial (Fabrizi, 2007).

Posteriormente se ha demostrado su viabilidad técnica a escala de prototipo $\left(300 \mathrm{~kW}_{\mathrm{th}}\right)$ en ENEA (Gaggioli et al., 2014, 2015, 2016).

El principio de funcionamiento del prototipo en modo descarga es el siguiente: la circulación del agua a través del generador de vapor viene fijada mediante una bomba (se verá en §2.2), por eso se hablará de circulación forzada en el lado agua-vapor. Con este tipo de operación el fluido solo pasa una vez por el generador de vapor, por eso se denomina también circulación once through. Así, dependiendo de las condiciones térmicas del tanque, el fluido que sale del generador se puede presentar en forma de vapor sobrecalentado, vapor húmedo o agua subenfriada.

Por el contrario, las sales circulan por efecto de la gravedad a través de los intersticios existentes en la matriz de tubos que conforma el generador (se verá en §2.4). Su movimiento 
se debe a que al ceder calor a los tubos (más fríos por el agua-vapor que circula por su interior) disminuyen su temperatura aumentando su densidad. Este movimiento inducido se conoce como circulación natural y el caudal de sales asociado, $\dot{m}_{m s}$, depende del equilibrio entre dicha fuerza motriz y las pérdidas de carga al atravesar el generador.

Por tanto, el funcionamiento del generador de vapor integrado en modo descarga se caracteriza por un flujo interno de agua-vapor ascendente que absorbe calor de otro flujo externo de sales fundidas descendente que se enfría (equivalente a un intercambiador de calor a contracorriente).

Durante las descargas, la circulación natural ocasiona que las sales en el interior del tanque de almacenamiento se estratifiquen. Es decir, aparecen una zona fría en la parte inferior del tanque, procedente de las sales que ya han pasado por el generador de vapor, una zona caliente en la parte superior con sales que aún no han entrado en contacto con el generador de vapor, y una zona intermedia o termoclina cuyo espesor depende de las condiciones térmicas del tanque, Figura 1.12 .

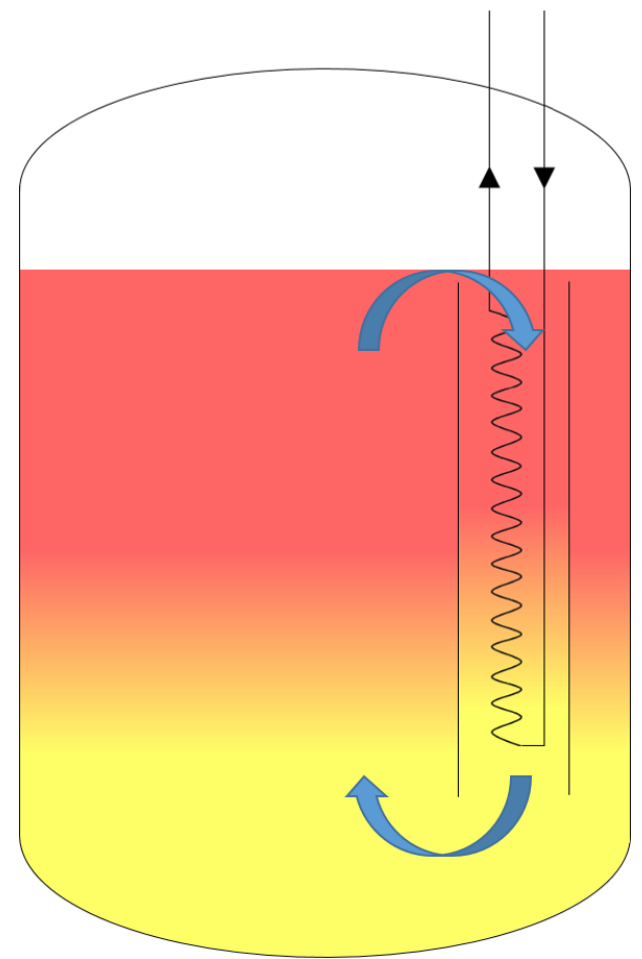

Figura 1.12: Esquema de funcionamiento del prototipo en modo descarga.

Dicha circulación se irá ralentizando a medida que pasa el tiempo como consecuencia de la paulatina disminución de la fuerza motriz asociada a la cota de sales calientes que las impulsa a atravesar el generador, por eso, se hablará de caudal de sales variable. Esta disminución es el resultado del progresivo incremento de la altura (y volumen) de las sales frías en el almacenamiento al descargarse el mismo. Por ello en un instante $t_{1}$ habrá un caudal másico de sales $\dot{m}_{t_{1}}$ en el generador de vapor, y en un instante posterior $t_{2}$ habrá un caudal $\dot{m}_{t_{2}}$ 
menor, al disminuir el volumen de sales calientes y aumentar el volumen de sales frías, tal y como se muestra en la Figura 1.13 .

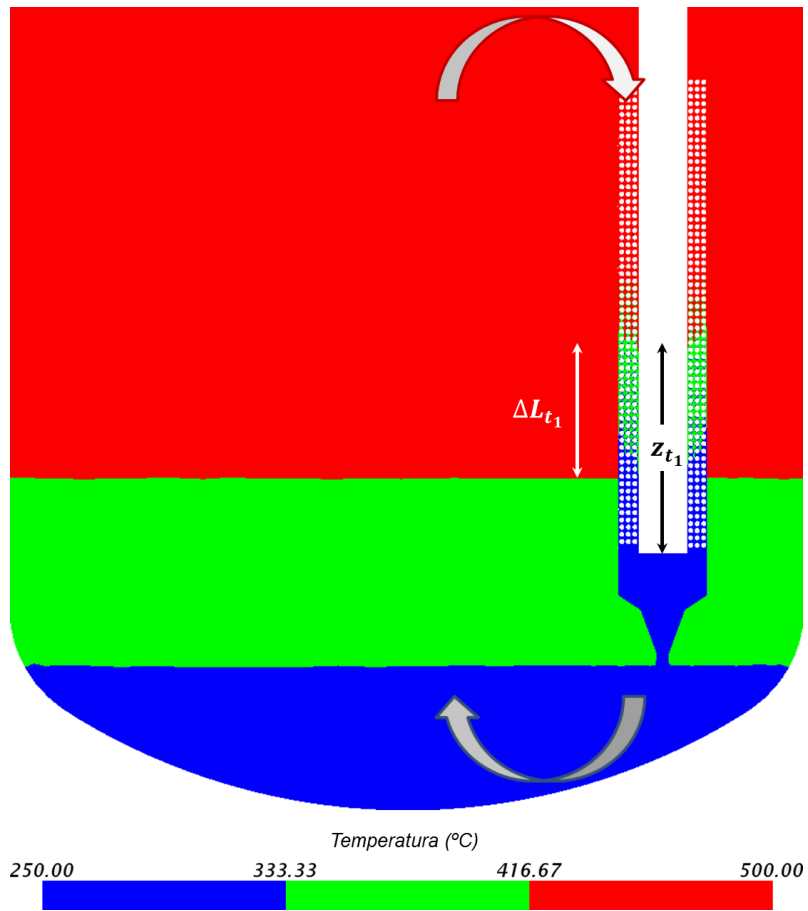

(a) Instante $t_{1}$

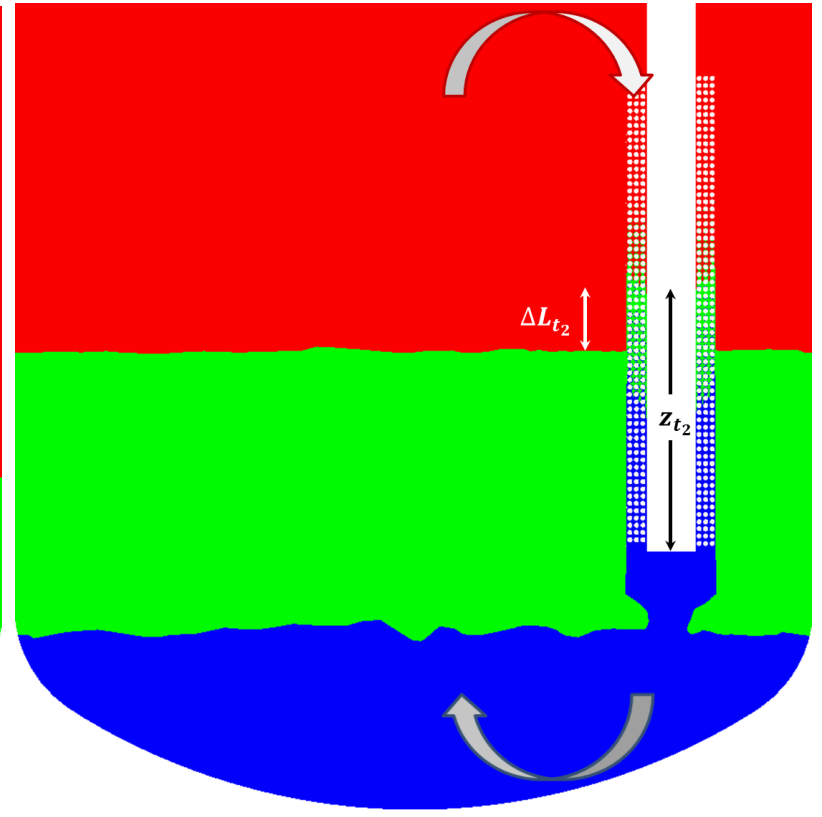

Temperatura $\left({ }^{\circ} \mathrm{C}\right)$

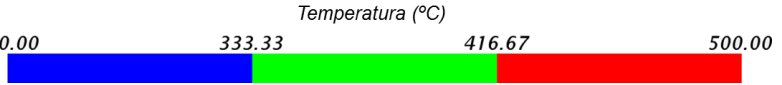

(b) Instante $t_{2}$

Figura 1.13: Campo de temperaturas simplificado en el lado sales fundidas en dos instantes de tiempo $t_{1}$ y $t_{2}$, siendo $t_{1}<t_{2}$, durante una de las descargas del prototipo. (Fuente: modelo CFD del Capítulo 4 .

Este funcionamiento conlleva una limitación para las descargas del sistema, ya que es necesario un $\Delta L$ mínimo en el tanque para asegurar que las sales circulan a través del generador de vapor. No obstante, se debe indicar que éste no sería el caso si el tanque estuviese siendo compensado mediante inyección de sales calientes por la parte superior, y succión de sales frías por la inferior, tal y como llevaron a cabo (Gaggioli et al., 2015).

El efecto que tiene la variabilidad del caudal sobre el intercambio de calor entre las sales fundidas y el agua-vapor es que, a medida que pasa el tiempo, cada vez es menos eficiente y, en consecuencia, se necesita una mayor área de intercambio para completar el cambio de fase agua-vapor a lo largo del generador de vapor integrado. Es decir, durante las descargas, irá paulatinamente aumentando la longitud del tramo bifásico, z, de modo que, dados dos instantes de tiempo tiempo $t_{1}$ y $t_{2}$, siendo $t_{1}<t_{2}$, entonces $z_{t_{1}}<z_{t_{2}}$, tal y como se muestra en la Figura 1.13. Notar que el proceso de descarga afecta a la estratificación de las sales en el tanque.

El siguiente paso en su desarrollo supondría llevarlo a escala de planta comercial, bien sea de producción electrica o de calor de proceso. Entre los diferentes proyectos representativos de este concepto, un ejemplo ha sido el Proyecto Europeo OPTS 2011-2014 (OPtimization of 
a Thermal energy Storage system with integrated Steam Generator), que ha contado con un presupuesto general de $13726033.80 €$ y la participation de CEA (Francia), CNRS (Francia), Sociedad Fraunhofer (Alemania), Instituto de Ciencias Weizmann (Israel), CREF (Chipre), ANSALDO NUCLEARE S.p.A (Italia), CIEMAT (España), COBRA INSTALACIONES Y SERVICIOS S.A. (España), LNEG (Portugal) y KT - KINETICS TECHNOLOGY S.p.A (Italia), (CORDIS, 2014).

En OPTS, el objetivo principal consistía en demostrar la eficiencia y la viabilidad técnico-económica de este prototipo innovador de almacenamiento térmico, a $550{ }^{\mathrm{O}} \mathrm{C}$ de temperatura máxima, para la próxima generación de plantas termosolares. En concreto, el programa experimental se centraba en el desarrollo de un prototipo demostrador de 12.5 $\mathrm{MW}_{\text {th }}$, que es el tamaño seleccionado como aquel mínimo que conservaría los parámetros fluido-dinámicos de un sistema a escala de planta termosolar comercial, $125 \mathrm{MW}_{\mathrm{th}}$. No obstante, el gran interés suscitado por el diseño de tanque termoclino con generador integrado hizo que el objetivo final se ampliase al estudio de tal diseño empleando diferentes fluidos de transferencia de calor, siendo finalmente éste el núcleo fundamental del proyecto.

Para ello, uno de los puntos clave del diseño termo-hidráulico es el cálculo de la transferencia de calor en el generador de vapor integrado. Éste requiere de modelos simplificados, pero, a la vez, bien adaptados, tanto a su funcionamiento como a sus características geométricas. Por ejemplo, fijada una potencia de diseño, $\dot{Q}$, el generador de vapor integrado se podría discretizar en altura en una serie de secciones idealizadas $i$, con $i=1, \ldots, \mathrm{n}$, de tal manera que en cada instante de tiempo $t$ :

$$
\dot{Q}=\sum_{i=1}^{n} \dot{Q}_{i}
$$

siendo $\dot{Q}_{i}$ la potencia intercambiada en la sección $i$ (ver Figura 1.14.

Suponiendo que en cada $i$ la transferencia de calor se produce en condiciones de régimen estacionario, $\dot{Q}_{i}$ vendría dada por:

$$
\dot{Q}_{i}=\dot{m}_{m s}\left(\bar{H}_{O U T}-\bar{H}_{I N}\right)_{m s, i}=\dot{m}_{w s}\left(\bar{H}_{O U T}-\bar{H}_{I N}\right)_{w s, i}=U_{i} S_{i} \Delta T_{l n, i}
$$

dónde:

- $\dot{m}_{m s} \mathrm{y} \dot{m}_{w s}$, son los caudales másicos de sales fundidas y agua-vapor respectivamente

- $\left(\bar{H}_{O U T}-\bar{H}_{I N}\right)_{m s, i}$ y $\left(\bar{H}_{O U T}-\bar{H}_{I N}\right)_{w s, i}$, las diferencias de entalpías medias entre la entrada y la salida de las sales fundidas y el agua-vapor respectivamente en $i$

- $U_{i}$ el coeficiente de transferencia de calor global en $i$

- $S_{i}$, el área de intercambio en $i$ 


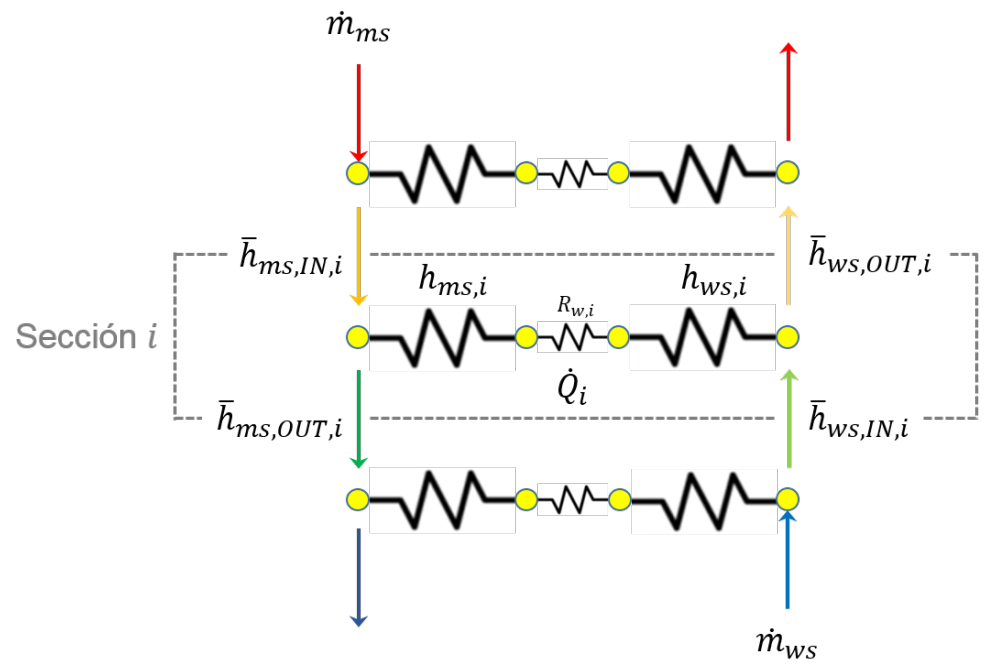

Figura 1.14: Modelo simplificado para el cálculo de la transferencia de calor en el generador de vapor integrado con resistencias térmicas equivalentes.

- $\Delta T_{l n, i}$ la diferencia de temperaturas logarítmica entre las sales fundidas y el agua-vapor en $i$

y $U_{i}$ vendría dado por:

$$
U_{i}=\frac{1}{\frac{1}{d_{o} h_{m s, i}}+R_{w, i}+\frac{1}{d_{i} h_{w s, i}}} \frac{1}{d_{o}}
$$

dónde:

- $d_{o}$ y $d_{i}$ son los diámetros externo e interno de la matriz de tubos que conforma el generador de vapor integrado

- $R_{w, i}$ la resistencia térmica de las paredes en $i$

- $\bar{h}_{m s, i}$ y $\bar{h}_{w s, i}$ los coeficientes de transferencia de calor locales o promedio (Anexo A) de las sales fundidas y el agua-vapor respectivamente en $i$

Teniendo en cuenta los mecanismos de transferencia de calor asociados al funcionamiento del generador de vapor integrado durante las descargas: circulación natural en el lado sales fundidas, conducción a través de las paredes y ebullición en convección forzada en el lado agua-vapor, cabría pensar que el primero de todos es el menos eficaz transfiriendo calor (Kreith et al. 2012), por lo que los $U_{i}$ serían más sensibles a los $\bar{h}_{m s, i}$ que a las $R_{w, i}$ o los $\bar{h}_{w s, i}$. Aún así, este grado de sensibilidad podría variar en cada $i$ dependiendo del tipo de flujo presente en el lado agua-vapor: monofásico (de agua subenfriada o vapor sobrecalentado) o bifásico. Además, en el último caso, éste también podría variar dependiendo del tipo de régimen de flujo bifásico existente en cada $i$ (se verá en §1.4.1). Concretamente, en el caso de la región de superficie seca, comúnmente denominada postdryout, el grado de sensibilidad podría variar drásticamente ya que su comienzo lleva implícito una disminución de los $\bar{h}_{w s, i}$, 
en algunos casos de entre uno y dos órdenes de magnitud respecto de otros tipos de regímenes de flujo bifásico (Collier y Thome, 1994.

De ahí la crucial importancia de disponer de correlaciones adecuadas para el cálculo, por un lado, de los $\bar{h}_{m s, i}$ y, por otro, del título de vapor local asociado al comienzo de la región de superficie seca, comúnmente denominado dryout, para el tipo de generador de vapor integrado (en este caso una matriz de tubos helicoidales, se verá en §2.4) a la hora de llevar a cabo su escalado.

La dificultad que supone su obtención es debida a que, a nivel experimental, la instrumentación del prototipo de ENEA (se verá en §2.4) es insuficiente para su obtención.

\subsection{Fenómenos físicos involucrados en el lado sales fundidas}

Los denominados NCLs (Natural Circulation Loops) o termosifones son circuitos en los que se tiene una fuente y un sumidero de calor conectados entre sí mediante dos ramas (la caliente y la fría), dónde el sumidero está situado por encima de la fuente, ver Figura 1.15. Es decir, que la diferencia de alturas, $\Delta L$, entre ambas ramas permanece constante.

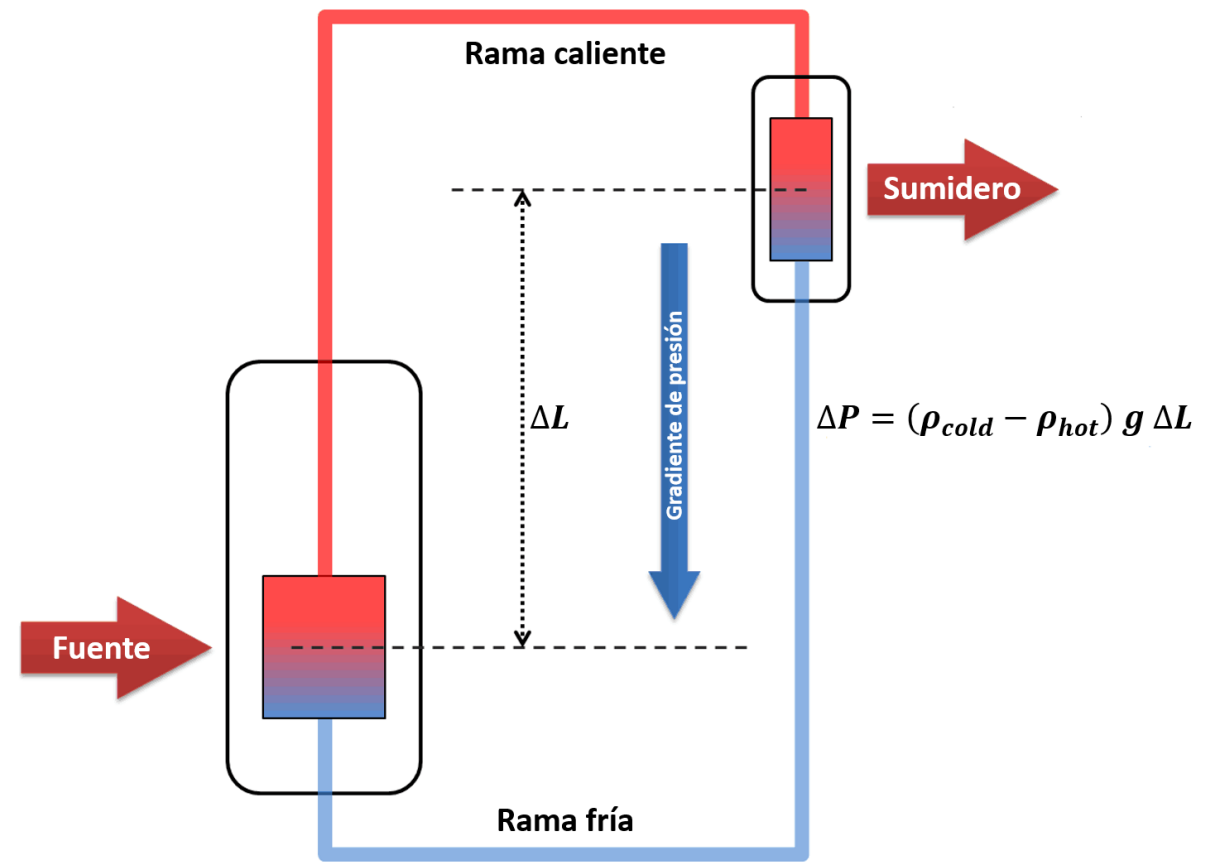

Figura 1.15: Circulación natural en un NCL. (Fuente: Elaboración propia a partir de Nuclear-Power (2020)).

Esta configuración crea un gradiente de densidad en el fluido de trabajo del circuito que, en presencia de la gravedad, genera la aparición de un gradiente de presión en el mismo. 
Dicho gradiente induce la circulación del fluido (circulación natural) desde la fuente hasta el sumidero sin necesidad de partes móviles en el circuito. Es decir, que los NCLs son sistemas de circulación pasiva y se encuentran en numerosas aplicaciones industriales. Por ejemplo: en dispositivos de calentamiento solar, sistemas de refrigeración, enfriamiento de motores de combustión interna, turbinas de gas, reactores nucleares, etc. (Zvirin, 1982, Greif, 1988 , D'Auria y Vigni, 1990).

Los NCLs pueden ser monofásicos y bifásicos, según que el fluido de trabajo permanezca en fase líquida o coexistan dos fases, líquido/vapor, en cierta proporción a lo largo del circuito. Atendiendo a la orientación de la fuente y el sumidero, se clasifican en:

- HHHC (Horizontal heater and horizontal cooler), donde tanto la fuente como el sumidero están en horizontal

- HHVC (Horizontal heater and vertical cooler), donde la fuente está orientada en horizontal y el sumidero en vertical

- VHVC (Vertical heater and vertival cooler), donde ambos están en vertical

- VHHC (Vertical heater and horizontal cooler), donde la fuente está en vertical y el sumidero en horizontal

En el caso del TES-SG de ENEA, tal y como se ha explicado previamente, en el lado de las sales fundidas, la circulación natural transporta continuamente el calor desde la fuente (el tanque) hasta el sumidero (el generador de vapor integrado), de forma equivalente a un NCL monofásico de tipo VHVC, Figura 1.16.

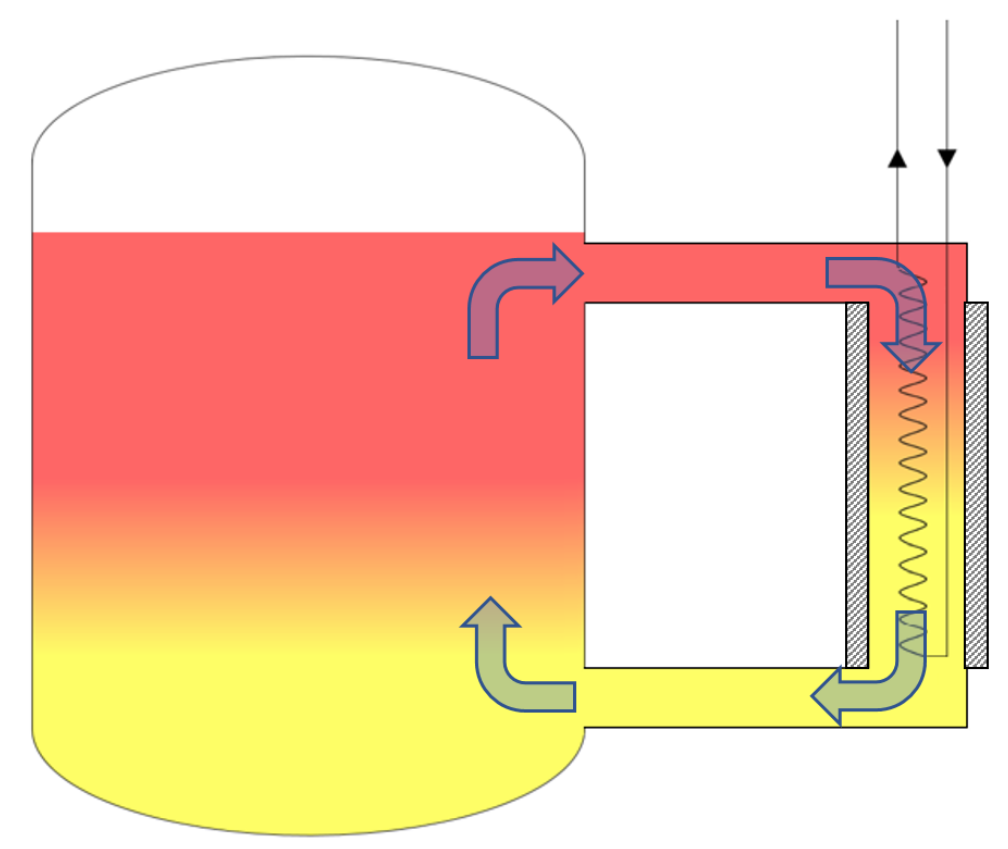

Figura 1.16: NCL equivalante del TES-SG en modo descarga. 
Para determinar la capacidad de transferencia de calor en este tipo de sistemas es esencial conocer el caudal a través del circuito. Este problema termo-hidráulico supone resolver un conjunto de ecuaciones acopladas. Es decir, las variaciones de energía que experimenta el fluido de trabajo dan lugar a variaciones de momento, de ahí el acoplamiento de las ecuaciones de conservación.

En los casos de NCLs simples existen soluciones analíticas del sistema de ecuaciones (Massoud, 1987). En este sentido, son relevantes los estudios realizados por Vijayan et al. (2000) y Vijayan (2002) sobre NCLs en cualquier orientación (HHHC, HHVC, VHHC y VHVC) y operando en estado estacionario.

En ellos se establece que, siempre que el factor de fricción a lo largo del circuito, $f f$, pueda expresarse como:

$$
f f=p R e^{-b}
$$

siendo $p$ y $b$ dos contantes que dependen de la naturaleza del flujo: laminar o turbulento, el caudal en circulación puede obtenerse, de forma generalizada, a partir de la expresión:

$$
R e=c\left(\frac{G r_{m}}{d / L_{e f f, T o t}}\right)^{r}
$$

donde $d$ es el diámetro del circuito, $R e$ es el número de Reynolds, $G r_{m}$ es el número de Grashof modificado, $L_{e f f, T o t}$, es la longitud equivalente del circuito $\left(L_{e f f, T o t}=L_{T o t} F_{\text {eff }}\right.$, siendo $L_{T o t}$ la longitud total del circuito y $F_{\text {eff }}$ un factor que da cuenta de las posibles pérdidas de carga concentradas a lo largo del mismo), y c y $r$ dos contantes relacionadas con la naturaleza del flujo de la siguiente forma:

$$
\begin{gathered}
c=(2 / p)^{r} \\
r=1 /(3-b)
\end{gathered}
$$

En estos trabajos, Vijayan, empleando los datos experimentales de diferentes tipos de NCLs (tanto UDLs (Uniform Diameter Loops como NDLs (Non uniform Diameter Loops), cuyas condiciones de operación estaban comprendidas entre: $400<G r_{m} \frac{L_{e f f, T o t}}{d}<2 \cdot 10^{14} \mathrm{y}$ $3.5<R e<2 \cdot 10^{5}$, encontró que, para flujos completamente laminares (donde: $p=64$ y $b=1$ ) o completamente turbulentos (donde: $p=0.316$ y $b=0.25$ ), sus valores eran: $c=0.1768$ y $r=0.5$ en el primer caso y $c=1.96$ y $r=0.364$ en el segundo. Además, hipotetizó que para flujos en transición cabría esperar un cambio continuo tanto en $c$ como en $r$. Es decir, valores comprendidos entre (0.1768-1.96) y (0.364-0.5) respectivamente.

Posteriormente Swapnalee y Vijayan (2011) verificaron esta hipótesis utilizando los datos experimentales de un UDL en las cuatro orientaciones posibles y cuyas condiciones de 
operación estaban comprendidas entre: $6.7 \cdot 10^{6}<G r_{m} \frac{L_{e f f, T o t}}{d}<2.17 \cdot 10^{10}$ y $428<R e<$ 10100. Así, dedujeron que, para flujos en transición (donde: $p=1.2063$ y $b=0.416$ ) sus valores eran: $c=1.216$ y $r=0.387$.

Sin embargo, para NCLs complejos, la interacción entre las fuerzas puestas en juego (inerciales, viscosas y la gravedad) es complicada y no lineal, por lo que no existen soluciones analíticas del sistema de ecuaciones, y se requiere el uso de técnicas numéricas para su estudio. Estos sistemas suelen dar lugar a flujos convectivos locales diversos.

Es por esto que, al no existir un conjunto general de correlaciones para la transferencia de calor por circulación natural en NCLs complejos, es común en la práctica el uso de correlaciones de convección forzada. Esta simplificación implica cierta pérdida de precisión en algunos casos (Knaani y Zvirin, 2006).

\subsubsection{Transferencia de calor por convección forzada alrededor de matrices de tubos}

La transferencia de calor por convección forzada alrededor de matrices de tubos depende en gran medida de los regímenes de flujo dados. En esta sección, se muestran y describen los principales regímenes de flujo que se pueden dar en este tipo de intercambiadores de calor en los que, puesto que el área de paso cambia continuamente a lo largo de la trayectoria del flujo, éste se acelera y se ralentiza periódicamente influyendo en la transferencia de calor alrededor de los tubos.

Una de las fuentes de datos más extensa sobre transferencia de calor en intercambiadores de tubos es la de Kays y London (1984).

En las siguientes imágenes se plasman los regímenes de flujo que se observan alrededor de diferentes matrices de tubos de distinto tamaño y configuración: tubos dispuestos en línea Figura 1.17 y escalonados Figura 1.18, respectivamente, para Re bajos.

Estas imágenes se obtuvieron mediante técnicas experimentales de visualización dispersando polvo de aluminio en el fluido, en este caso agua.

Los regímenes de flujo que se observan alrededor de los tubos de las primeras filas son similares a los regímenes que se observarían alrededor de un tubo individual (Lienhard, 2013). Centrando la atención en uno de ellos, para la configuración de tubos dispuestos en línea, se puede ver que la capa límite se separa a ambos lados de dicho tubo y se forma una estela turbulenta detrás de él. Esta estela se extiende hasta el tubo consecutivo de la segunda fila. Como resultado de la alta turbulencia de la estela, la capa límite alrededor de este tubo y las de los tubos siguientes, se hacen progresivamente más delgadas. 


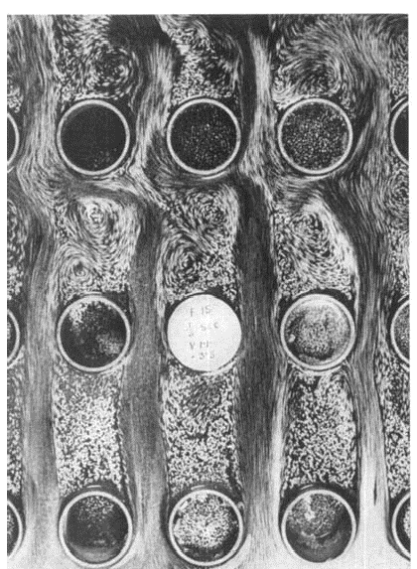

(a)

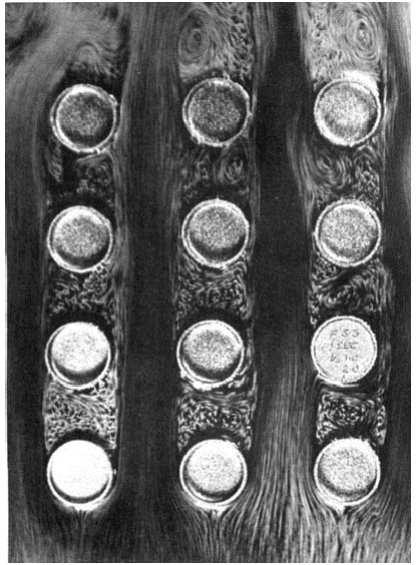

(c)

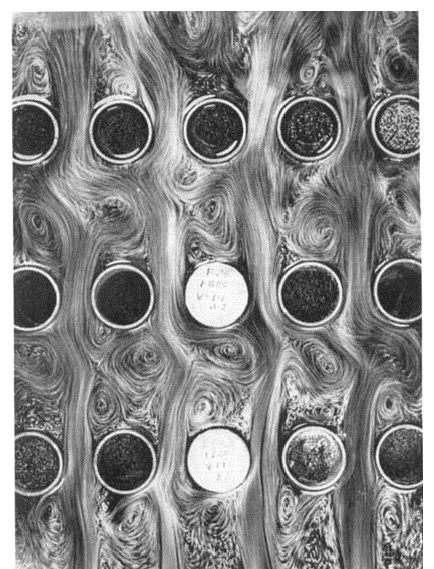

(b)

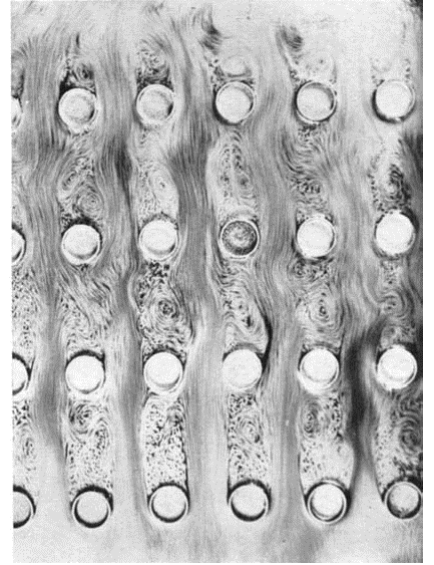

(d)

Figura 1.17: Patrones de flujo para matrices de tubos en línea (Wallis, 1939). El flujo en todas las imágenes es ascendente.

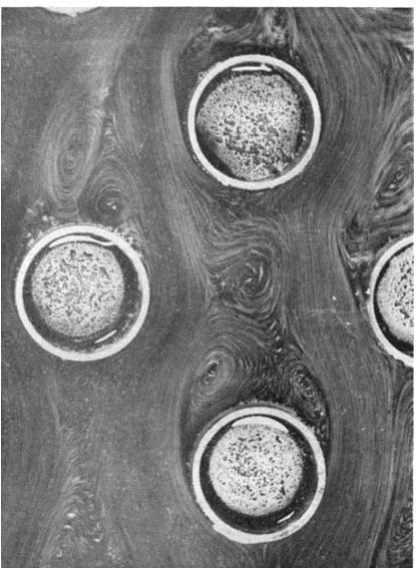

(a)

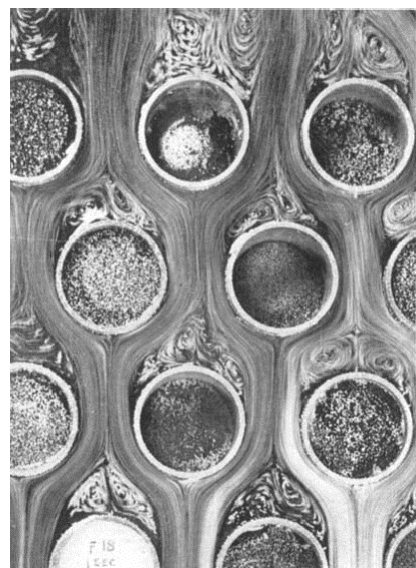

(b)

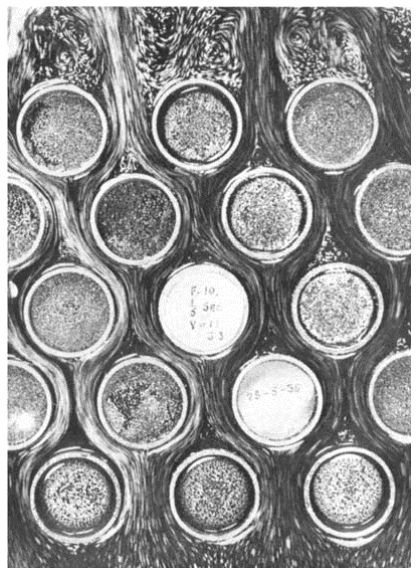

(c)

Figura 1.18: Patrones de flujo para matrices de tubos escalonados (Wallis, 1939). El flujo en todas las imágenes es ascendente. 
Por lo tanto, es de esperar que, para flujos turbulentos alrededor de matrices de tubos, los coeficientes de transferencia de calor medios en las primeras filas sean menores que en las filas consecutivas. En cambio, para flujos laminares, se ha observado una tendencia opuesta debido al efecto de sombreado de los tubos precedentes (Meece, 1949).

Para una disposición de tubos escalonados poco separados (Figura 1.18), la estela turbulenta detrás de cada tubo es algo más pequeña que para una disposición de tubos similares en línea, aunque no hay una reducción apreciable en la transferencia total de calor.

Los experimentos realizados empleando diversos tipos de configuraciones de matrices de tubos escalonados demuestran que:

- en régimen turbulento la relación entre la transferencia de calor y la disipación de energía depende principalmente de la velocidad del fluido, el tamaño de los tubos y la distancia entre ellos

- en régimen de transición la transferencia de calor en una configuración de tubos escalonados poco separados es algo superior a la de una de tubos similares en línea

- en régimen laminar la primera fila presenta una transferencia de calor más baja que las filas consecutivas, justo el comportamiento opuesto de la configuración de tubos en línea.

Estos experimentos han demostrado que, en flujos alrededor de matrices de tubos escalonados, la transición de régimen laminar a turbulento es más gradual que la que se daría en flujos alrededor de tubos individuales mientras que, para matrices de tubos en línea, la transición se asemeja a la que se observaría alrededor de un solo tubo (Lienhard, 2013). En cualquier caso, la transición de régimen laminar a turbulento comienza a partir de $R e>200$ y el flujo llega a ser completamente turbulento a partir de $R e>6000$.

Los estudios disponibles sobre transferencia de calor por convección forzada alrededor de matrices de tubos se basan enteramente en correlaciones en función de números adimensionales cuyos coeficientes y/o exponentes se ajustan experimentalmente debido a que los regímenes de flujo que se pueden llegar a dar alrededor de ciertas configuraciones geométricas son demasiado complejos para ser tratados analíticamente. A modo de ejemplo, en la Figura 1.19 se muestra la distribución del flujo de sales fundidas alrededor de la matriz de tubos helicoidales que conforma el generador de vapor integrado del prototipo ENEA, obtenida mediante el modelo de fluido-dinámica computacional, CFD (Computational Fluid Dynamics), descrito en el Capítulo 4.

\footnotetext{
${ }^{2}$ Técnica numérica que emplea el código CFD para la visualización de las líneas de corriente a partir del campo de velocidades. Esta técnica fue introducida por Cabral y Leedom (1993) para la obtención de imágenes de campos vectoriales en $2 \mathrm{D}$. Su principal ventaja es que permite visualizar campos vectoriales complejos con muy alta resolución y una de sus limitaciones es que está diseñada para utilizar la GPU del
} 


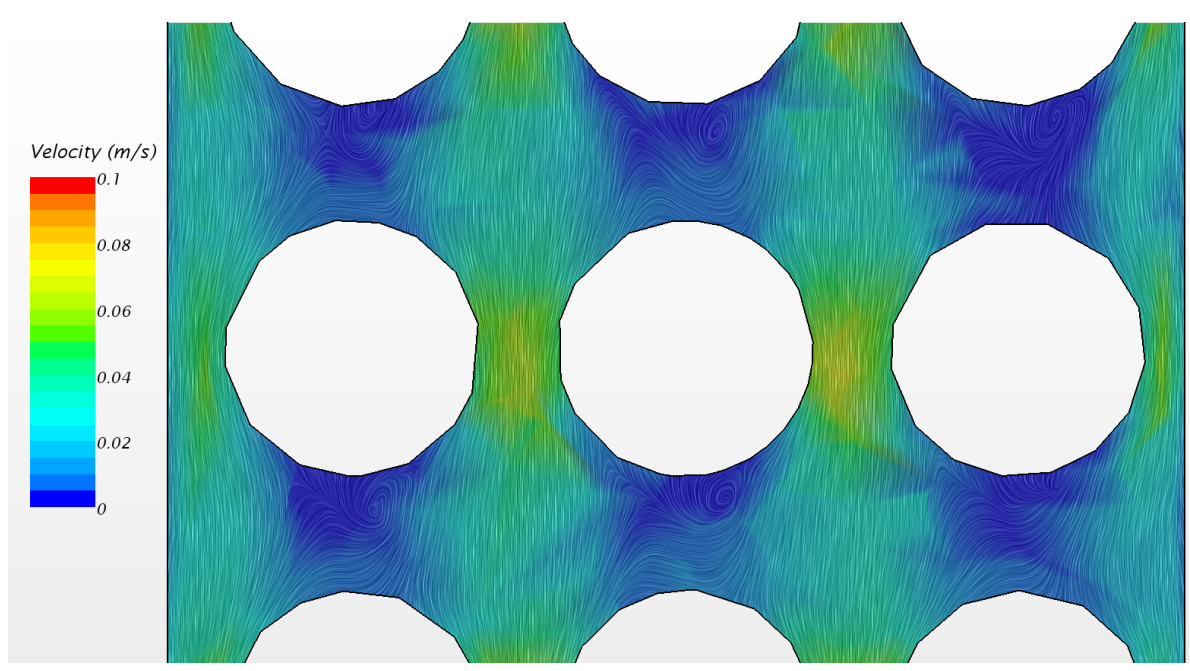

Figura 1.19: LIC (Line Integral Convolution) ${ }^{2}$ del campo de velocidaes en el lado sales fundidas durante una de las descargas del prototipo. Fuente: modelo CFD del Capítulo 4

\subsubsection{Revisión del estado de la técnica de las correlaciones para} la transferencia de calor por convección forzada alrededor de matrices de tubos

Independientemente de la configuración de las matrices de tubos (tubos dispuestos en línea, Figura 1.20 a) o escalonados, Figura 1.20 b) y c)), éstas se caracterizan por el diámetro externo de los tubos, $d_{o}$, el paso vertical, $X_{v e r}$, y el paso horizontal, $X_{h o r}$, ver Figura 1.20 .

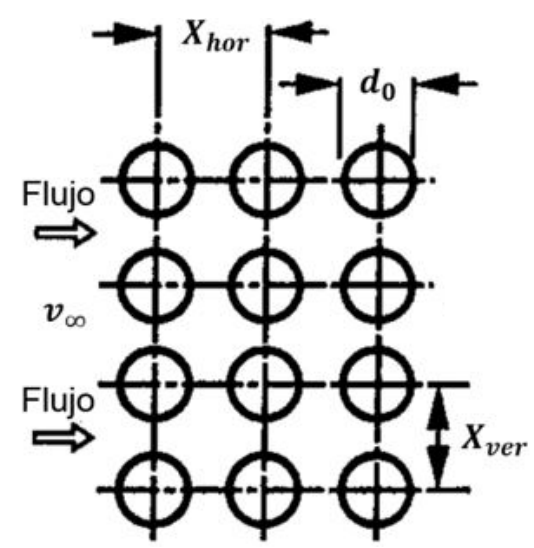

(a)

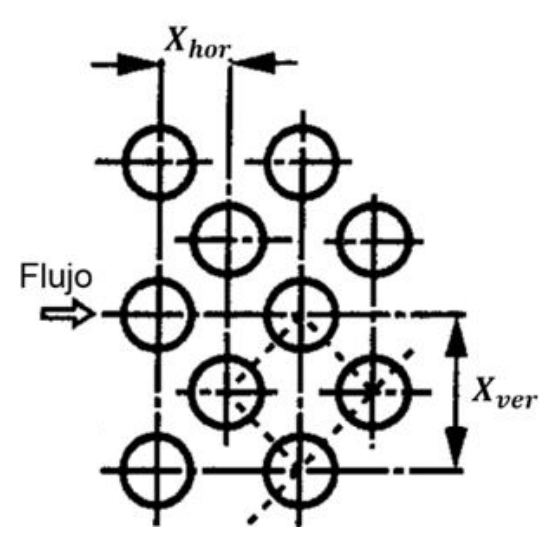

(b)

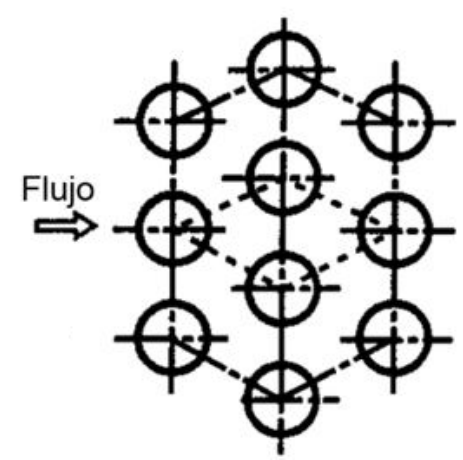

(c)

Figura 1.20: Esquema de las configuraciones más comunes de matrices de tubos y parámetros característicos: a) en línea; b y c) escalonados (Kakaç et al. (1987)).

Las matrices de tubos se clasifican generalmente en función de su compacidad definida matemáticamente como $\frac{\sqrt{X_{h o r} X_{\text {ver }}}}{d_{o}}$, ver Figura 1.21 . No obstante, en la práctica, la mayoría de los casos están en el rango de 'casos intermedios'.

hardware por lo que, junto con el renderizado de software, puede funcionar lentamente. 


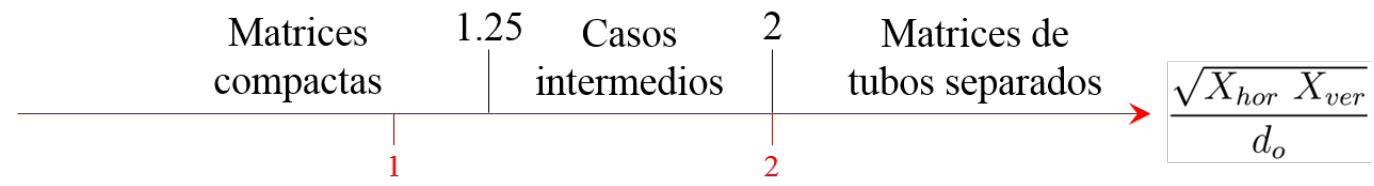

Figura 1.21: Clasificación de la compacidad en matrices de tubos.

La transferencia de calor por convección forzada alrededor de matrices de tubos fue estudiada, entre otros, por Zukauskas y Ulinskas (1988). En la Figura 1.22 se muestran, a modo de ejemplo, las distribuciones de $N u \sqrt{R e}$ obtenidas por estos autores en el interior de matrices de tubos separados (con temperaturas de pared uniformes) en función del ángulo de ataque del flujo respecto de la matriz, $\theta$, para configuraciones tanto en línea como escalonadas, en comparación con la de un tubo individual.

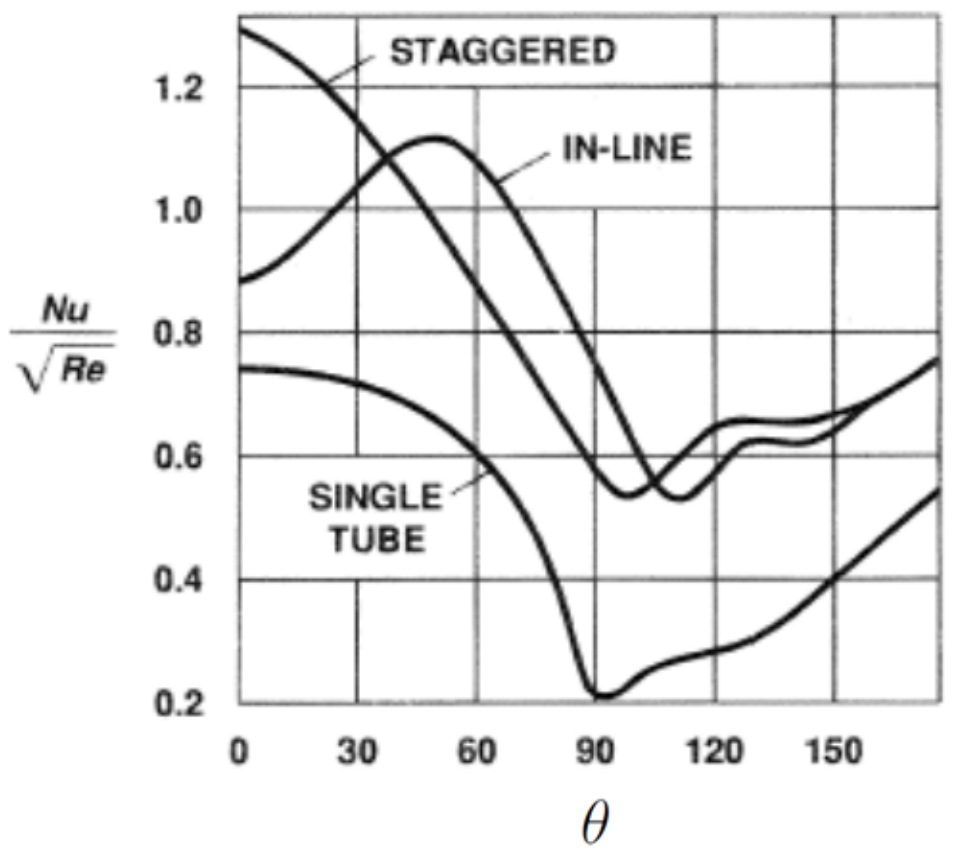

Figura 1.22: Variación de la transferencia de calor local alrededor de 1) un tubo individual y una matriz de tubos separados configurada 2) en linea o 3) escalonada (Zukauskas y Ulinskas, 1988).

Como se puede ver:

- la distribución obtenida para la configuración de tubos escalonados es similar a la de un cilindro individual: con el máximo situado en $\theta \approx 0^{\circ}$. En cambio, para la configuración de tubos en línea el máximo se sitúa en $\theta \approx 45^{\circ}$

- en ambas configuraciones la transferencia de calor es más elevada que en el caso de un tubo individual. Esto se debe al aumento de la turbulencia en la corriente libre (debido a la interacción con las filas precedentes) y al estrés generado por las contantes variaciones de la sección de paso del flujo. 
Aunque, para un mismo fluido de trabajo y fijadas unas ciertas condiciones de contorno, estas distribuciones pueden variar dependiendo de la configuración y geometría de la matriz de tubos, el régimen del flujo, la propia posición en el interior de la matriz, etc.

Un ejemplo de ello son las distribuciones de $N u / \bar{N} u$ obtenidas por Beale (1992), Figura 1.23, en el interior de una matriz cuadrada $\left(X_{h o r}=X_{v e r}=X\right)$ de tubos cuasi-compactos configurada en línea, en función del ángulo de ataque, considerando la temperatura de la pared constante y para un fluido de trabajo con número de Prandtl, $\operatorname{Pr}=1$.

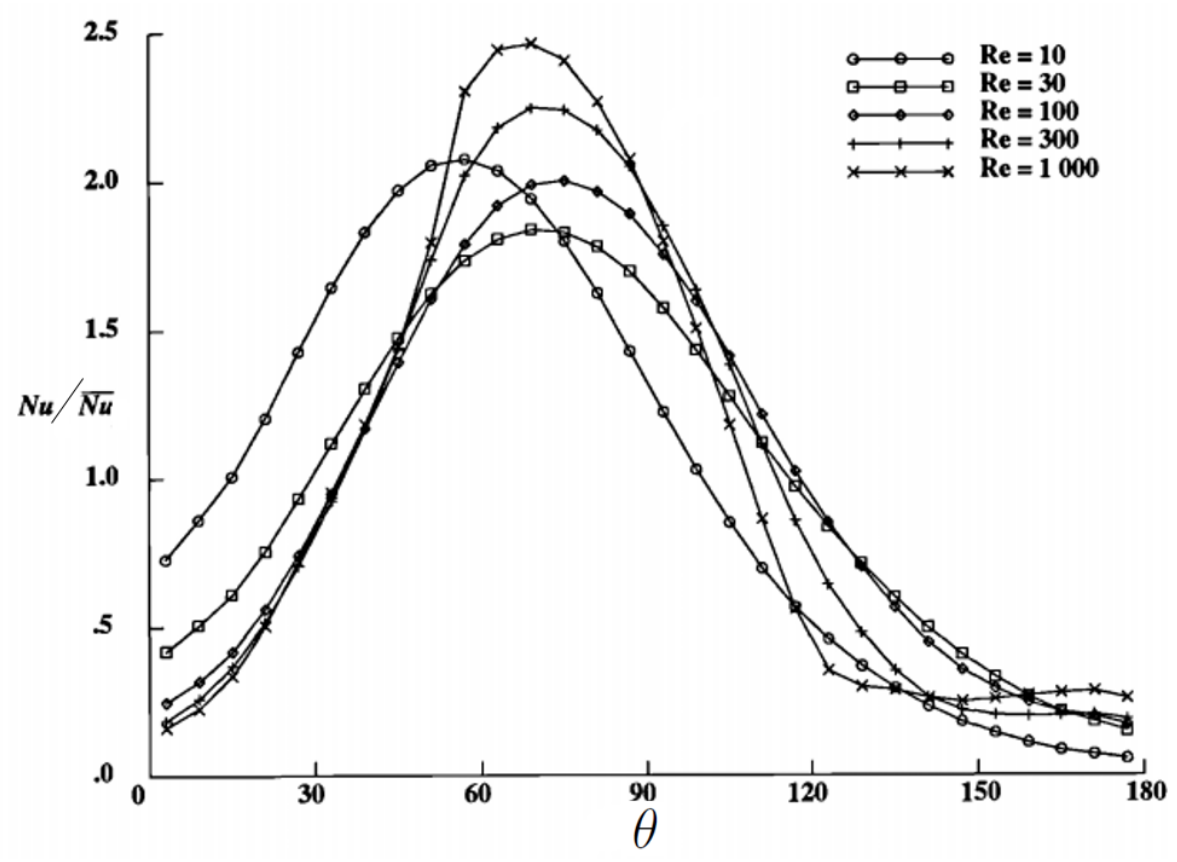

Figura 1.23: Variación de la transferencia de calor local en una matriz cuadrada de tubos cuasi-compactos $\left(X / d_{o}=1.5\right)$ configurada en linea, para diferentes valores de $R e(\overline{B e a l e}, \overline{1992})$.

Tal y como se puede apreciar, para $R e=10$ la transferencia de calor local es un poco más del doble del valor medio en $\theta \approx 55^{\circ}$. Para $R e=30$, el valor máximo se mueve hasta $\theta \approx 70^{\circ}$, y disminuye a 1.8. A medida que $R e$ aumenta, la tendencia se invierte con el valor máximo aumentando en valor y moviéndose ligeramente hacia arriba en posición.

Beale (1992) también observó que para una matriz cuadrada de tubos compactos $\left(X / d_{o}=\right.$ 1.25) dicha inversión es menos marcada y se produce a menor Re y para una matriz cuadrada de tubos separados $\left(X / d_{o}=2\right)$ ocurre todo lo contrario.

Por tanto, de todo ello se deduce que, para una correcta descripción de la transferencia de calor local alrededor de matrices de tubos, es de vital importancia el estudio de las distribuciones de los coeficientes de transferencia de calor.

El trabajo más destacado por otros autores hasta la fecha sobre correlaciones experimentales para predecir los coeficientes de transferencia de calor locales alrededor de matrices de tubos es la revisión llevada a cabo por Zukauskas (1987). 
Según Zukauskas, la transferencia de calor promedio alrededor de matrices de tubos viene dada por la forma general:

$$
\overline{N u}_{d_{o}}=C Z \operatorname{Re}^{m} \operatorname{Pr}^{n}\left(\frac{P r}{P r_{w}}\right)^{p}
$$

donde las propiedades del fluido se evalúan a la temperatura promedio en el seno del fluido, $T_{\infty}$, y el número de Prandtl de la pared, $P r_{w}$, se estima a la temperatura de la pared, $T_{w}$. $C Z, m, n$ y $p$ son constantes ajustables de la correlación.

El parámetro $C Z$, para configuraciones de tubos escalonados, se puede sustituir por el parámetro geométrico $X_{v e r} / X_{h o r}$ con un exponente de 0.2 , si $X_{v e r} / X_{\text {hor }}<2$. Si $X_{v e r} / X_{\text {hor }}>$ 2 se sustituye por un valor constante de 0.40. Para configuraciones de tubos en línea, en el rango $10^{3}<R e<2 \cdot 10^{5}$, el efecto del paso vertical, $X_{v e r}$, o del horizontal, $X_{h o r}$, no es evidente y $C Z$ se puede sustituir por un valor constante de 0.27 .

En la Tabla 1.4, se resumen las diferentes formas de la Ecuación 1.13 propuestas por Zukauskas para flujos cruzados alrededor de matrices de tubos en línea en función del número de Reynolds.

Tabla 1.4: Correlaciones propuestas por Zukauskas para flujos cruzados alrededor de matrices de tubos en línea, en función del número de Reynolds (Kakaç et al., 1987).

\begin{tabular}{|c|c|}
\hline Correlación & Rango de Aplicabilidad \\
\hline \hline $\bar{N} u_{d_{o}}=0.9 c z_{n} \operatorname{Re}^{0.4} \operatorname{Pr}^{0.36}\left(\frac{P r}{\operatorname{Pr}_{w}}\right)^{0.25}$ & $\operatorname{Re} \in\left[1-10^{2}\right]$ \\
\hline $\bar{N} u_{d_{o}}=0.52 c z_{n} \operatorname{Re}^{0.5} \operatorname{Pr}^{0.36}\left(\frac{P r}{\operatorname{Pr}_{w}}\right)^{0.25}$ & $\operatorname{Re} \in\left[10^{2}-10^{3}\right]$ \\
\hline $\bar{N} u_{d_{o}}=0.27 c z_{n} \operatorname{Re}^{0.63} \operatorname{Pr}^{0.36}\left(\frac{P r}{P r_{w}}\right)^{0.25}$ & $\operatorname{Re} \in\left[10^{3}-2 \cdot 10^{5}\right]$ \\
\hline $\bar{N} u_{d_{o}}=0.033 c z_{n} \operatorname{Re}^{0.9} \operatorname{Pr}^{0.4}\left(\frac{P r}{P r_{w}}\right)^{0.25}$ & $\operatorname{Re} \in\left[2 \cdot 10^{5}-2 \cdot 10^{6}\right]$ \\
\hline
\end{tabular}

donde $c z_{n}$ es un factor de corrección debido al tamaño de las matrices (se denota por $\mathrm{n}$ al al número de fila de una matriz de tubos). El efecto sobre la transferencia de calor del número de filas de una matriz se hace despreciable cuando $n>16$, como se muestra en la Figura 1.24 .

Para flujos cruzados alrededor de matrices de tubos escalonados, en la Tabla 1.5, se resumen las diferentes formas de la de la Ecuación 1.13 propuestas por Zukauskas en función del número de Reynolds.

Estas correlaciones son válidas para $0.35<\operatorname{Pr}<500$ y son aplicables, principalmente, a los tubos de las filas internas de las matrices. 


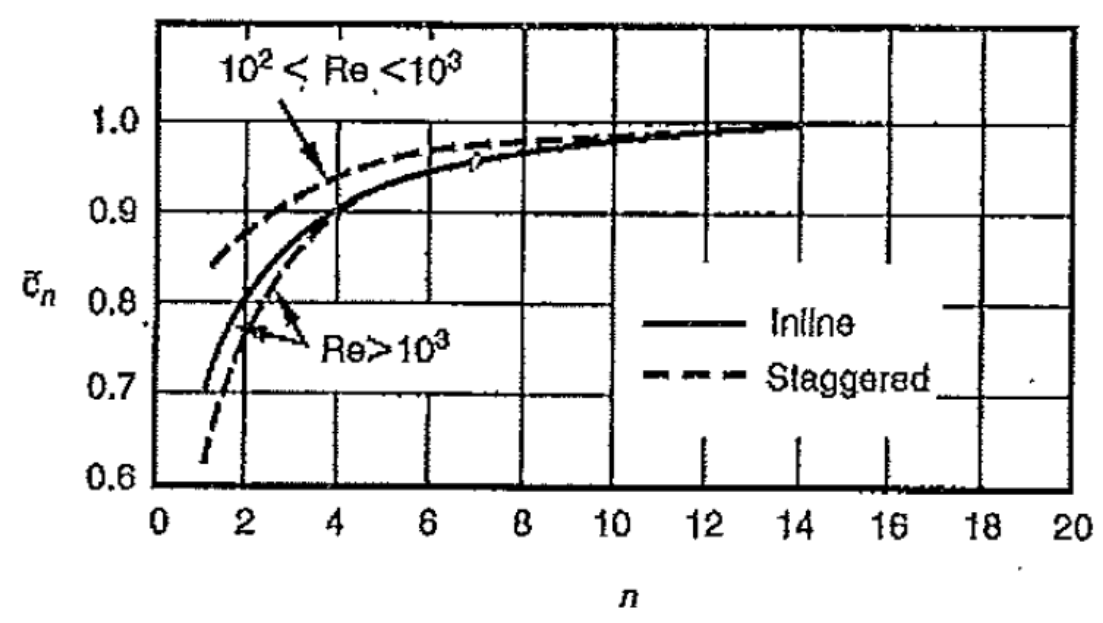

Figura 1.24: Factor de corrección para la transferencia de calor, $c z_{n}$, en función del número de filas de una matriz de tubos (Kakaç et al., 1987).

Tabla 1.5: Correlaciones propuestas por Zukauskas para flujos cruzados alrededor de matrices de tubos escalonados en función del número de Reynolds (Kakaç et al., 1987).

\begin{tabular}{|c|c|}
\hline Correlación & Rango de Aplicabilidad \\
\hline \hline $\bar{N} u_{d_{o}}=1.04 c z_{n} \operatorname{Re}^{0.4} \operatorname{Pr}^{0.36}\left(\frac{P r}{P r_{w}}\right)^{0.25}$ & $R e \in\left[1-5 \cdot 10^{2}\right]$ \\
\hline $\bar{N} u_{d_{o}}=0.71 c z_{n} \operatorname{Re}^{0.5} \operatorname{Pr}^{0.36}\left(\frac{P r}{P r_{w}}\right)^{0.25}$ & $\operatorname{Re} \in\left[5 \cdot 10^{2}-10^{3}\right]$ \\
\hline $\bar{N} u_{d_{o}}=0.35 c z_{n} \operatorname{Re}^{0.6} \operatorname{Pr}^{0.36}\left(\frac{P r}{P r_{w}}\right)^{0.25}\left(\frac{X_{v e r}}{X_{h o r}}\right)^{0.2}$ & $R e \in\left[10^{3}-2 \cdot 10^{5}\right]$ \\
\hline $\bar{N} u_{d_{o}}=0.35 c z_{n} \operatorname{Re}^{0.6} \operatorname{Pr}^{0.36}\left(\frac{P r}{P r_{w}}\right)^{0.25}\left(\frac{X_{v e r}}{X_{h o r}}\right)^{0.2}$ & $R e \in\left[2 \cdot 10^{5}-2 \cdot 10^{6}\right]$ \\
\hline
\end{tabular}

Aunque los coeficientes de transferencia de calor locales para las filas 3, 4, 5, etc. son indistinguibles entre sí, las segundas filas suelen exhibir una transferencia de calor de entre un $10 \%$ a un $25 \%$ menor que la de las filas internas para $R e<10^{4}$, y una misma transferencia de calor para $R e>10^{4}$. La transferencia de calor de las primeras filas puede ser de entre un $60 \%$ a un $75 \%$ menor que la de las filas internas, dependiendo del paso horizontal $X_{h o r}$.

La incertidumbre del resultado de estas ecuaciones está dentro de $\pm 15 \%$.

Se debe indicar que el número de Reynolds, $R e$, está basado en la velocidad media en la sección más estrecha de la matriz de tubos, es decir, la velocidad máxima promedio del flujo, $v_{\infty}$. 


\subsubsection{Revisión del estado de la técnica de las correlaciones para la transferencia de calor por convección forzada alrededor de matrices de tubos helicoidales}

El uso de matrices de tubos helicoidales se restringe habitualmente a fluidos sin impurezas, y son particularmente útiles cuando se requiere un intercambio de calor entre un volumen pequeño de un fluido a alta presión y un volumen grande de otro fluido a baja presión, tal y como sucede en el sistema de ENEA.

El diseño de intercambiadores de calor de tubos helicoidales fue patentado por Hampson (1895), y posteriormente re-patentado por AirLiquide (1934). No obstante, no fue hasta 1960 cuando esta geometría comenzó a cobrar importancia cuando Smith presentó un informe industrial relacionado con ella (Smith, 2006). Posteriormente, en 1964, Smith publicó brevemente sus principales resultados (Smith, 2006).

Los estudios sobre transferencia de calor por convección forzada en intercambiadores de calor de tubos helicoidales en el lado de la carcasa son escasos en la literatura, y las configuraciones estudiadas se limitan a condiciones de operación y configuraciones muy específicas. Messa et al. (1969) propusieron varias correlaciones para la transferencia de calor basadas en un trabajo experimental realizado con seis intercambiadores de calor de tubos helicoidales de diferentes ángulos de inclinación, los cuales iban desde $4^{\underline{0}} 30^{\prime}$ hasta $18^{\mathrm{O}} 30^{\prime}$, empleando aire y agua como fluidos de trabajo. Smith (2006) llevó a cabo el diseño térmico del sistema de transferencia de calor helio-vapor del reactor de alta temperatura DRAGON del experimento de la OECD/NEA (Organisation for Economic Co-operation and Development/Nuclear Energy Agency) utilizando la correlación resultante del programa experimental de Smith y Coombs (1972) y Smith y King (1978). Abadzic (1974), citado por Smith (2006) examinó los datos de transferencia de calor de diversas fuentes recomendando el uso de tres correlaciones genéricas que barren un amplio rango de números de Reynolds, Re. Aunque la mayoría de los datos correlacionados por este autor correspondían a matrices de tubos helicoidales con ángulos de inclinación de alrededor de $9^{\underline{O}}$, éstas no eran uniformes. Genić et al. (2012) presentaron una correlación basada en un trabajo experimental realizado con tres intercambiadores de calor helicoidales con ángulos de inclinación de $4^{\mathrm{O}} 26^{\prime}$ hasta $42^{\mathrm{O}}$ 28 ' y sentidos de giro de los tubos paralelos u opuestos. Las primeras correlaciones se basan en el diámetro exterior de los tubos helicoidales, $d_{0}$, y la última en su diámetro hidráulico, $d_{h}$.

Finalmente, He et al. (2014) estudiaron la transferencia de calor por convección forzada de las sales fundidas alrededor de una matriz de tubos rectos y propusieron una correlación válida para números de Prandtl $\operatorname{Pr}$, de entre 20 y 100, y diámetro hidráulico $d_{h}=0.0432 \mathrm{~m}$. 
En la Tabla 1.6 se resumen las correlaciones mencionadas en los trabajos anteriores, así como los rangos considerados de número de Reynolds, Re.

Tabla 1.6: Correlaciones para la transferencia de calor por convección forzada alrededor matrices de tubos helicoidales y rectos.

\begin{tabular}{|c|c|c|}
\hline Autor/es & Correlación & Rango de Aplicabilidad \\
\hline \multirow{6}{*}{$\begin{array}{l}\text { Messa et al. } \\
(1969)\end{array}$} & (1) $N u_{d_{o}}=0.0567 R e^{0.71} \operatorname{Pr}^{0.93}$ & $R \quad R e \in\left[5 \cdot 10^{2}-4.5 \cdot 10^{4}\right]$ \\
\hline & (2) $N u_{d_{o}}=0.0085 R e^{0.84} \operatorname{Pr}^{0.57}$ & $R e \in\left[9 \cdot 10^{2}-7.5 \cdot 10^{3}\right]$ \\
\hline & (3) $N u_{d_{o}}=0.0305 \operatorname{Re}^{0.85} \operatorname{Pr}^{0.7}$ & $R e \in\left[4 \cdot 10^{2}-7.5 \cdot 10^{3}\right]$ \\
\hline & (4) $N u_{d_{o}}=0.032 R e^{0.83} \operatorname{Pr}^{1.14}$ & $R e \in\left[8 \cdot 10^{2}-1.2 \cdot 10^{4}\right]$ \\
\hline & (5) $N u_{d_{o}}=0.0851 R e^{0.71} \operatorname{Pr}^{1.02}$ & $R e \in\left[4 \cdot 10^{2}-3.7 \cdot 10^{4}\right]$ \\
\hline & (6) $N u_{d_{o}}=0.0214 R e^{0.86} \operatorname{Pr}^{0.83}$ & $\operatorname{Re} \in\left[5 \cdot 10^{2}-7 \cdot 10^{3}\right]$ \\
\hline \multirow[t]{2}{*}{$\operatorname{Smith}(2006)$} & $N u_{d_{o}}=0.0559 R e^{0.794}$ & $R e \in\left[10^{3}-10^{4}\right]$ \\
\hline & (1) $N u_{d_{o}}=0.332 \operatorname{Re}^{0.6} \operatorname{Pr}^{0.36}$ & $R e \in\left[10^{3}-2 \cdot 10^{4}\right]$ \\
\hline \multirow[t]{2}{*}{ Abadzic (1974) } & (2) $N u_{d_{o}}=0.123 R e^{0.7} \operatorname{Pr}^{0.36}$ & $R e \in\left[2 \cdot 10^{4}-2 \cdot 10^{5}\right]$ \\
\hline & (3) $N u_{d_{o}}=0.036 \operatorname{Re}^{0.8} \operatorname{Pr}^{0.36}$ & $R e \in\left[2 \cdot 10^{5}-9 \cdot 10^{5}\right]$ \\
\hline Genić et al. (2012) & $N u_{d_{h}}=0.50 \operatorname{Re}^{0.55} \operatorname{Pr}^{0.33}\left(\frac{\mu}{\mu_{w}}\right)^{0.14}$ & $R e \in\left[10^{3}-9 \cdot 10^{3}\right]$ \\
\hline He et al. $(2014)$ & $N u_{d_{h}}=1.61\left(\frac{R e P r}{l / d_{h}}\right)^{0.63}\left(\frac{\mu}{\mu_{w}}\right)^{0.32}$ & $R e \in\left[4 \cdot 10^{2}-2.3 \cdot 10^{3}\right]$ \\
\hline
\end{tabular}

La correlación de Smith no incluye los efectos del número de $\operatorname{Pr}$, las de Abadzic sólo fueron validadas para gases $(\operatorname{Pr} \sim 1)$ y las de Messa et al. (1), (3), (4), (5) y (6) aunque fueron validadas para gases y líquidos, solo son aptas para números de $\operatorname{Pr}$ bajos (hasta 2.6). En cambio, las correlaciones de Geníc et al. y Messa et al. (2) son adecuadas para líquidos con números de $\operatorname{Pr}$ de hasta 6 en el primer caso y hasta $\sim 7.8$ en el segundo. Aunque en el caso de Messa et al. (2), la configuración de la matriz para la que fuere validada (tubos escalonados) difiere considerablemente de la del diseño de ENEA (tubos en linea, se verá en §2.4).

En el caso de la correlación de $\mathrm{He}$ et al., a pesar de ser adecuada para sales fundidas $(\operatorname{Pr}=4.5-10)$, la configuración para la cual fue validada es menos efectiva transfiriendo calor que una matriz de tubos helicoidales: matriz de tubos rectos.

Por tanto, en base a la revisión del estado de la técnica llevada a cabo se concluye que las correlaciones revisadas no son totalmente adecuadas para describir la transferencia de calor en el generador de vapor integrado de ENEA, bien sea por el tipo de fluido utilizado (sales fundidas) o por el tipo de intercambiador de calor empleado (matriz de tubos helicoidales configurados en línea). 


\subsection{Fenómenos físicos involucrados en el lado agua-vapor}

\subsubsection{Transferencia de calor por convección forzada en flujos internos en ebullición}

La transferencia de calor por convección forzada en flujos internos en ebullición es un problema complejo, ya que, dependiendo del tipo de régimen de flujo presente, los mecanismos de transferencia de calor son diferentes, lo cual, determina el valor de los coeficientes de transferencia de calor locales.

En la Figura 1.25 se muestran los regímenes de flujo y los mecanismos de transferencia de calor que, comúnmente, se dan en un flujo interno ascendente en ebullición circulando en convección forzada por un tubo recto calentado uniformemente.

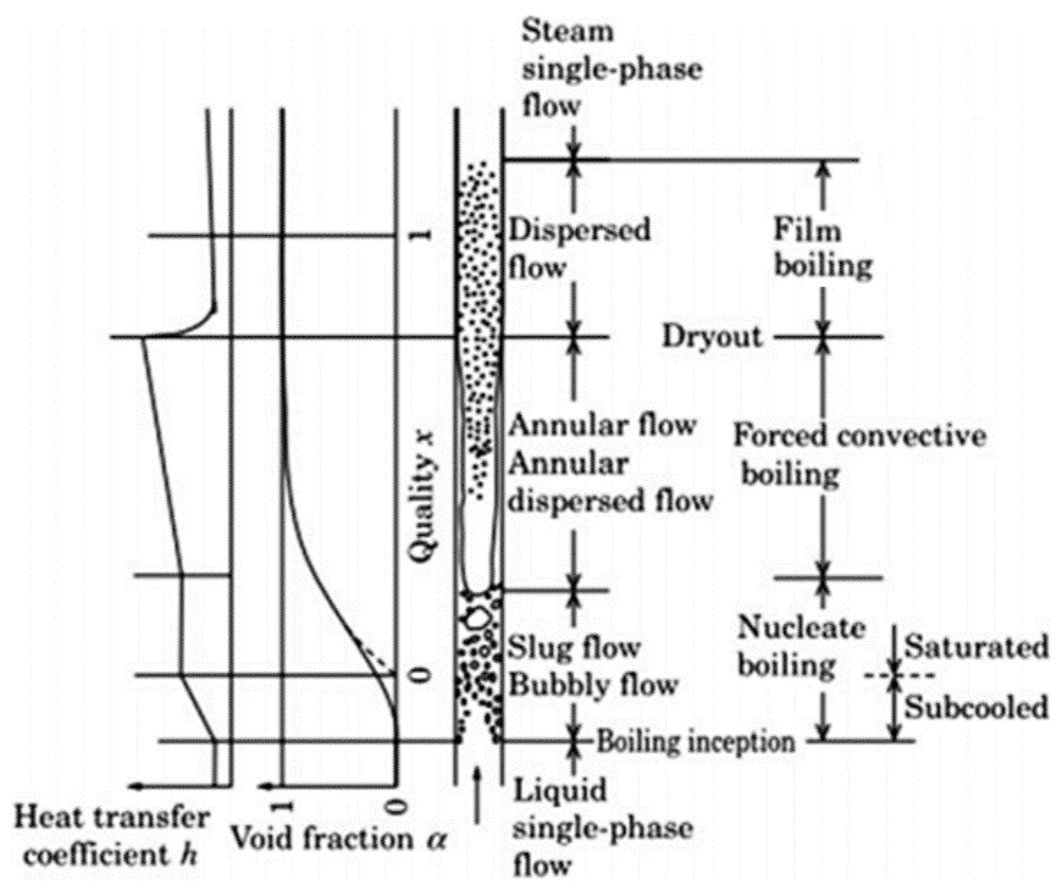

Figura 1.25: Regímenes de flujo y mecanismos de transferencia de calor en un tubo recto calentado uniformemente Akimoto et al. (2016).

A medida que el líquido asciende se va calentando, después cambia de fase y, finalmente, el vapor producido se sobrecalienta, distinguiéndose los siguientes regímenes de flujo durante el proceso.

- A la entrada del tubo, la temperatura de las paredes no supera la temperatura de saturación del líquido, aunque la temperatura del líquido aumenta debido a la transferencia de calor por convección forzada al flujo monofásico. 
- A continuación del tubo, la temperatura de las paredes ya supera la temperatura de saturación del líquido y en la zona sobrecalentada adyacente a las paredes comienzan a formarse burbujas (inicio de la ebullición). La temperatura en el interior de la corriente fluida sigue siendo más baja que la temperatura de saturación (seno subenfriado), por lo que las burbujas generadas sobre las paredes que entran en contacto con él vuelven a condensar. Este proceso se denomina ebullición subenfriada y viene acompañado de un aumento progresivo de los coeficientes de transferencia de calor locales.

- Una vez la temperatura del seno alcanza la temperatura de saturación las burbujas que entran en contacto con él ya no condensan. A partir de aquí, el proceso se denomina ebullición saturada y el primer régimen de flujo que se encuentra es el de burbujeo, caracterizado por contener burbujas aisladas inmersas en la fase líquida, pudiendo ser pequeñas y esféricas o grandes y en forma de casquete esférico.

- Continuando hacia arriba a lo largo del tubo, prosigue la formación de burbujas. Una vez generadas sobre las paredes crecen por coalescencia al ir avanzando en altura, dando lugar a la aparición de nuevos regímenes de flujo: el de pistón, seguido del anular y después el anular disperso (Figura 1.25). Se caracterizan:

- el primero, por contener, desde burbujas grandes, prácticamente del mismo diámetro que el tubo, separadas entre sí por agua líquida (que viene arrastrada por el flujo), hasta mezclas caóticas de burbujas grandes y pequeñas (que frenen el ascenso del líquido)

- el segundo, por contener una película líquida anular deslizándose por las paredes y un núcleo central continuo de vapor desplazándose a gran velocidad

- el tercero, igual que el anterior pero, por contener en su seno pequeñas gotas de líquido (que también vienen arrastradas por el flujo). Durante el régimen anular disperso, dependiendo del acabado superficial del tubo, de la presión, y del caudal másico, llega un momento en el que comienzan a aparecer zonas secas sobre las paredes (o dryout). En ese momento se produce la transición del régimen anular disperso al disperso. Estas zonas van aumentando hasta que las pequeñas gotas de líquido que quedan en el seno desaparecen completamente

Entonces, el cambio de fase finaliza y el título del vapor, $x \approx 1$.

- Así se llega a tener vapor seco circulando por el tubo y da comienzo su recalentamiento. La transferencia de calor se produce por convección forzada al flujo monofásico.

Si el flujo de calor sobre las paredes es relativamente bajo, $Q \approx 3 \cdot 10^{5} \mathrm{~W} \cdot \mathrm{m}^{-2}$, se distinguen las siguientes regiones de transferencia de calor dependiendo del mecanismo de transferencia predominante: región de ebullición nucleada, región de ebullición convectiva forzada y región 
de superficie seca (comúnmente denominada post-dryout), Figura 1.25 .

En las zonas de ebullición subenfriada y de ebullición saturada con bajo título de vapor $(x<0.5)$, los regímenes de flujo presentes son el de burbujeo y el de pistón. En ellos la ebullición nucleada es el mecanismo de transferencia de calor dominante, por eso aquí los coeficientes de transferencia de calor locales suelen ser constantes.

En la zona de ebullición saturada con título de vapor entre $x \approx 0.5$ y $x \approx 0.9$, los regímenes de flujo presentes son el anular y el anular disperso. En ellos, la ebullición en convección forzada a través de la película líquida anular es el mecanismo de transferencia de calor dominante. Este mecanismo de transferencia de calor es más eficiente que el anterior, por lo que da lugar a coeficientes de transferencia de calor locales mayores. Además, puesto que la película líquida es cada vez más fina, los coeficientes de transferencia de calor locales aumentan progresivamente.

La región de superficie seca comienza a partir de la transición del régimen anular disperso al disperso: se modifica de forma drástica la refrigeración de las paredes, pasando de estar bañadas por líquido a estar bañadas por vapor. La ausencia de líquido en contacto con las paredes provoca una disminución brusca de los coeficientes de transferencia de calor locales, ocasionando una mala respuesta térmica fluido-estructura que implica un aumento de la temperatura de las paredes del tubo (Collier y Thome, 1994). Además la transferencia de calor del vapor a las pequeñas gotas de líquido que vienen arrastradas en su seno es muy poco eficiente y, por tanto, el calor aplicado es empleado prácticamente todo en sobrecalentar dicho vapor por convección forzada de las paredes al vapor.

El comienzo de la región de superficie seca viene representado por el título de vapor local asociado, es decir, por el título de vapor medio en el plano perpendicular a la dirección del flujo.

\subsubsection{Revisión del estado de la técnica de las correlaciones para el cálculo del título de vapor local asociado al comienzo del régimen de superficie seca en flujos en ebullición en convección forzada en tubos helicoidales en vertical}

Una de las mayores diferencias entre flujos en ebullición en convección forzada en tubos verticales rectos y helicoidales es el comienzo del régimen de superficie seca. Mientras que en los rectos ocurre a la vez en todos los puntos de la superficie a una misma altura (dryout, $x_{\text {dryout }}$ ), en los helicoidales, comienza en determinados puntos de la superficie (primer dryout, $x_{1}$ ) y se extiende en altura hasta que todos los puntos de la superficie se secan completamente 
a una altura determinada (dryout total, $x_{T o t}$ ). La Figura 1.26 muestra el tramo de alturas donde los tubos están parcialmente secos y parcialmente húmedos.

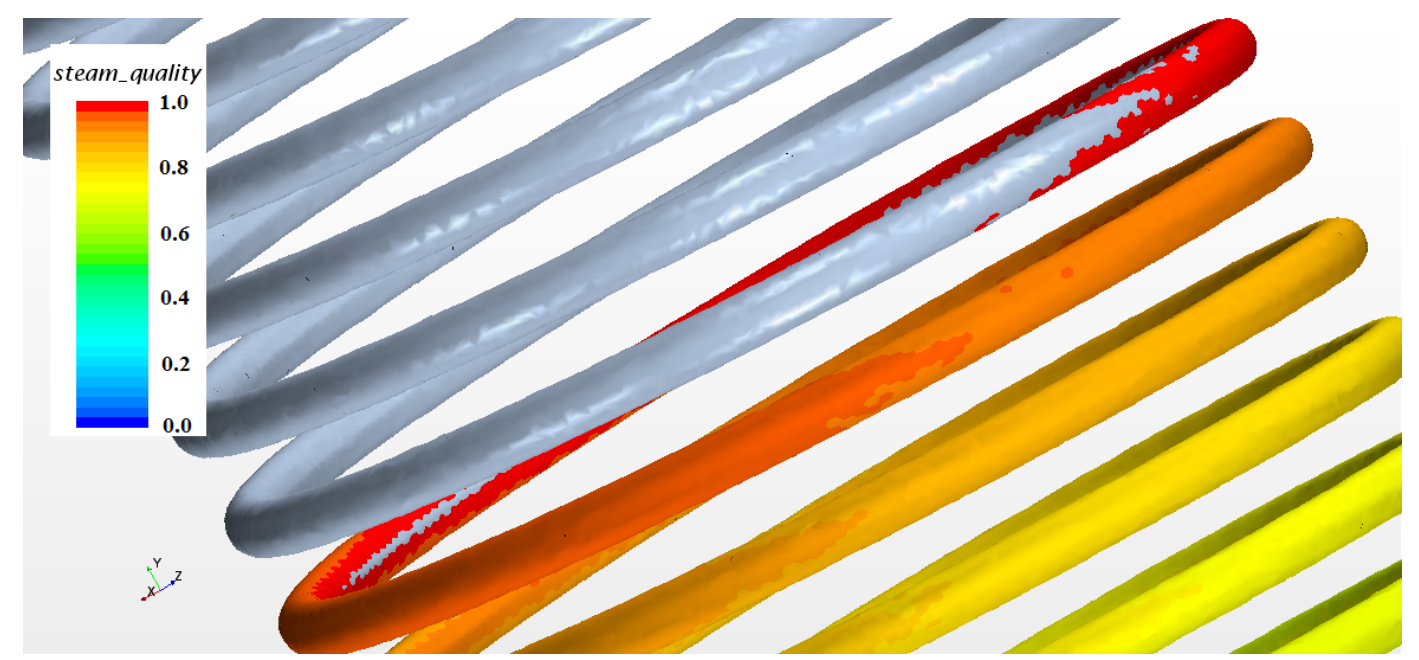

Figura 1.26: Simulación del comienzo del régimen de superficie seca (primer dryout y dryout total) en un tubo helicoidal. Fuente: modelo CFD del Capítulo 6 .

Esta diferencia es debida a la acción conjunta de las fuerzas de rozamiento, viscosas y centrífugas, que origina que el flujo bifásico experimente un flujo secundario, Owhadi et al. (1968), perpendicular al principal, que ayuda a que la superficie extradós de los tubos (o lado exterior) se mantenga húmeda hasta calidades de vapor más elevadas que en tubos rectos, retrasando el dryout. Los estudios comparativos llevados a cabo por Cumo et al. (1972) y Styrikovich et al. (1984) entre un tubo vertical recto y otro helicoidal, ponen de manifiesto tal diferencia. Las características geométricas de los tubos empleados y el rango de condiciones de trabajo barridas en cada estudio se resumen en la Tabla 1.7.

De las correlaciones encontradas en la literatura para el cálculo del título de vapor asociado al dryout en flujos en ebullición en convección forzada en tubos helicoidales en vertical, las condiciones de trabajo de presión $(P)$, flujo másico $(G)$ y flujo de calor en las paredes $(Q)$ y las características geométricas de los tubos empleados son los principales factores involucrados, como se infiere de la Tabla 1.7.

El efecto de la presión y el flujo másico fue analizado por Styrikovich et al. (1984), quien observó que, al aumentar la presión y el caudal, el título de vapor durante el dryout total disminuía evidenciando, en consecuencia, la dependencia con éstas. De todas las correlaciones revisadas, sólo la de Naitoh et al. (1974), Tabla 1.7, es independiente del flujo másico.

Berthoud y Jayanti (1990) en su trabajo basado en los datos de Carver et al. (1964); Roumy (1971); Ünal et al. (1981); Ünal (1981); Breus y Belyakov (1983); Styrikovich et al. (1984), proponen tres correlaciones para determinar el título de vapor durante el primer dryout dependiendo del tipo de régimen anular (Tabla 1.7). Para identificar el tipo de régimen 
emplean un mapa 2D (Figura 1.27) donde en el eje de abscisas, se representa el número adimensional $x_{0}$ por la expresión:

$$
x_{0}=\frac{G}{\rho_{v} \sqrt{g D}}
$$

donde $\rho_{v}$ es la densidad del vapor, $g$ la aceleración de la gravedad y $D$ el diámetro de hélice. Este parámetro es una medida de la fuerza centrífuga actuando sobre la fase gaseosa y del arrastre de las gotas que da cuenta del proceso de re-deposición. Y, en el eje de ordenadas, se representa el número adimensional $y_{0}$, equivalente al número de Reynolds del líquido, que vienen dado por la expresión:

$$
y_{0}=\frac{G d^{*}}{\mu_{l}}
$$

donde $d^{*}$ es un parámetro geométrico dado por $d^{*}=d_{i} \sqrt{d_{i} / 0.02}$ (siendo $d_{i}$ el diámetro interno de los tubos) y $\mu_{l}$ la viscosidad dinámica del líquido. $y_{0}$ da cuenta del proceso de arrastre de las gotas a través del núcleo.

En la Figura 1.27 se pueden distinguir tres zonas dependiendo de los factores anteriormente citados:

- Zona de dominio de la gravedad: caracterizada por $D$ alto, $G$ bajo y $P$ alta, donde el comienzo del dryout se produce a calidades bajas. En este caso los flujos suelen estar muy estratificados.

- Zona de dominio de la re-deposición de gotas: caracterizada por $D$ bajo, $G$ alto y $P$ baja, donde el comienzo del dryout se produce a calidades altas. En este caso los flujos suelen estar poco estratificados y la superficie extradós del tubo suele estar bien refrigerada.

- Zona de dominio del arrastre de las gotas a través del núcleo: caracterizada por $D$ muy alto, $G$ muy alto y $P$ moderada, donde el comienzo del dryout se produce a calidades medias. En este caso los flujos suelen estar poco estratificados y la superficie intradós (o lado interior) del tubo bien refrigerada.

Berthoud y Jayanti (1990) también proponen una correlación para determinar el título de vapor durante el dryout total, notando que ésta también depende sólo del tipo de régimen anular (Tabla 1.7). A diferencia de las expresiones anteriores, esta última es independiente del flujo de calor en las paredes. 
Tabla 1.7: Correlaciones para el cálculo del título de vapor durante el primer dryout y en el dryout total en tubos helicoidales

\begin{tabular}{|c|c|c|c|}
\hline Autor/es & Fluido & Geometría & Condiciones \\
\hline Styrikovich et al. (1984) & $\begin{array}{c}\mathrm{H}_{2} \mathrm{O} \\
\text { (en sentido ascendente } \\
\text { o descendente) }\end{array}$ & $\begin{array}{c}\text { Tubo recto vs. Tubo helicoidal } \\
L=1.709 \mathrm{~m} ; d_{i}=0.010 \mathrm{~m} ; \\
D=0.136 \mathrm{~m} ; X_{\text {ver }}=0.055 \mathrm{~m} \\
\varphi=11.43^{\circ}\end{array}$ & $\begin{array}{c}G \in[500,1500] \mathrm{kg} \cdot \mathrm{s}^{-1} \cdot \mathrm{m}^{-2} \\
Q \in[100,1500] \mathrm{kW} \cdot \mathrm{m}^{-2} \\
P \in[98.1,176] \mathrm{bar}\end{array}$ \\
\hline Cumo et al. (1972) & $\begin{array}{c}\mathrm{R} 12 \\
\text { (en sentido ascendente) }\end{array}$ & $\begin{array}{c}\text { Tubo recto vs. Tubo helicoidal } \\
L=2 \mathrm{~m} ; d_{i}=0.00475 \mathrm{~m} ; \\
d_{o}=0.00635 \mathrm{~m} ; \\
D=0.18 \mathrm{~m} ; X_{v e r}=0.07 \mathrm{~m} \\
\varphi=11^{\circ}\end{array}$ & $\begin{array}{c}G \in[500,1800] \mathrm{kg} \cdot \mathrm{s}^{-1} \cdot \mathrm{m}^{-2} \\
Q=120 \mathrm{~kW} \cdot \mathrm{m}^{-2} \\
P \in[65,240] \mathrm{bar}\end{array}$ \\
\hline Berthoud y Jayanti 1990 & $\begin{array}{c}\mathrm{H}_{2} \mathrm{O} / \mathrm{R} 12 \\
\text { (en sentido ascendente) }\end{array}$ & $\begin{array}{l}1 \text { Tubo helicoidal } \\
d_{i}=[0.008,0.02] \mathrm{m} \\
D=[0.08,3.3] \mathrm{m}\end{array}$ & $\begin{array}{c}G \in[100,1900] \mathrm{kg} \cdot \mathrm{s}^{-1} \cdot \mathrm{m}^{-2} \\
Q \in[10,1800] \mathrm{kW} \cdot \mathrm{m}^{-2} \\
P \in[11,200] \mathrm{bar}\end{array}$ \\
\hline Santini et al. (2014) & $\begin{array}{c}\mathrm{H}_{2} \mathrm{O} \\
\text { (en sentido ascendente) }\end{array}$ & $\begin{array}{c}\text { 1 Tubo helicoidal } \\
L=32 \mathrm{~m} ; d_{i}=0.01253 \mathrm{~m} ; \\
d_{o}=0.01724 \mathrm{~m} ; \\
D=1 \mathrm{~m} ; X_{v e r}=0.79 \mathrm{~m} \\
\varphi=21.55^{\circ}\end{array}$ & $\begin{array}{c}G \in[199,810] \mathrm{kg} \cdot \mathrm{s}^{-1} \cdot \mathrm{m}^{-2} \\
Q \in[43.6,209.3] \mathrm{kW} \cdot \mathrm{m}^{-2} \\
P \in[10.7,60.7] \mathrm{bar}\end{array}$ \\
\hline $\begin{array}{c}\text { Jensen } 1980 ; \\
\text { Jensen y Bergles }(1981, \\
\text { (1982), (1983) }\end{array}$ & $\begin{array}{c}\text { R113 } \\
\text { (sentido ascendente) }\end{array}$ & $\begin{array}{c}3 \text { Tubos helicoidales } \\
L=0.635 \mathrm{~m}, 1.27 \mathrm{~m} \\
1.295 \mathrm{~m}, 1.257 \mathrm{~m} \\
(\text { solo parte calentada) } \\
d_{i}=0.00762 \mathrm{~m}, 0.00744 \mathrm{~m} \\
d_{o}=0.00777 \mathrm{~m}, 0.00769 \mathrm{~m} \\
D=0.4096 \mathrm{~m}, 0.2159 \mathrm{~m} \\
0.1175 \mathrm{~m} ; d_{i} / D=0.0182 \\
0.0353,0.0649 \\
X_{\text {ver }}=0.0254 \mathrm{~m}, 0.01270 \mathrm{~m} \\
0.01588 \mathrm{~m} \\
\varphi=1.78^{\circ}, 1.68^{\circ}, 3.87^{\circ}\end{array}$ & $\begin{array}{c}G \in[570,5470] \mathrm{kg} \cdot \mathrm{s}^{-1} \cdot \mathrm{m}^{-2} \\
Q \in[54,800] \mathrm{kW} \cdot \mathrm{m}^{-2} \\
P=9.4 \mathrm{bar} \\
\Delta T_{\text {sub }} \in[0,110]{ }^{\circ} \mathrm{C} \\
x_{\text {Tot }} \in[0.55,0.94]\end{array}$ \\
\hline $\begin{array}{l}\text { Ünal et al. }(1981) ; \\
\text { Ünal }[1981)\end{array}$ & $\begin{array}{c}\mathrm{H}_{2} \mathrm{O} \\
\text { (en sentido ascendente) }\end{array}$ & $\begin{array}{c}2(3) \text { Tubos helicoidales } \\
L=40.13 \mathrm{~m}, 35.50 \mathrm{~m} \\
(26.67 \mathrm{~m}) ; d_{i}=0.018 \mathrm{~m} \\
D=1.5 \mathrm{~m}, 0.7 \mathrm{~m} \\
X_{\text {ver }}=0.41 \mathrm{~m}, 0.46 \mathrm{~m} \\
\varphi=7.77^{\circ}, 8.83^{\circ}\end{array}$ & $\begin{array}{c}G \in[112,1829] \mathrm{kg} \cdot \mathrm{s}^{-1} \cdot \mathrm{m}^{-2} \\
Q \in[41,731] \mathrm{kW} \cdot \mathrm{m}^{-2} \\
P \in[147,202] \mathrm{bar} \\
\Delta T_{\text {sub }} \in[35.6,156.8]{ }^{\circ} \mathrm{C} \\
\quad x_{\text {Tot }} \in[0.08,1.00]\end{array}$ \\
\hline Naitoh et al. 1974 & $\begin{array}{c}\mathrm{H}_{2} \mathrm{O} \\
\text { (en sentido ascendente) }\end{array}$ & $d_{i} / D=0.0165$ & $P$ hasta 175 bar \\
\hline Duchatelle et al. 1975 & $\begin{array}{c}\mathrm{H}_{2} \mathrm{O} \\
\text { (en sentido ascendente) }\end{array}$ & $\begin{array}{c}4 \text { Tubos helicoidales } \\
d_{i} / D=0.032,0.025 \\
0.011,0.007\end{array}$ & $\begin{array}{c}G \in[375,3500] \mathrm{kg} \cdot \mathrm{s}^{-1} \cdot \mathrm{m}^{-2} \\
Q \in[310,1500] \mathrm{kW} \cdot \mathrm{m}^{-2} \\
P \in[45,175] \mathrm{bar}\end{array}$ \\
\hline Ruffell (1974) & $\begin{array}{c}\mathrm{H}_{2} \mathrm{O} \\
\text { (en sentido ascendente) }\end{array}$ & $\begin{array}{c}\text { 3 Tubos helicoidales } \\
L=8.2 \mathrm{~m} \text { (sólo parte calentada) } \\
d_{i}=0.0125 \mathrm{~m} \\
D=0.58 \mathrm{~m}, 1.32 \mathrm{~m}, 2.36 \mathrm{~m} \\
d_{i} / D=0.0216,0.0095,0.0053\end{array}$ & $\begin{array}{l}G \in[300,1800] \mathrm{kg} \cdot \mathrm{s}^{-1} \cdot \mathrm{m}^{-2} \\
Q / G \in[0.06,0.34] \mathrm{J} \cdot \mathrm{G}^{-1} \\
P \in[60,180] \mathrm{bar} *\end{array}$ \\
\hline
\end{tabular}

*Aunque válida para otras condiciones mediante modelización. 


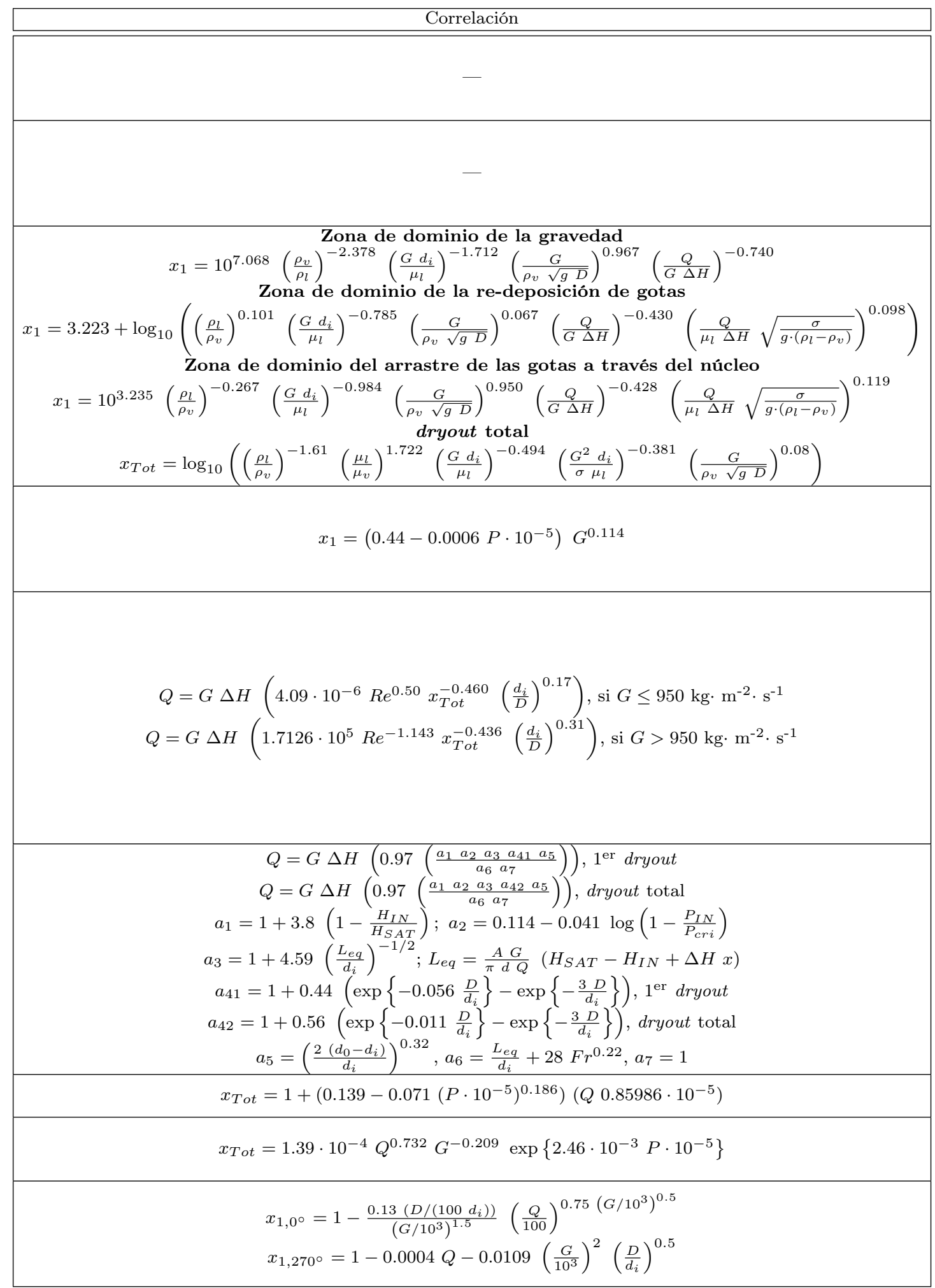




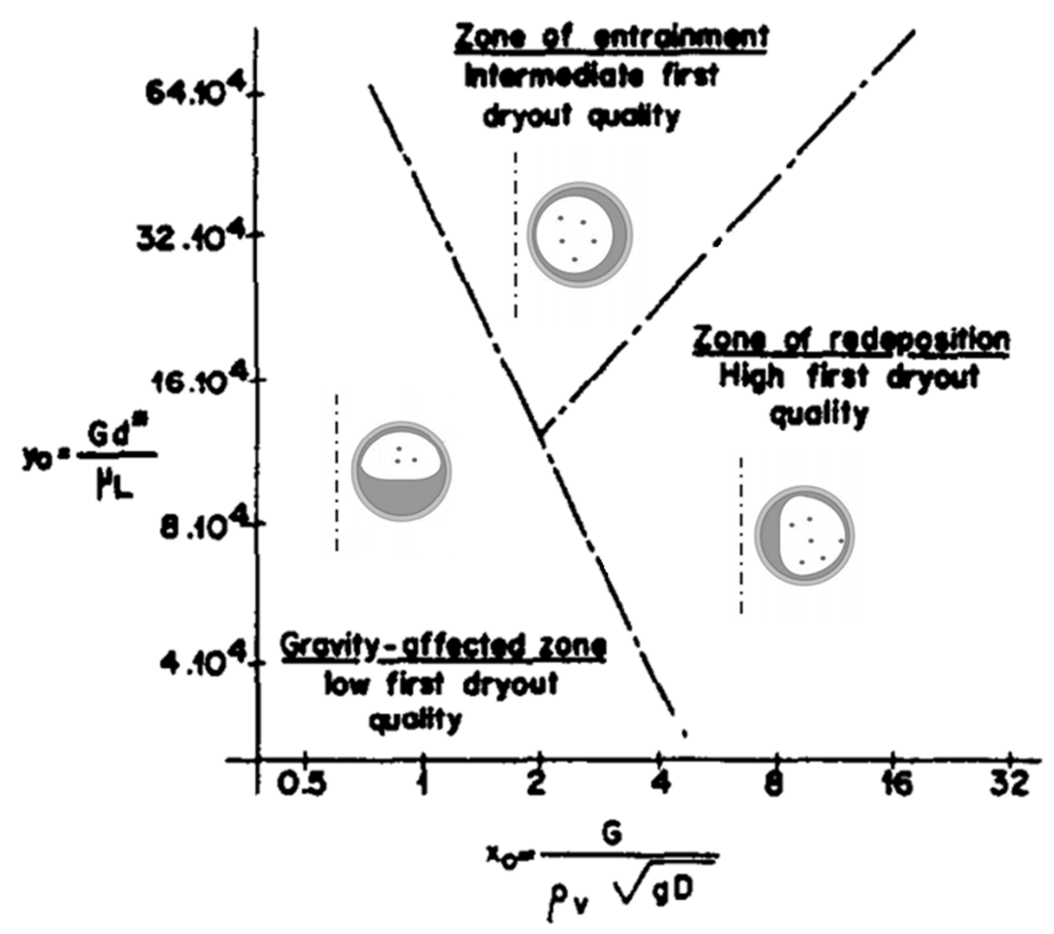

Figura 1.27: Mecanismos que gobiernan el primer dryout en tubos helicoidales. Mapa 2D de Berthoud y Jayanti (1990).

Para tratar de discernir la dependencia/independencia con el flujo de calor en las paredes hay que recurrir a otros trabajos: mientras que en las correlaciones propuestas por Duchatelle et al. (1975), Ünal et al. (1981), Ünal (1981), Jensen (1980); Jensen y Bergles 1981, 1982, 1983) y Ruffell (1974) aparece explícitamente esta magnitud, en la propuesta por Santini et al. (2014) se prescinde de ella (Tabla 1.7). Las tres primeras fueron obtenidas a partir de calentamientos no uniformes, mientras que la cuarta y la quinta lo fueron a partir de datos de tubos a escala de laboratorio calentados de forma uniforme y controlada:

a) Duchatelle et al. usaron los datos de un generador de vapor real intercambiando calor con un flujo de sodio líquido a contracorriente,

b) Ünal et al. emplearon los datos de tres tubos concéntricos calentados con sodio líquido circulando externamente a contracorriente $\mathrm{y}$,

c) Jensen et al. trabajaron con tres tubos calentados de forma no uniforme pero controlada, aplicando flujos más altos en el extradós que en el intradós.

Es decir, que las metodologías de calentamiento empleadas (uniforme o no uniforme) para su obtención son muy diferentes y, por tanto, es difícil deducir de forma clara la posible dependencia/independencia con el flujo de calor en las paredes a partir de la revisión del estado de la técnica.

Por otro lado, la correlación de Jensen et al. no es aplicable puesto que sus condiciones 
de trabajo están muy alejadas de las del prototipo de interés en términos de presión y del fluido que utiliza: (emplea R113). Tampoco las de Duchatelle et al. y Ünal et al. puesto que las condiciones de trabajo para las que están diseñadas también quedan lejos de las del prototipo, en particular, la primera es para flujos de calor y caudales muy altos y, la segunda para grados de subenfriamiento y presiones de trabajo muy elevados.

Se observa que en la mayor parte de los estudios donde se trabaja con pocos tubos en paralelo, el flujo bifásico presenta inestabilidades. En este sentido, cabe destacar el Capítulo 7 de Ünal (1981), donde se desarrolla un estudio sobre las DWOs (Density Wave Oscillations) que se observan durante la operación de un generador de vapor a escala real, y el estudio de Naitoh et al. (1974), quien investigó el dryout acompañado de DWOs. Este último concluyó que el periodo de las fluctuaciones del dryout en presencia de DWOs era de entre $3 \mathrm{~s}$ y $20 \mathrm{~s}$, resultado compatible con los datos experimentales del prototipo de ENEA (Anexo B).

Finalmente, hay muy pocos autores que analizan el efecto de las características geométricas de los tubos empleados. Según Ruffell (1974), el ángulo de inclinación de los tubos, $\varphi$, influye fuertemente sobre el primer dryout y según Ünal et al. (1981); Ünal (1981), si $D / d_{i} \geq 38.9$, el efecto de la geometría sobre la potencia necesaria, $\dot{Q}_{n e c}$, para llegar al primer dryout es despreciable, pero para llegar al dryout total no.

A la vista de esta revisión bibliográfica se concluye que es difícil discernir a priori cuál o cuáles de las correlaciones de la literatura aplicables para las condiciones de trabajo de este estudio (Tabla 1.7) son las más adecuadas para el cálculo del título de vapor local asociado al dryout, ya que, no todas dependen de los mismos factores; posiblemente, debido a que las metodologías de trabajo empleadas para su obtención son muy diferentes, limitación que, por otro lado, también detectaron Santini et al. (2014), Jensen (1980); Jensen y Bergles (1981, 1982, 1983), Ünal et al. (1981); Ünal (1981) y Ruffell (1974) en sus trabajos.

\subsection{Objetivos}

Por todo lo argumentado anteriormente se fijan los siguientes objetivos para este trabajo:

El objetivo general es el análisis experimental y el modelado numérico del comportamiento térmico y fluido-dinámico de un sistema de almacenamiento térmico innovador a escala de prototipo $\left(300 \mathrm{~kW}_{\text {th }}\right)$ en modo descarga con el fin de obtener información para su correcto escalado y potencial de uso en aplicaciones industriales de calor de proceso y/o generación de electricidad. El diseño lo constituyen un tanque de sales fundidas termoclino y un generador de vapor integrado (matriz de tubos helicoidales). 
Además se plantean los siguientes objetivos específicos:

(I) El análisis experimental del comportamiento térmico y fluido-dinámico del prototipo durante una de sus descargas, con objeto de extraer las condiciones iniciales y de contorno necesarias y suficientes para los modelos numéricos, así como información adecuada para su validación.

(II) La obtención de los coeficientes de transferencia de calor locales entre las sales fundidas y el generador de vapor mediante el uso de un modelo de dinámica de fluidos computacional, CFD, aplicado al prototipo.

(III) La proposición de una nueva correlación para el número de Nusselt, $N u$, para el tipo de geometría y condiciones de trabajo dados. Y el estudio de la adecuación de las correlaciones existentes en la bibliografía.

(IV) La caracterización del flujo bifásico mediante la localización del comienzo de la región de superficie seca, primer dryout y dryout total, y de la calidad de vapor asociada a cada uno de ellos para el tipo de geometría y condiciones de trabajo dados. Y el estudio de la adecuación de las correlaciones existentes en la bibliografía.

Los Objetivos I, II y III se enmarcaron en la tarea 2.2 del proyecto europeo OPTS CORDIS, 2014).

Desafortunadamente, debido al abandono del socio industrial responsable de aportar el gerneador de vapor para el prototipo demostrador, y dada la imposibilidad de encontrar un nuevo socio que se responsabilizara de las tareas del primero, no fue posible finalizar el proyecto con tal propósito. No obstante, el Objetivo IV, abordado con posterioridad al proyecto, también contribuye al desarrollo de este tipo de sistemas de almacenamiento a nivel comercial.

\subsubsection{Metodología}

La metodología a utilizar en este trabajo es el modelado numérico, el cual se apoya en el análisis de los datos experimentales del prototipo de que se dispone.

Para la descripción de la transferencia de calor por circulación natural entre las sales fundidas y el generador de vapor se necesita recurrir a modelos CFD, ya que, hasta el momento, son los únicos capaces de simular explícitamente el efecto de geometrías complejas sobre las distribuciones de velocidades, temperaturas y flujos de calor en un fluido. Para ello, los modelos CFD resuelven numéricamente las ecuaciones de Navier-Stokes sobre un mallado con alta resolución espacial. La aproximación más sencilla es la llamada RANS (Reynolds Averaged Navier-Stokes). En ésta, se parametrizan completamente los fenómenos 
turbulentos en el fluido, y sólo se resuelve el flujo medio (Anexo A). RANS tiene un coste computacional elevado, pero asequible frente a otras aproximaciones mucho más complejas (por ejemplo: LES (Large Eddy Simulation) o DNS (Direct Numerical Simulation). Los modelos CFD requieren información experimental detallada, tanto para la implementación de las condiciones iniciales y de contorno, como para su posterior validación. Dicha información se ha obtenido a partir de un ensayo de descarga del prototipo

El desarrollo de este trabajo se ha estructurado en seis capítulos, más uno de conclusiones, en los que se describirá explícitamente la consecución de los objetivos anteriormente enumerados.

En este capítulo se pretende establecer el marco científico tecnológico de los sistemas de almacenamiento térmico para aplicaciones industriales de calor de proceso y/o generación de electricidad. De este estudio surgirá el interés por el desarrollo de nuevos diseños como el del tanque de sales fundidas y generador de vapor integrado, y la necesidad de información para el correcto escalado del prototipo.

En el Capítulo 2 se presenta la instalación experimental del Centro de Casaccia en ENEA (Italia) de la cual forma parte el prototipo. Se describirá el circuito agua-vapor que lo alimenta, así como su principio de funcionamiento durante las descargas, y se enumerará la instrumentación con la que cuenta para su estudio experimental. A continuación, se hará una descripción detallada del tanque de sales fundidas y el generador de vapor integrado: sus componentes e instrumentación. Finalmente, se indica la metodología seguida durante las descargas.

En el Capítulo 3 se analizarán, desde el punto de vista de la transferencia de calor, los datos obtenidos en un ensayo de descarga realizado en el marco del proyecto OPTS, el del 29 de octubre de 2012, con el fin de extraer resultados y conclusiones experimentales, tanto locales como globales, que permitan cumplir con el Objetivo I previamente indicado.

En el Capítulo 4 se abordará la simulación del proceso de descarga del prototipo mediante la modelización CFD no estacionaria. Para ello, se empleará un modelo geométrico en 3D del dominio de las sales fundidas, un modelo de malla para éste, un modelo físico que describa la fenomenología de las sales fundidas durante las descargas y un método de cálculo. A partir de los resultados simulados obtenidos, previa validación de los mismos, se calcularán las distribuciones de los coeficientes de transferencia de calor en las paredes externas de los tubos helicoidales y los coeficientes promedio en función de la altura. Ello permitirá cumplir con el Objetivo II.

En el Capítulo 5 se desarrollará la metodología seguida en la obtención de la correlación que se propone en este trabajo para la transferencia de calor en el lado de las sales fundidas. Con ello se alcanzará el Objetivo III. 
En el Capítulo 6 se llevará a cabo la simulación del proceso de descarga del prototipo mediante la modelización CFD, en este caso, estacionaria. Además, se empleará un modelo geométrico en 3D del dominio tanto de las sales fundidas como del agua-vapor, así como de las paredes de la matriz de tubos helicoidales, un modelo de malla para todo el conjunto, modelos físicos adecuados que describan la transferencia de calor conjugada entre las sales fundidas y el agua-vapor y un método de cálculo. A partir de los resultados simulados, previa validación de los mismos, se calcularán las distribuciones de los títulos de vapor en las paredes internas de los tubos helicoidales y los títulos promedio en función de la altura. Ello permitirá afrontar el Objetivo IV.

Las conclusiones más relevantes se recogerán en el Capítulo 7, en el que también se propondrán una serie de líneas de investigación futuras que puedan ser relevantes para el desarrollo y potencial uso de este tipo de diseño de sistema de almacenamiento térmico a nivel comercial. 


\section{Capítulo 2}

\section{Dispositivo experimental}

En este capítulo se describe la instalación experimental del Centro de la Casaccia (Roma) utilizada para el desarrollo de este trabajo: los circuitos de los cuales forma parte el prototipo de almacenamiento térmico con generador de vapor integrado, sus elementos principales y los sistemas de control y adquisición de datos con los que cuenta para el estudio experimental. Se explica su funcionamiento durante las descargas y se enumera y describe la instrumentación empleada.

La instalación, diseñada por el personal de ENEA, lleva en funcionamiento desde el año 2003.

A continuación se detalla el tanque de almacenamiento térmico, así como, el generador de vapor de tubos helicoidales con su instrumentación asociada.

Finalmente, se indica la metodología seguida durante las descargas y se introduce el ensayo utilizado en este trabajo.

\section{$2.1 \quad$ Instalación experimental}

El prototipo forma parte, por un lado, de un circuito de sales fundidas y, por otro, de un circuito agua-vapor que alimenta al generador de vapor durante las descargas.

El circuito de sales fundidas, línea roja en Figura 2.1, puede funcionar en uno de los tres modos siguientes:

- en circulación estándar: caracterizado porque la circulación de las sales fundidas se produce a través de todos los componentes del circuito

- en stand-by caliente: caracterizado porque las sales fundidas se hallan estancas en el 
interior del tanque de almacenamiento térmico, a cierta temperatura listas para poder ser enfriadas mediante el generador de vapor integrado. Mientras, el resto de elementos del circuito se mantienen a una temperatura mínima por encima de la de solidificación $\left(\approx 265^{\circ} \mathrm{C},(\mathrm{SQM}, 2018)\right)$ mediante sistemas auxiliares de traceado térmico

- en stand-by frío: caracterizado porque las sales fundidas se hallan estancas en el interior del tanque de almacenamiento térmico a la temperatura mínima de seguridad, que se mantiene mediante un calentador eléctrico inmerso en él

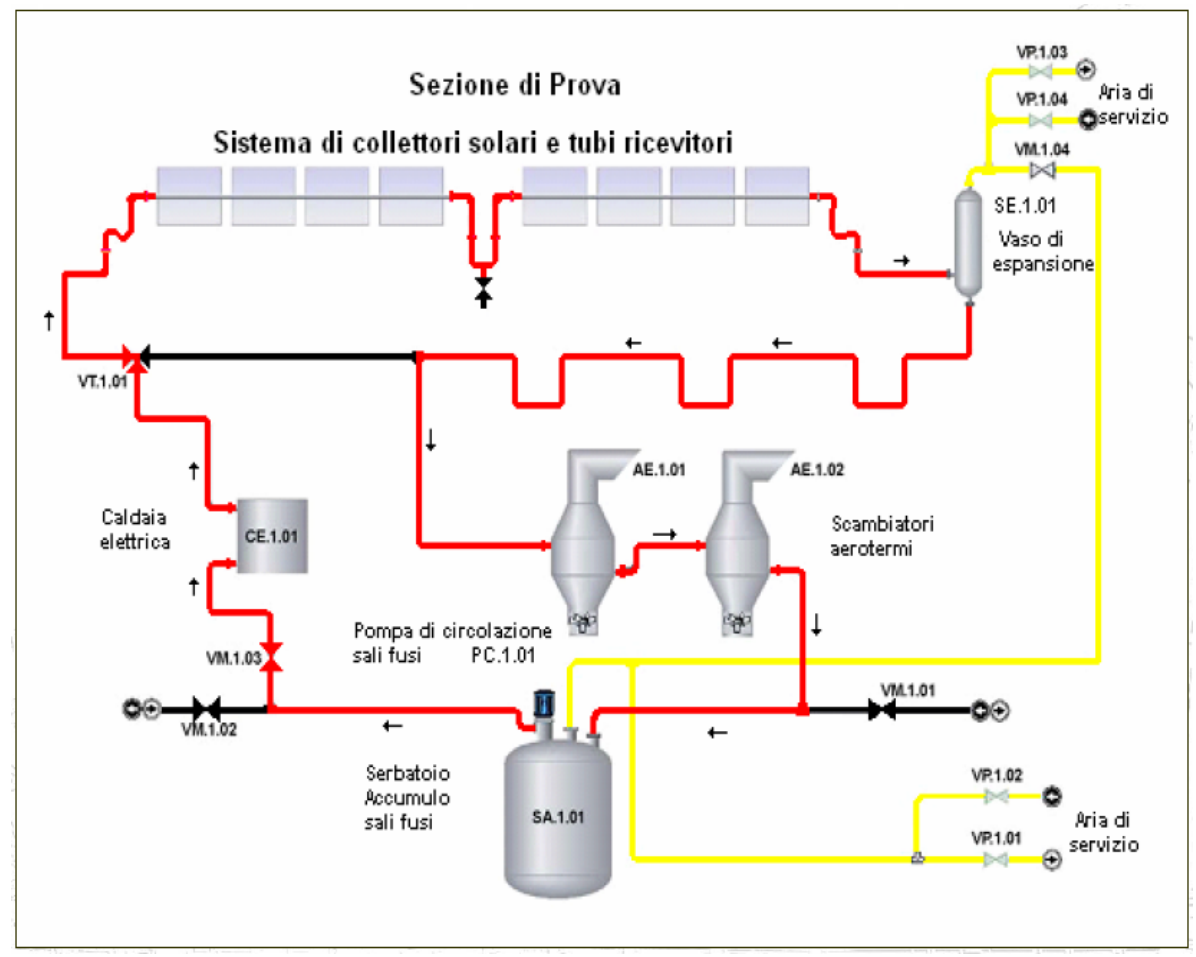

Figura 2.1: Esquema del circuito de sales del cual forma parte el tanque de almacenamiento térmico (SA. 1.01). La línea roja muestra el recorrido de las sales fundidas en el modo circulación estándar (Gaggioli, 2007).

El elemento principal del circuito es el tanque de almacenamiento térmico (elemento SA. 1.01, Figura 2.1) que cuenta con una bomba de sales inmersa en él (elemento PC. 1.01, Figura 2.1) la cual fija el caudal y la presión de las sales fundidas en el circuito cuando éste funciona en modo circulación estándar.

Se debe indicar que el modo de funcionamiento circulación estándar está ideado para llevar a cabo estudios dinámicos de las sales fundidas: por ejemplo, las cargas del prototipo mediante el campo solar. Los otros dos modos de funcionamiento están ideados para llevar a cabo estudios estáticos. En este trabajo, el ensayo utilizado parte del modo de funcionamiento stand-by caliente, por tanto con la bomba de sales desconectada.

Adyacente al circuito de sales fundidas se encuentra el circuito agua-vapor (Figura 2.2. Dicho circuito se construyó para simular y estudiar el proceso de descarga del tanque de 
almacenamiento térmico mediante el generador de vapor integrado. Está dividido en dos ramas (Figura 2.2): una caliente (zona roja) y otra fría (zona azul), y consta de varios elementos. Los más relevantes son: la bomba de agua, la caldera eléctrica, el aerotermo, el recuperador, el intercambiador de calor de agua de red, un depósito de suministro y recogida de agua, el generador de vapor, valvulería e instrumentación.

Como se puede deducir de la relación de componentes anterior, el vapor que se produce en el circuito agua-vapor no se envía a una turbina para producir electricidad, como sería de esperar en una planta termosolar de este tipo, sino que se enfría y se recircula sucesivamente. La instalación cuenta con un sistema de control, que permiten actuar sobre ella, así como recoger los datos que se obtienen durante los ensayos mediante un sistema de adquisición de datos. El sistema, en conjunto, está organizado de modo que existe cierto nivel de independencia entre el control y la adquisición de datos.

El control se lleva a cabo mediante el DCS (Distributed Control System), que es un sistema jerárquico caracterizado por su modularidad, es decir, porque permite ir añadiendo nuevos módulos de control en función de los requerimientos de cada ensayo. Además, permite las operaciones lógicas de control en tiempo real sin necesidad de parada.

La adquisición de datos se lleva a cabo a través del DAQ (Data Acquisition System). Éste tiene acceso a la mayor parte de las magnitudes medidas con el objetivo de controlar la instalación y de registrar las magnitudes de mayor interés experimental.

El modo de funcionamiento de este circuito durante las descargas es en circulación forzada en el lado agua-vapor, que se establece de la siguiente forma: primero, mediante la bomba de agua se fija el caudal de operación (que es el mismo que atravesará el generador de vapor). A continuación, el agua bombeada se hace pasar por la caldera eléctrica donde se precalienta hasta cierta temperatura antes de entrar en el generador.

Posteriormente, ya a la salida del generador, el fluido obtenido durante el intercambio sales fundidas/agua-vapor (en este caso en forma de vapor sobrecalentado) se hace pasar por el aerotermo donde se condensa obteniéndose agua líquida caliente. Después, el agua líquida caliente se dirige al recuperador, que sirve de conexión entre la rama caliente y la rama fría del circuito agua-vapor. 


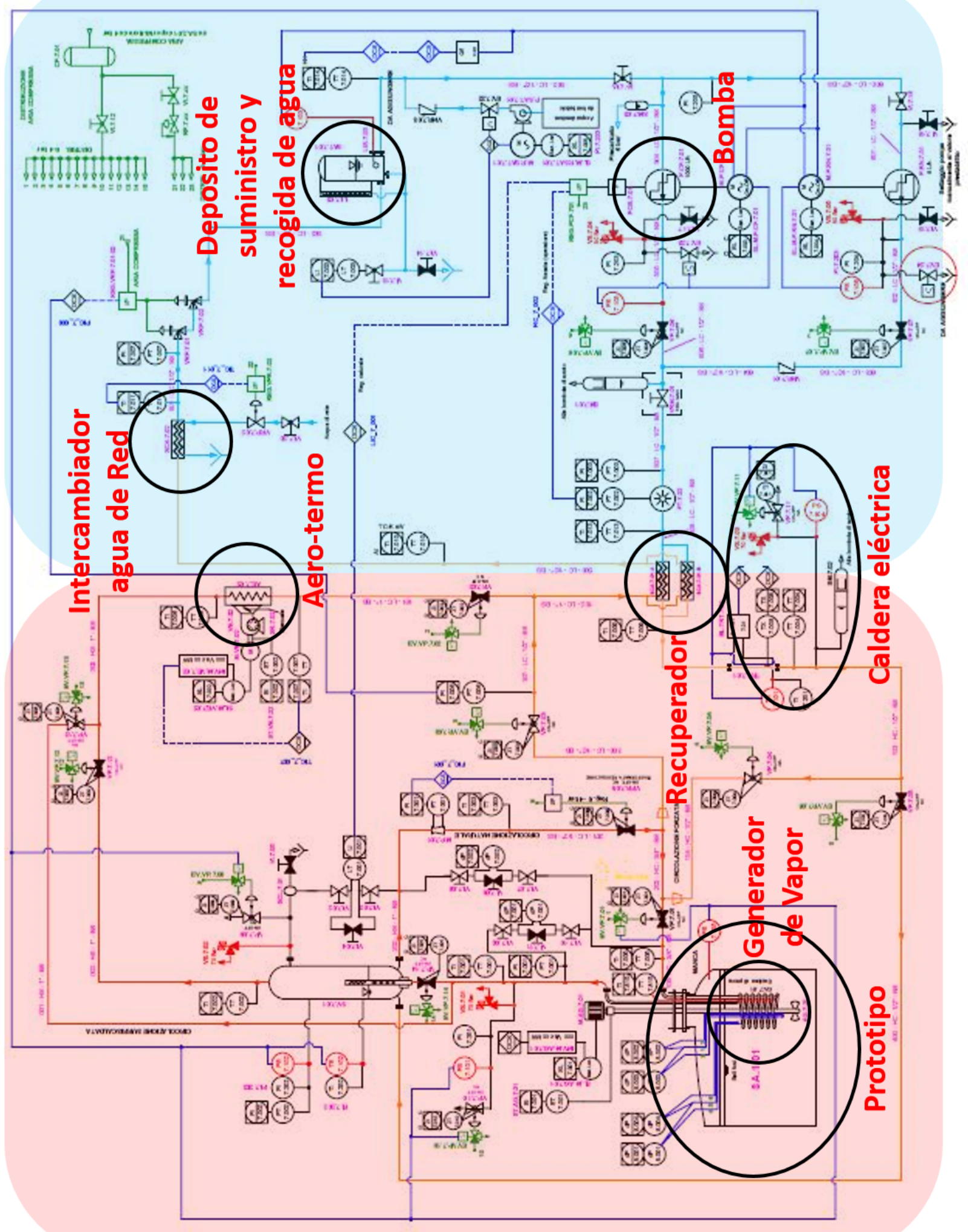

Figura 2.2: Circuito agua-vapor. La zona roja es la rama caliente y la azul la fría. Fuente: ENEA. 
En el recuperador, el agua proveniente de la rama caliente del circuito cede calor al agua a temperatura ambiente proveniente de la rama fría del circuito convirtiéndose en agua templada. A continuación, el agua templada llega al intercambiador de calor de agua de red de donde sale ya a temperatura ambiente. Finalmente, una vez que el agua llega al depósito de suministro y recogida de agua se cierra el ciclo puesto que desde allí es bombeada de nuevo.

La magnitud más relevante del circuito agua-vapor durante las descargas es el caudal volumétrico (FI) de agua. Éste se mide mediante un caudalímetro de molino situado entre la bomba y el recuperador (FI_ 7002, Figura 2.3).

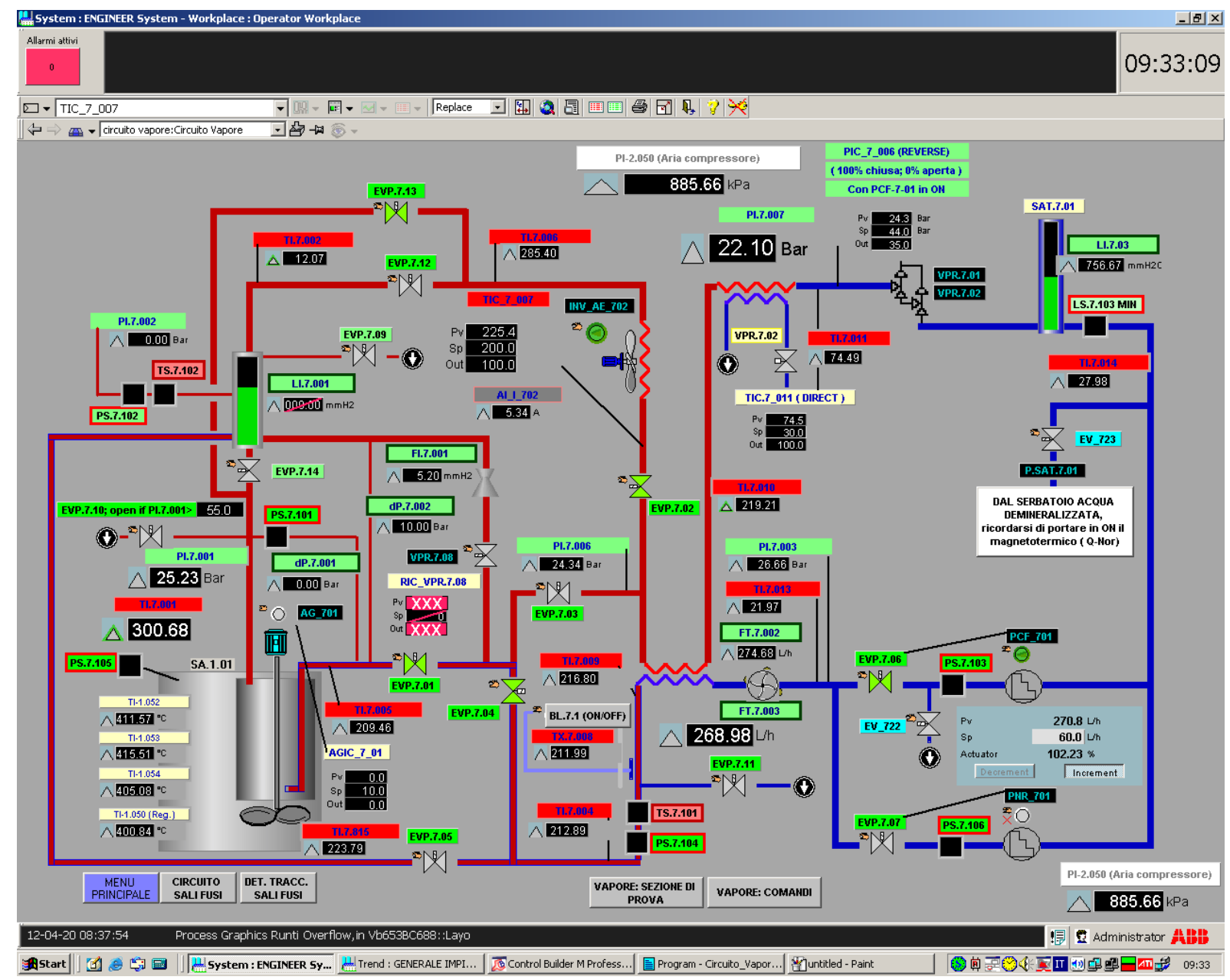

Figura 2.3: Interfaz gráfica del circuito agua-vapor en un determinado instante de un ensayo de descarga del prototipo. Fuente: ENEA.

En el circuito agua-vapor, e inmediatamente a continuación del caudalímetro, también se toman medidas de temperatura (TI) TI_ 7013, y de presión (PI) PI_ 7003. Para la medida de temperatura se emplea un termopar de tipo $\mathrm{K}(\mathrm{Ni} 10 \% \mathrm{Cr} / \mathrm{Ni} 5 \% \mathrm{Al})$ de $2 \mathrm{~mm}$ de diámetro de clase 1 y para la medida de presión un transductor de presión. La información relativa a esta instrumentación se puede ver en la Tabla 2.1. 
Tabla 2.1: Precisión de la instrumentación utilizada en el lado agua-vapor. Fuente: ENEA.

\begin{tabular}{|c|c|c|c|}
\hline Magnitud & Fabricante/Modelo & Referencia & Precisión* $( \pm)$ \\
\hline \hline $\begin{array}{c}\text { Caudal volumétrico } \\
\text { total }\end{array}$ & HEINRICHS/TMU 010 & FI_7002 & $0.15 \%$ \\
\hline $\begin{array}{c}\text { Presión absoluta } \\
\begin{array}{c}\text { Caudal volumétrico } \\
\text { individual }\end{array}\end{array}$ & APLISENS/APC-2000 & $\begin{array}{c}\text { PI_7003, } \\
\text { PI_8_200,210 }\end{array}$ & $0.075 \%$ \\
\hline Temperatura & TC Direct/Tipo K clase 1 & $\begin{array}{c}\text { TI_8_200, } \\
.201, .202, .203, \\
.211, .212, .213\end{array}$ & $0.15 \%$ \\
\hline
\end{tabular}

*Todos los sensores están conectados directamente a DCS con una precisión de $0.1 \%$.

Tras esta introducción a la instalación experimental en su conjunto, a continuación, se describe en detalle el prototipo propiamente dicho.

\subsection{Tanque de almacenamiento térmico}

Se trata de un tanque de $1.98 \mathrm{~m}$ de diámetro y $2.8 \mathrm{~m}$ de altura, cuyo interior alberga alrededor de $12000 \mathrm{~kg}$ de sal solar en atmósfera de aire (Figura 2.4).

Las paredes son de acero inoxidable, de $1.5 \mathrm{~mm}$ de espesor, y todo el tanque se halla cubierto por un aislante compuesto de lana cerámica y lana de roca de $400 \mathrm{~mm}$ de espesor.

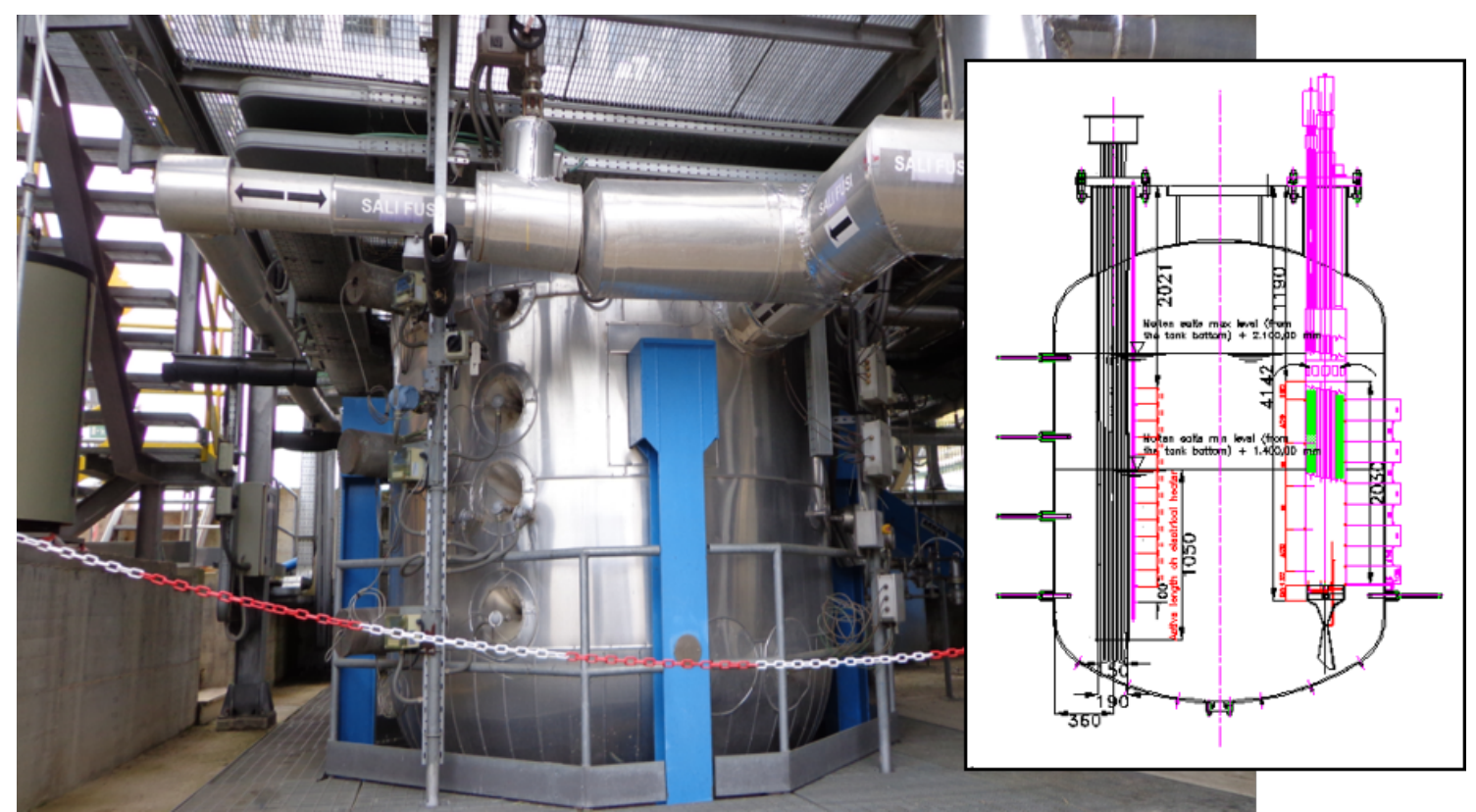

Figura 2.4: Tanque de almacenamiento térmico con generador de vapor integrado (Fabrizi et al. 2012). 
Sus principales componentes son:

- el generador de vapor, localizado en un lateral del tanque

- un calentador eléctrico inmerso en las sales fundidas de $100 \mathrm{~kW}$ y localizado en el lateral opuesto al generador de vapor que mantiene la temperatura de las sales por encima de la de su temperatura de solidificación (desconectado en el ensayo utilizado)

- una bomba de sales localizada como se aprecia en la Figura 2.5 (desconectada en el ensayo utilizado).

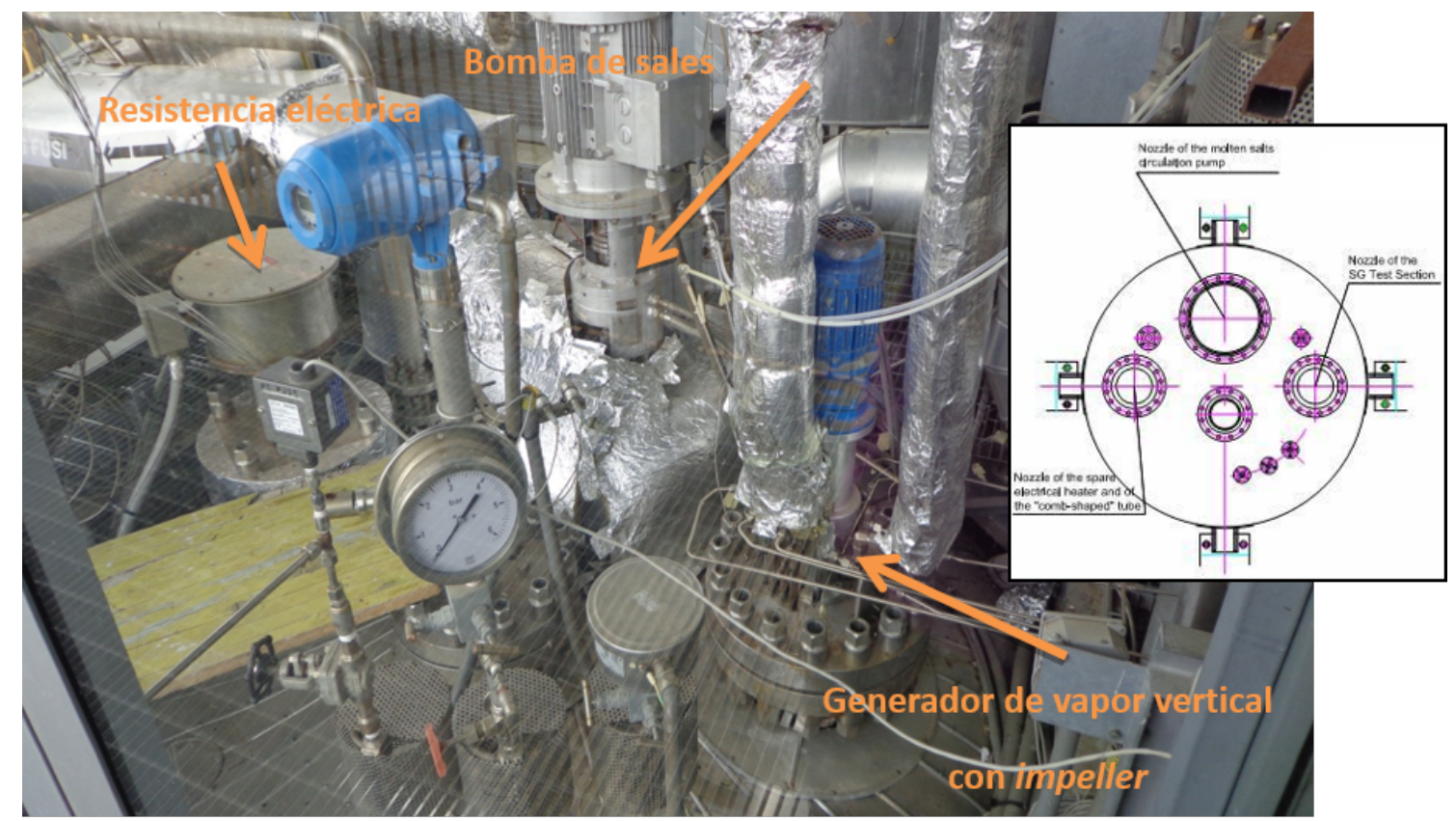

Figura 2.5: Elementos presentes en el prototipo (Fabrizi et al., 2012).

El tanque de almacenamiento cuenta con medidas de temperatura (TI) a varias alturas, tanto de las sales fundidas del seno del tanque como de aquellas próximas a las paredes externas. También se mide la temperatura de la pared exterior aislante del generador a varias alturas, así como la del aire que hay en la cúpula del tanque. Esta información se recoge en la Tabla 2.2 y en la Figura 2.12.

Estas medidas se realizaron empleando termopares de tipo $\mathrm{K}(\mathrm{Ni} 10 \% \mathrm{Cr} / \mathrm{Ni} 5 \% \mathrm{Al})$ de 2 mm de diámetro de clase 1 , los cuales estaban preparados para soportar temperaturas de hasta $600^{\circ} \mathrm{C}$. La precisión de dichos instrumentos era de $\pm 1.5^{\circ} \mathrm{C}$.

Este conjunto de medidas queda registrado en intervalos de $5 \mathrm{~s}$.

El generador de vapor integrado, por su diseño novedoso, se describe en detalle a continuación. 


\subsection{Generador de vapor}

El generador de vapor (Figura 2.6, Figura 2.7 y Figura 2.8 lo constituyen dos carcasas cilíndricas concéntricas (denominadas downcomer y shell), una matriz de tubos helicoidales, en el espacio que delimitan ambas carcasas, y una hélice impulsora o impeler (desconectado en el ensayo utilizado). Todo ello fabricado en acero inoxidable AISI 321 (H) Gaggioli, 2007).

Tabla 2.2: Instrumentación en el tanque de almacenamiento. Fuente: ENEA.

\begin{tabular}{|c|c|c|c|}
\hline Magnitud & Descripción elemento medida & Referencia & Notas/Comentarios \\
\hline Temperatura & $\begin{array}{l}\text {-Árbol de } 14 \text { termopares } \\
\text { dispuestos a diferentes alturas } \\
\text { a lo largo del calentador } \\
\text { y a } 30 \mathrm{~cm} \text { de las paredes } \\
\text { laterales del tanque } \\
\text {-Conjunto de } 5 \text { termopares } \\
\text { dispuestos a diferentes alturas } \\
\text { a } 10 \mathrm{~cm} \text { de las paredes } \\
\text { laterales del tanque }\end{array}$ & $\begin{array}{l}\text { TI_8_501,.502, } \ldots, .514 \\
\left(\mathbf{T I} \_8 \_5 \mathrm{nn}\right)\end{array}$ & $\begin{array}{l}\text { Altura desde fondo }(\mathrm{m}) \text { : } \\
1.893,1.793,1.693,1.593, \\
1.493,1.393,1.293,1.193, \\
0.693,0.5931 \\
\text { Altura desde fondo }(\mathrm{m}) \text { : } \\
0.636,2.076,1.596,1.116, \\
0.636\end{array}$ \\
\hline \multicolumn{4}{|c|}{ PAREDES CAMISA GENERADOR DE VAPOR } \\
\hline Magnitud & Descripción elemento medida & Referencia & Notas/Comentarios \\
\hline Temperatura & $\begin{array}{l}\text {-Conjunto de } 5 \text { termopares } \\
\text { dispuestos a diferentes alturas } \\
\text { en la parte exterior }\end{array}$ & 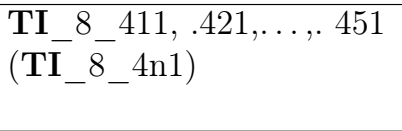 & $\begin{array}{l}\text { Altura desde fondo }(\mathrm{m}) \text { : } \\
1.848,1.558,1.298,1.038 \\
0.778\end{array}$ \\
\hline \multicolumn{4}{|c|}{ AIRE } \\
\hline Magnitud & Descripción elemento medida & Referencia & Notas/Comentarios \\
\hline Temperatura & -1 termopar & TI_8_051 & $\begin{array}{l}\text { Altura desde fondo }(\mathrm{m}) \text { : } \\
2.376\end{array}$ \\
\hline
\end{tabular}

Por el interior de los tubos helicoidales circula el agua a presión que cambia de fase y por el espacio intersticial entre las carcasas cilíndricas circulan las sales fundidas.

Cada una de las carcasas concéntricas cumple una función:

- el downcomer, o bajante del generador (Figura 2.6), permite que el circuito agua-vapor acceda hasta la parte inferior del generador sin entrar en contacto directo con las sales fundidas. De esta forma, se favorece que, en el interior de los tubos helicoidales, se produzca el cambio de fase agua-vapor en sentido ascendente

- la shell, o camisa del generador (Figura 2.7 y Figura 2.8), aísla térmicamente las sales fundidas que circulan por el interior del generador (por el espacio intersticial) del resto de sales del tanque. Ésta, a su vez, también la componen dos carcasas cilíndricas concéntricas: la interna, de $2.5 \mathrm{~mm}$ de espesor, y la externa, de $1 \mathrm{~mm}$ de espesor, y, entre ellas, un aislante de lana de roca de $10.5 \mathrm{~mm}$.

La shell posee, en la parte superior, una abertura variable por donde entran las sales fundidas calientes al generador y, en su parte inferior, un difusor por donde salen frías. 

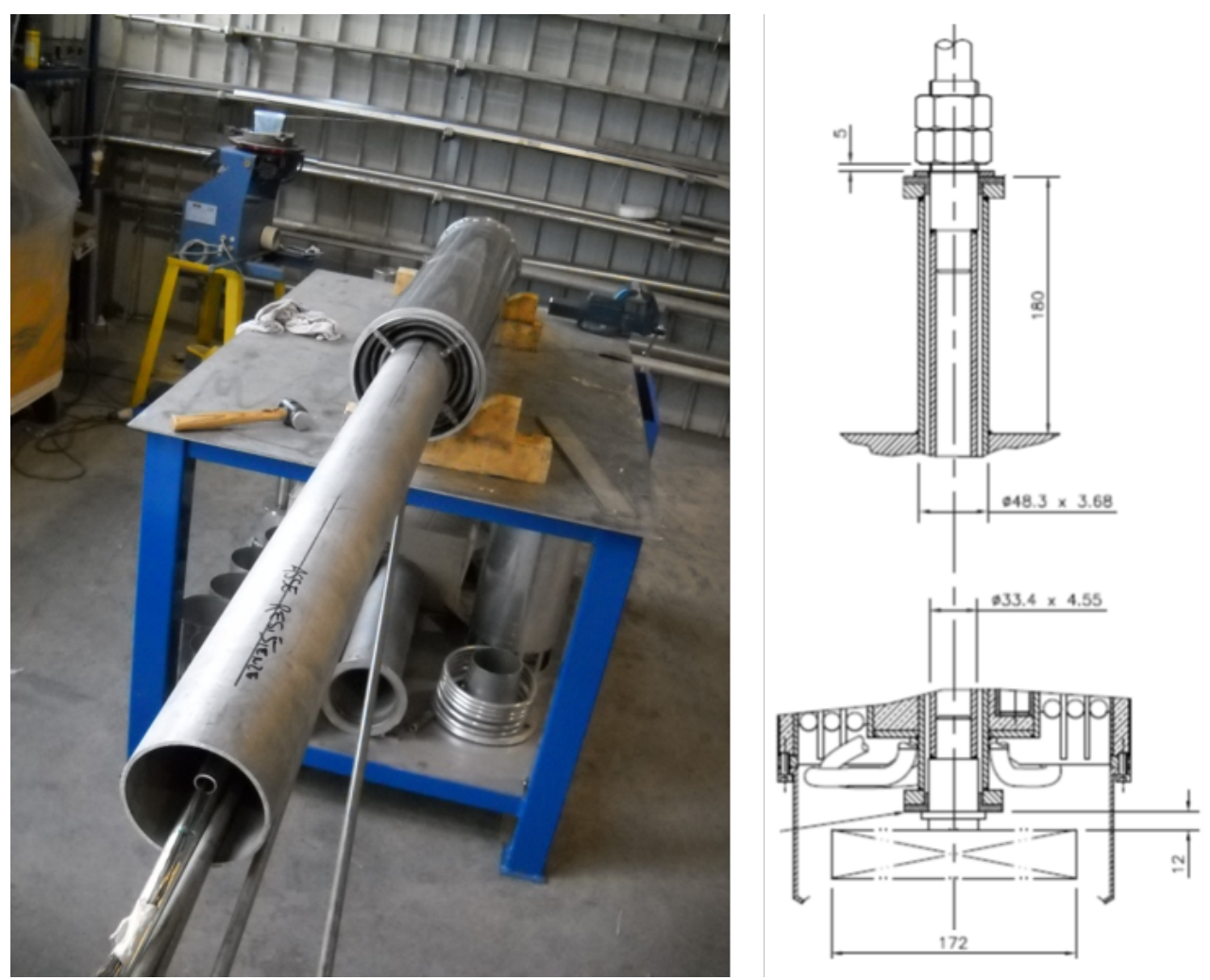

Figura 2.6: Generador de vapor: downcomer. Fuente: ENEA.
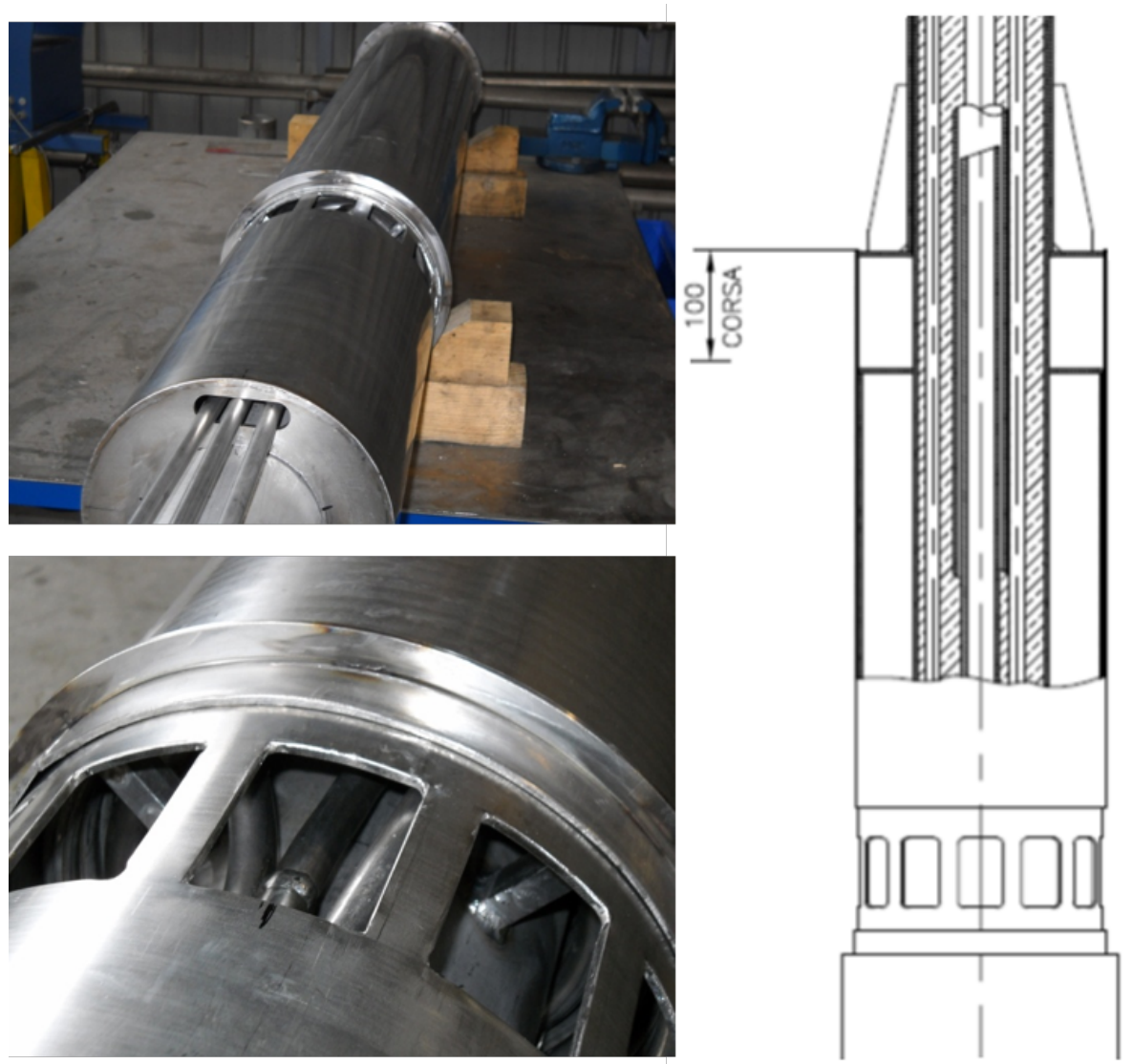

Figura 2.7: Generador de vapor. shell y abertura variable. Fuente: ENEA. 